\title{
TRADE POLICY AND ECONOMIC GROWTH: A SKEPTIC'S GUIDE TO \\ THE CROSS-NATIONAL EVIDENCE
}

\author{
Francisco Rodríguez \\ Dani Rodrik
}

Working Paper 7081

http://www.nber.org/papers/w7081

\author{
NATIONAL BUREAU OF ECONOMIC RESEARCH \\ 1050 Massachusetts Avenue \\ Cambridge, MA 02138 \\ April 1999
}

We thank Dan Ben-David, Sebastian Edwards, Jeffrey Sachs, and Andrew Warner for generously sharing their data with us. We are particularly grateful to Warner, Sachs, Ben-David and Romain Wacziarg for helpful e-mail exchanges. We also thank Roger Betancourt, Allan Drazen, Gene Grossman, Ann Harison, Frank Levy, Douglas Irwin, Arvind Panagariya, and Eduardo Zambrano for helpful comments, Vladimir Kliouev for excellent research assistance and the Weatherhead Center for International Affairs at Harvard for partial financial support. The views expressed in this paper are those of the authors and do not reflect those of the National Bureau of Economic Research.

( 1999 by Francisco Rodríguez and Dani Rodrik. All rights reserved. Short sections of text, not to exceed two paragraphs, may be quoted without explicit permission provided that full credit, including ${ }^{\circledR}$ notice, is given to the source. 
Trade Policy and Economic Growth: A Skeptic's

Guide to the Cross-National Evidence

Francisco Rodríguez and Dani Rodrik

NBER Working Paper No. 7081

April 1999

JEL No. O57, F13

\begin{abstract}
Do countries with lower policy-induced barriers to international trade grow faster, once other relevant country characteristics are controlled for? There exists a large empirical literature providing an affirmative answer to this question. We argue that methodological problems with the empirical strategies employed in this literature leave the results open to diverse interpretations. In many cases, the indicators of "openness" used by researchers are poor measures of trade barriers or are highly correlated with other sources of bad economic performance. In other cases, the methods used to ascertain the link between trade policy and growth have serious shortcomings. Papers that we review include Dollar (1992), Ben-David (1993), Sachs and Warner (1995), and Edwards (1998). We find little evidence that open trade policies--in the sense of lower tariff and non-tariff barriers to trade--are significantly associated with economic growth.
\end{abstract}

Francisco Rodríguez

Department of Economics

University of Maryland

College Park, MD 20742

\author{
Dani Rodrik \\ John F. Kennedy School of Government \\ Harvard University \\ 79 Kennedy Street \\ Cambridge, MA 02138 \\ and NBER \\ dani_rodrik@harvard.edu
}


TRADE POLICY AND ECONOMIC GROWTH:

\title{
A SKEPTIC'S GUIDE TO THE CROSS-NATIONAL EVIDENCE
}

\begin{abstract}
"It isn't what we don't know that kills us. It's what we know that ain't so."
\end{abstract}
-- Mark Twain

\section{Introduction}

Do countries with lower barriers to international trade experience faster economic progress? Few questions have been more vigorously debated in the history of economic thought, and none is more central to the vast literature on trade and development.

The prevailing view in policy circles in North America and Europe is that recent economic history provides a conclusive answer in the affirmative. Multilateral institutions such as the World Bank, IMF, and the OECD regularly promulgate advice predicated on the belief that openness generates predictable and positive consequences for growth. A recent report by the $\operatorname{OECD}(1998,36)$ states: "More open and outward-oriented economies consistently outperform countries with restrictive trade and [foreign] investment regimes." According to the $\operatorname{IMF}(1997,84)$ : "Policies toward foreign trade are among the more important factors promoting economic growth and convergence in developing countries."

This view is widespread in the economics profession as well. Krueger $(1998,1513)$, for example, judges that it is straightforward to demonstrate empirically the superior growth performance of countries with "outer-oriented" trade strategies. ${ }^{2}$ According to Stiglitz (1998a, $36), "[\mathrm{~m}]$ ost specifications of empirical growth regressions find that some indicator of external openness--whether trade ratios or indices of price distortions or average tariff level--is strongly associated with per-capita income growth." ${ }^{3}$

Such statements notwithstanding, if there is an inverse relationship between trade barriers and economic growth, it is not one that immediately stands out in the data. See for example Figures I.1 and I.2. The figures display the (partial) associations over the 1975-1994 period between the growth rate of per-capita GDP and two measures of trade restrictions. The first is an average tariff rate, calculated by dividing total import duties by the volume of imports. The

\footnotetext{
${ }^{1}$ The IMF quote cites research by Sachs and Warner and by Ben-David, which we shall review in this paper.

${ }^{2}$ Krueger cites Sachs and Warner (1995).

${ }^{3}$ Stiglitz here cites Sachs and Warner (1995) as well. Elsewhere Stiglitz (1998b) writes: "there is by and large a consensus among economists - based on a wealth of studies - that trade liberalization brings significant economic gains" to contrast the apparent consensus on trade liberalization with the lack of consensus with regard to capitalaccount liberalization.
} 
second is a coverage ratio for non-tariff barriers to trade. ${ }^{4}$ The figures show the relationship between these measures and growth after controlling for levels of initial income and secondary education. In both cases, the slope of the relationship is only slightly negative and nowhere near statistical significance. This finding is not atypical. Simple measures of trade barriers tend not to enter significantly in well-specified growth regressions, regardless of time periods, subsamples, or the conditioning variables employed.

Of course, neither of the two measures we used above is a perfect indicator of trade restrictions. Simple tariff averages underweight high tariff rates because the corresponding import levels tend to be low. Such averages are also poor proxies for overall trade restrictions when tariff and non-tariff barriers are substitutes. As for the non-tariff coverage ratios, they do not do a good job of discriminating between barriers that are highly restrictive and barriers with little effect. And conceptual flaws aside, both indicators are clearly measured with some error (due to smuggling, weaknesses in the underlying data, coding problems, etc.).

In part because of concerns related to data quality, the recent literature on openness and growth has resorted to more creative empirical strategies. These strategies include: (a) constructing alternative indicators of openness (Dollar 1992; Sachs and Warner 1995); (b) testing robustness by using a wide range of measures of openness, including subjective indicators (Edwards 1992, 1998); and (c) comparing convergence experience among groups of liberalizing and non-liberalizing countries (Ben-David 1993). This recent round of empirical research is generally credited for having yielded stronger and more convincing results on the beneficial consequences of openness than the previous, largely case-based literature. Indeed, the cumulative evidence that has emerged from such studies provides the foundation for the previously-noted consensus on the growth-promoting effects of trade openness.

Our goal in this paper is to scrutinize this new generation of research. We do so by focussing on what the existing literature has to say on the following question: Do countries with lower policy-induced barriers to international trade grow faster, once other relevant country characteristics are controlled for? We take this to be the central question of policy relevance in this area. To the extent that the empirical literature demonstrates a positive causal link from openness to growth, the main operational implication is that governments should dismantle their barriers to trade. Therefore, it is critical to ask how well the evidence supports the presumption that doing so would raise growth rates.

Note that this question differs from an alternative one we could have asked: Does international trade raise growth rates of income? This is a related, but conceptually distinct question. Trade policies do affect the volume of trade, of course. But there is no strong reason to expect their effect on growth to be quantitatively (or even qualitatively) similar to the consequences of changes in trade volumes that arise from, say, reductions in transport costs or increases in world demand. To the extent that trade restrictions represent policy responses to real or perceived market imperfections or, at the other extreme, are mechanisms for rent-extraction, they will work differently from natural or geographical barriers to trade and other exogenous

\footnotetext{
${ }^{4}$ Data for the first measure come from the World Bank's World Development Indicators 1998. The second is taken from Barro and Lee (1994), and is based on UNCTAD compilations.
} 
determinants. Frankel and Romer (1998) recognize this point in their recent paper on the relationship between trade volumes and income levels. These authors use the geographical component of trade volumes as an instrument to identify the effects of trade on income levels. They appropriately caution that their results cannot be directly applied to the effects of trade policies.

From an operational standpoint, it is clear that the relevant question is the one having to do with the consequences of trade policies rather than trade volumes. Hence we focus on the recent empirical literature that attempts to measure the effect of trade policies. Our main finding is that this literature is largely uninformative regarding the question we posed above. There is a significant gap between the message that the consumers of this literature have derived and the "facts" that the literature has actually demonstrated. The gap emerges from a number of factors. In many cases, the indicators of "openness" used by researchers are problematic as measures of trade barriers or are highly correlated with other sources of poor economic performance. In other cases, the empirical strategies used to ascertain the link between trade policy and growth have serious shortcomings, the removal of which results in significantly weaker findings.

The literature on openness and growth through the late 1980s was usefully surveyed in a paper by Edwards (1993). This survey covered detailed multi-country analyses (such as Little et al. 1970 and Balassa 1971) as well as cross-country econometric studies (such as Feder 1983, Balassa 1985, and Esfahani 1991). Most of the cross-national econometric research that was available up to that point focussed on the relationship between exports and growth, and not on trade policy and growth. Edwards' evaluation of this literature was largely negative (1993, 1389):

$[\mathrm{M}]$ uch of the cross-country regression based studies have been plagued by empirical and conceptual shortcomings. The theoretical frameworks used have been increasingly simplistic, failing to address important questions such as the exact mechanism through which export expansion affects GDP growth, and ignoring potential determinants of growth such as educational attainment. Also, many papers have been characterized by a lack of care in dealing with issues related to endogeneity and measurement errors. All of this has resulted, in many cases, in unconvincing results whose fragility has been exposed by subsequent work.

Edwards argued that such weaknesses had reduced the policy impact of the cross-national econometric research covered in his review.

Our paper picks up where Edwards' survey left off. We focus on a number of empirical papers that either were not included in or have appeared since that survey. Judging by the number of citations in publications by governmental and multilateral institutions, this recent round of empirical research has been considerably more influential in policy circles. Our detailed analysis covers the four papers that are probably the best known in the field: Dollar (1992), Sachs and Warner (1995), Ben-David (1993), and Edwards (1998).

A few words about the selection of papers. The paper by Dollar (1992) was not reviewed in Edwards' survey, perhaps because it had only recently been published. We include it here since it is, by our count, the most heavily cited empirical paper on the link between openness and 
growth. Sachs and Warner (1995) is a close second, and the index of "openness" constructed therein has now been widely used in the cross-national research on growth. ${ }^{5}$ The other two papers are also well known, but in these cases our decision was based less on citation counts than on the fact that they are representative of different types of methodologies. Ben-David (1993) considers income convergence in countries that have integrated with each other (such as the European Community countries). Edwards (1998) undertakes a robustness analysis using a wide range of trade-policy indicators, including some subjective indicators. Some of the other recent studies on the relationship between trade policy and growth will be discussed in the penultimate section of the paper.

Our bottom line is that the nature of the relationship between trade policy and economic growth remains very much an open question. The issue is far from having been settled on empirical grounds. We are in fact skeptical that there is a general, unambiguous relationship between trade openness and growth waiting to be discovered. We suspect that the relationship is a contingent one, dependent on a host of country and external characteristics. Research aimed at ascertaining the circumstances under which open trade policies are conducive to growth (as well as those under which they may not be) and at scrutinizing the channels through which trade policies influence economic performance is likely to prove more productive.

Finally, it is worth reminding the reader that growth and welfare are not the same thing. Trade policies can have positive effects on welfare without affecting the rate of economic growth. Conversely, even if policies that restrict international trade were to reduce economic growth, it does not follow that they would necessarily reduce the level of welfare. Negative coefficients on policy variables in growth regressions are commonly interpreted as indicating that the policies in question are normatively undesirable. Strictly speaking, such inferences are invalid..$^{6}$ Our paper centers on the relationship between trade policy and growth because this is the issue that has received the most attention in the existing literature. We caution the reader that the welfare implications of empirical results regarding this link (be they positive or negative) must be treated with caution.

The outline of this paper is as follows. We begin with a conceptual overview of the issues relating to openness and growth. We then turn to an in-depth examination of each of the four papers mentioned previously (Dollar 1992; Sachs and Warner 1995; Edwards 1998; and Ben-David 1993). The penultimate section discusses briefly three other papers (Lee 1993; Harrison 1996; and Wacziarg 1998). We offer some final thoughts in the concluding section.

\footnotetext{
${ }^{5}$ From its date of publication, Dollar's paper has been cited at least 80 times, according to the Social Science Citations Index. Sachs and Warner (1995) is a close second, with 76 citations. Edwards (1992), Ben-David (1993) and Lee (1993) round off the list, with 53, 25 and 16 citations respectively.

${ }^{6}$ Some of the main problems with economic growth as a measure of welfare are that: (i) the empirically identifiable effect of policies on rates of growth--especially over short intervals--could be different from their effect on levels of income; (ii) levels of per capita income may not be good indicators of welfare because they do not capture the distribution of income or the level of access to primary goods and basic capabilities; and (iii) high growth rates could be associated with suboptimally low levels of present day consumption. Hall and Jones (1999) come closest to addressing the first of these problems by studying the effect of openness on output per worker. We shall criticize their measure of openness--the Sachs-Warner openness dummy-in section IV below.
} 


\section{Conceptual issues}

Think of a small economy that takes world prices of tradable goods as given. What is the relationship between trade restrictions and real GDP in such an economy? The modern theory of trade policy as it applies to such a country can be summarized in the following three propositions:

1. In static models with no market imperfections and other pre-existing distortions, the effect of a trade restriction is to reduce the level of real GDP at world prices. In the presence of market failures such as externalities, trade restrictions may increase real GDP (although they are hardly ever the first-best means of doing so).

2. In standard models with exogenous technological change and diminishing returns to reproducible factors of production (e.g., the neo-classical model of growth), a trade restriction has no effect on the long-run (steady-state) rate of growth of output. ${ }^{7}$ This is true regardless of the existence of market imperfections. However, there may be growth effects during the transition to the steady state. (These transitional effects could be positive or negative depending on how the long-run level of output is affected by the trade restriction.)

3. In models of endogenous growth generated by non-diminishing returns to reproducible factors of production or by learning-by-doing and other forms of endogenous technological change, the presumption is that lower trade restrictions boost output growth in the world economy as a whole. But a subset of countries may experience diminished growth depending on their initial factor endowments and levels of technological development.

Taken together, these points imply that there should be no theoretical presumption in favor of finding an unambiguous, negative relationship between trade barriers and growth rates in the types of cross-national data sets typically analyzed. ${ }^{8}$ The main complications are twofold. First, in the presence of certain market failures, such as positive production externalities in import-competing sectors, the long-run levels of GDP (measured at world prices) can be higher with trade restrictions than without. In such cases, data sets covering relatively short time spans will reveal a positive (partial) association between trade restrictions and the growth of output along the path of convergence to the new steady state. Second, under conditions of endogenous growth, trade restrictions may also be associated with higher growth rates of output whenever the restrictions promote technologically more dynamic sectors over others. In dynamic models, moreover, an increase in the growth rate of output is neither a necessary nor a sufficient condition for an improvement in welfare.

\footnotetext{
${ }^{7}$ Strictly speaking, this statement is true only when the marginal product of the reproducible factors ("capital") tends to zero in the limit. If this marginal product is bounded below by a sufficiently large positive constant, trade policies can have an effect on long-run growth rates, similar to their effect in the more recent endogenous growth models (point 3 below). See the discussion in Srinivasan (1997).

${ }^{8}$ See Buffie (1998) for an extensive theoretical discussion of the issues from the perspective of developing countries.
} 
Since endogenous growth models are often thought to have provided the missing theoretical link between trade openness and long-run growth, it is useful to spend a moment on why such models in fact provide an ambiguous answer. As emphasized by Grossman and Helpman (1991), the general answer to the question "does trade promote innovation in a small open economy" is: "it depends." 9 In particular, the answer varies depending on whether the forces of comparative advantage push the economy's resources in the direction of activities that generate long-run growth (via externalities in research and development, expanding product variety, upgrading product quality, and so on) or divert them from such activities. Grossman and Helpman (1991), Feenstra (1990), Matsuyama (1992), and others have worked out examples where a country that is behind in technological development can be driven by trade to specialize in traditional goods and experience a reduction in its long-run rate of growth. Such models are in fact formalizations of some very old arguments about infant industries and about the need for temporary protection to catch up with more advanced countries.

The issues can be clarified with the help of a simple model of a small open economy with learning-by-doing. The model is a simplified version of that in Matsuyama (1992), except that we analyze the growth implications of varying the import tariff, rather than simply comparing free trade to autarky. The economy is assumed to have two sectors, agriculture $(a)$ and manufacturing $(m)$, with the latter subject to learning-by doing that is external to individual firms in the sector but internal to manufacturing as a whole. Let labor be the only mobile factor between the two sectors, and normalize the economy's labor endowment to unity. We can then write the production functions of the manufacturing and agricultural sectors, respectively, as:

$$
\begin{gathered}
X_{t}^{m}=M_{t} n_{t}^{\alpha} \\
X_{t}^{a}=A\left(1-n_{t}\right)^{\alpha},
\end{gathered}
$$

where $n_{t}$ stands for the labor force in manufacturing, $\alpha$ is the share of labor in value added in the two sectors (assumed to be identical for simplicity), and $t$ is a time subscript. The productivity coefficient in manufacturing $M_{t}$ is a state variable evolving according to:

$$
\dot{M}_{t}=\delta X_{t}^{m}
$$

where an overdot represents a time derivative and $\delta$ captures the strength of the learning effect.

We assume the economy has an initial comparative disadvantage in manufacturing, and normalize the relative price of manufactures on world markets to unity. If the ad-valorem import tariff on manufactures is $\tau$, the domestic relative price of manufactured goods becomes $(1+\tau)$. Instantaneous equilibrium in the labor market requires the equality of value marginal products of labor in the two sectors:

$$
A\left(1-n_{t}\right)^{\alpha-1}=(1+\tau) M_{t} n_{t}^{\alpha-1}
$$

It can be checked that an increase in the import tariff has the effect of allocating more of the economy's labor to the manufacturing sector:

$$
\frac{d n_{t}}{d \tau}>0
$$

\footnotetext{
${ }^{9}$ This is a slight paraphrase of Grossman and Helpman $(1991,152)$.
} 
Further, for a constant level of $\tau, n_{t}$ evolves according to:

where a $" \wedge "$ denotes proportional changes.

$$
\hat{n}_{t}=\left(\frac{\delta}{1-\alpha}\right)\left(1-n_{t}\right) n_{t}^{\alpha},
$$

Let $Y_{t}$ denote the value of output in the economy evaluated at world prices:

$$
Y_{t}=M_{t} n_{t}^{\alpha}+A\left(1-n_{t}\right)^{\alpha} \text {. }
$$

Then the instantaneous rate of growth of output at world prices can be expressed as follows:

$$
\hat{Y}_{t}=\delta\left[\lambda_{t}+\left(\frac{\alpha}{1-\alpha}\right)\left(\lambda_{t}-n_{t}\right)\right] n_{t}^{\alpha},
$$

where $\lambda_{t}$ is the share of manufacturing output in total output when both are expressed at world prices (i.e., $\lambda_{t}=X_{t}^{m} / Y_{t}$ ).

Consider first the case when $\tau=0$. In this case, it can be checked that $\lambda_{t}=n_{t}$ and the expression for the instantaneous growth rate of output simplifies to $\hat{Y}_{t}=\delta \lambda_{t} n_{t}^{\alpha}$, which is strictly positive whenever $n_{t}>0$. Growth arises from the dynamic effects of learning, and is faster the larger the manufacturing base $n_{t}$. A small tariff would have a positive effect on growth on account of this channel because it would enlarge the manufacturing sector (raise $n_{t}$ ).

When $\tau>0$, the manufacturing share of output at world prices is less than the labor share in manufacturing, and $\lambda_{t}<n_{t}$. Now the second term in the expression for $\hat{Y}_{t}$ is negative. The intuition is as follows. The tariff imposes a production-side distortion in the allocation of the economy's resources. For any given gap between $\lambda_{t}$ and $n_{t}$, the productive efficiency cost of this distortion rises as manufacturing output (the base of the distortion) gets larger.

Hence the tariff exerts two contradictory effects on growth. By pulling resources into the manufacturing sector, it enlarges the scope for dynamic scale benefits, thereby increasing growth. But it also imposes a static efficiency loss, the cost of which rises over time as the manufacturing sector becomes larger. ${ }^{10}$ Figure II. 1 shows the relationship between the tariff and the rate of growth of output (at world prices) for a particular parameterization of this model. Two curves are shown, one for the instantaneous rate of growth (based on the expression above), and the other for the average growth rate over a twenty-year horizon (calculated as $[1 / 20] \mathrm{x}\left[\ln Y_{20}\right.$ - $\left.\ln Y_{0}\right]$ ). In both cases, growth increases in $\tau$ until a critical level, and then diminishes in $\tau$. This pattern is, however, by no means general, and other types of results can be obtained under different parameterizations.

The model clarifies a number of issues. First, it shows that it is relatively straightforward to write a well-specified model that generates the conclusions that many opponents of trade

\footnotetext{
${ }^{10}$ We emphasize once again that these results on the growth of output do not translate directly into welfare consequences. In this particular model, the level effect of a tariff distortion also has to be taken into account before a judgement on welfare can be passed. Hence it is possible for welfare to be reduced (raised) even though the growth rate of output is (permanently) higher (lower).
} 
openness have espoused--namely that free trade can be detrimental to some countries' economic prospects, especially when these countries are lagging in technological development and have an initial comparative advantage in "non-dynamic" sectors. More broadly, the model illustrates that there is no determinate theoretical link between trade protection and growth once real-world phenomena such as learning, technological change, and market imperfections (here captured by a learning-by-doing externality) are taken into account. Third, it highlights the exact sense in which trade restrictions distort market outcomes. A trade barrier has resource-allocation effects because it alters a domestic price ratio: it raises the domestic price of import-competing activities relative to the domestic price of exportables, and hence introduces a wedge between the domestic relative-price ratio and the opportunity costs reflected in relative border prices. ${ }^{11}$ While this point is obvious, it bears repeating as some of the empirical work reviewed below interprets openness in a very different manner.

\section{David Dollar (1992)}

As mentioned previously, the paper by Dollar (1992) is one of the most heavily cited recent studies on the relationship between openness and growth. The principal contribution of Dollar's paper lies in the construction of two separate indices, which Dollar demonstrates are each negatively correlated with growth over the 1976-85 period in a sample of 95 developing countries. The two indices are an "index of real exchange rate distortion" and an "index of real exchange rate variability" (henceforth DISTORTION and VARIABILITY). These indices relate to "outward orientation," as understood by Dollar $(1992,524)$, in the following way:

Outward orientation generally means a combination of two factors: first, the level of protection, especially for inputs into the production process, is relatively low (resulting in a sustainable level of the real exchange rate that is favorable to exporters); and second, there is relatively little variability in the real exchange rate, so that incentives are consistent over time.

The indices DISTORTION and VARIABILITY are meant to capture these two dimensions of "outward orientation."

In order to implement his approach, Dollar uses data from Summers and Heston (1988, Mark 4.0) on comparative price levels. The Summers-Heston work compares prices of an identical basket of consumption goods across countries. Hence, letting the U.S. be the benchmark country, these data provide estimates of each country $i$ 's price level $\left(R P L_{i}\right)$ relative to the U.S.: $R P L_{i}=100 \times P_{i} /\left(e_{i} P_{U S}\right)$, where $P_{i}$ and $P_{U S}$ are the respective consumption price indices, and $e_{i}$ is the nominal exchange rate of country $i$ against the U.S. dollar (in units of home currency per dollar). ${ }^{12}$ Since Dollar is interested in the prices of tradable goods only, he attempts to purge the effect of systematic differences arising from the presence of non-tradables. To do this, he

\footnotetext{
${ }^{11}$ Some authors have stressed the effects that the high levels of discretion associated with trade policies can have on rent-seeking and thus on economic performance (Krueger, 1974; Bhagwati, 1982). These effects go beyond the direct impact on resource allocation that we discuss. They are however related more directly to the discretionary nature of policies than to their effect on the economy's openness. Discretionary export promotion policies--which will make an economy more open--should in principle be just as conducive to rent-seeking as protectionist policies.

${ }^{12}$ Our notation differs from Dollar's (1992). In particular, the exchange rate is defined differently.
} 
regresses $R P L_{i}$ on the level and square of GDP per capita and on regional dummies for Latin America and Africa, as well as year dummies. Let the predicted value from this regression be denoted $R \hat{P} L_{i}$. Dollar's index of DISTORTION is $R P L_{i} / R \hat{P} L_{i}$, averaged over the ten-year period 1976-1985. VARIABILITY is in turn calculated by taking the coefficient of variation of the annual observations of $R P L_{i} / R \hat{P} L_{i}$ for each country over the same period.

Dollar interprets the variation in the values of DISTORTION across countries as capturing cross-national differences in the restrictiveness of trade policy. He states: "the index derived here measures the extent to which the real exchange rate is distorted away from its freetrade level by the trade regime" (Dollar 1992, 524). Later on, referring to $R P L_{i}$, he writes:

if there were no non-tradables, cross-country variation in these price levels could be taken directly as a measure of inward or outward orientation caused by trade policy. For instance, a country sustaining a high price level over many years would clearly have to be a country with a relatively large amount of protection (inward orientation).

Since this type of claim is often made in other work as well, ${ }^{13}$ we shall spend some time on it before reviewing Dollar's empirical results. We will show that a comparison of price indices for tradables is informative about levels of trade protection only under very restrictive conditions that are unlikely to hold in practice. We will also show that the empirical relationship between DISTORTION and growth identified by Dollar (1992) is not robust to the inclusion of standard control variables, the use of updated Summers-Heston data, or to changes in the time period analyzed.

$\underline{\text { Trade policies and price levels }}$

We will not discuss further Dollar's method for purging the component of non-tradable goods prices that is systematically related to income and other characteristics. ${ }^{14}$ Assuming the method is successful, the DISTORTION measure approximates (up to a random error term) the price of a country's tradables relative to the U.S. Letting $P^{T}$ stand for the price index for tradables and neglecting the error, the DISTORTION index for country $i$ can then be expressed as $P_{i}^{T} /\left(e_{i} P_{U S}^{T}\right)$.

Let us, without loss of generality, fix the price level of tradables in the U.S., $P_{U S}^{T}$, and assume that free trade prevails in the U.S. The question is under what conditions will trade restrictions be associated with higher levels of $P_{i}^{T} /\left(e_{i} P_{U S}^{T}\right)$. Obviously, the answer depends on the effect of the restrictions on $P_{i}^{T}$ (and possibly on $e_{i}$ ).

\footnotetext{
${ }^{13}$ E.g., in Bhalla and Lau (1992), whose index is also used in Harrison (1996). We will discuss Harrison's paper in the penultimate section.

${ }^{14}$ For a good recent discussion of the problems that may arise on this account see Falvey and Gemmell (1999).
} 
Note that $P_{i}^{T}$ is an aggregate price index derived from the domestic prices of two types of tradables, import-competing goods and exportables. Hence $P_{i}^{T}$ can be expressed as a linearly homogenous function of the form:

$$
P_{i}^{T}=\pi\left(p_{i}^{m}, p_{i}^{x}\right)
$$

where $p_{i}^{m}$ and $p_{i}^{x}$ are the domestic prices of import-competing goods and exportables, respectively. Since Summers-Heston price levels are estimated for an identical basket of goods, the price-index function $\pi($.$) applies equally to the U.S.$

$$
P_{U S}^{T}=\pi\left(p_{U S}^{m}, p_{U S}^{x}\right)
$$

Next, define $t_{i}^{m}$ and as $t_{i}^{x}$ the ad-valorem equivalent of import restrictions and export restrictions, respectively. Assume that the law of one price holds (we shall relax this below). Then, $p_{i}^{m}=e_{i} p_{U S}^{m}\left(1+t_{i}^{m}\right)$ and $p_{i}^{x}=e_{i} p_{U S}^{x} /\left(1+t_{i}^{x}\right)$. Consequently, the domestic price of tradables relative to U.S. prices can be expressed as

$$
\frac{P_{i}^{T}}{e_{i} P_{U S}^{T}}=\frac{\pi\left(p_{U S}^{m}\left(1+t_{i}^{m}\right), p_{U S}^{x} /\left(1+t_{i}^{x}\right)\right)}{\pi\left(p_{U S}^{m}, p_{U S}^{x}\right)}=\frac{\left(1+t_{i}^{m}\right) \pi\left(p_{U S}^{m}, \frac{p_{U S}^{x}}{\left(1+t_{i}^{x}\right)\left(1+t_{i}^{m}\right)}\right)}{\pi\left(p_{U S}^{m}, p_{U S}^{x}\right)},
$$

where we have made use of the linear homogeneity of $\pi($.$) . Note that the nominal exchange rate$ has dropped out thanks to the assumption of the law of one price.

Consider first the case where there are binding import restrictions, but no export restrictions $\left(t_{i}^{m}>0\right.$ and $\left.t_{i}^{x}=0\right)$. In this instance, it is apparent that $P_{i}^{T}>e_{i} P_{U S}^{T}$, and trade restrictions do indeed raise the domestic price of tradables (relative to the benchmark country). Judging from the quotations above, this is the case that Dollar seems to have in mind.

On the other hand, consider what happens when the country in question rescinds all import restrictions and imposes instead export restrictions at an ad-valorem level that equals that of the import restrictions just lifted $\left(t_{i}^{m}=0\right.$ and $\left.t_{i}^{x}>0\right)$. From the Lerner (1936) symmetry theorem, it is evident that the switch from import protection to export taxation has no resourceallocation and distributional effects for the economy whatsoever. The relative price between tradables, $p_{i}^{m} / p_{i}^{x}$, remains unaffected by the switch. Yet, because export restrictions reduce the domestic price of exportables relative to world prices, it is now the case that $P_{i}^{T}<e_{i} P_{U S}^{T}$. The country will now appear, by Dollar's measure, to be outward oriented.

One practical implication is that economies that combine import barriers with export taxes (such as many countries in Sub-Saharan Africa) will be judged less protected than those that rely on import restrictions alone. Conversely, countries that dilute the protective impact of import restrictions by using export subsidies $\left(t_{i}^{x}<0\right)$ will appear more protected than countries that do not do so.

Hence the DISTORTION index is sensitive to the form in which trade restrictions are applied. This follows from the fact that trade policies work by altering relative prices within an economy; they do not have unambiguous implications for the level of prices in a country relative 
to another. A necessary condition for Dollar's index to do a good job of ranking trade regimes according to restrictiveness is that export policies (whether they tax or promote exports) play a comparatively minor role. Moreover, as we show in the next section, this is not a sufficient condition.

How relevant is the law of one price in practice?

The discussion above was framed in terms that are the most favorable to Dollar's measure, in that we assumed the law of one price (LOP) holds. Under this maintained hypothesis, the prices of tradable goods produced in different countries can diverge from each other, when expressed in a common currency, only when there exist trade restrictions (or transport costs).

However, there is a vast array of evidence suggesting that LOP does not accurately describe the world we live in. In a recent review article, Rogoff $(1996,648)$ writes of the "startling empirical failure of the law of one price." Rogoff concludes: "commodities where the deviations from the law of one price damp out very quickly are the exception rather than the rule" (Rogoff 1996, 650). Further, the evidence suggests that deviations from LOP are systematically related to movements in nominal exchange rates (see references in Rogoff 1996). Indeed, it is well known that (nominal) exchange-rate policies in many developing countries are responsible for producing large and sustained swings in real exchange rates. Trade barriers or transport costs typically play a much smaller role.

Dollar $(1992,525)$ acknowledges that "there might be short-term fluctuations [unrelated to trade barriers] if purchasing-power parity did not hold continuously," but considers that these fluctuations would average out over time. Rogoff $(1996,647)$ concludes in his survey that the speed of convergence to purchasing-power parity (PPP) is extremely slow, of the order of roughly 15 percent per year. At this speed of convergence, averages constructed over a time horizon of 10 years (the horizon used in Dollar's paper) would exhibit substantial divergence from PPP in the presence of nominal shocks.

Under this interpretation, a significant portion of the cross-national variation in price levels exhibited in DISTORTION would be due not to trade policies, but to monetary and exchange-rate policies. Unlike trade policies, nominal exchange-rate movements have an unambiguous effect on the domestic price level of traded goods relative to foreign prices when LOP fails: an appreciation raises the price of both import-competing and exportable goods relative to foreign prices, and a depreciation has the reverse effect. Countries where the nominal exchange rate was not allowed to depreciate in line with domestic inflation would exhibit an appreciation of the real exchange rate (a rise in domestic prices relative to foreign levels), and correspondingly would be rated high on the DISTORTION index. Countries with aggressive policies of devaluation (or low inflation relative to the trend depreciation of their nominal exchange rate) would receive low DISTORTION ratings.

Transport costs provide another reason why DISTORTION may be unrelated to trade policies, especially in a large cross-section of countries. Dollar's index would be influenced by geographic variables such as access to sea routes and distance to world markets, even when the 
LOP - appropriately modified to account for transport costs-holds. Hence in practice DISTORTION is likely to capture the effects of geography as well as of exchange-rate policies. Indeed, when we regress Dollar's DISTORTION index on the black market premium (a measure of exchange rate policy), a set of continent dummies, and two trade-related geographic variables (the coastal length over total land area and a dummy for tropical countries), we find that these explain 52 percent of the variation in Dollar's distortion index (Table III.1, column 1). Not only is the additional effect of two trade policy variables (tariffs and quotas) minor in comparison (column 2), but these enter with the wrong sign! Higher levels of tariffs and quotas seem to induce, if anything, lower levels of price distortions according to Dollar's index, after relevant geographic characteristics and exchange rate policy variables are controlled for.

To summarize, DISTORTION is theoretically appropriate as a measure of trade restrictions when three conditions hold: (a) there are no export taxes or subsidies in use; (b) the law of one price holds continuously; and (c) there are no systematic differences in national price levels due to transport costs and other geographic factors. Obviously, all of these requirements are counterfactual. Whether one believes that DISTORTION still provides useful empirical information on trade regimes depends on one's priors regarding the practical significance of the three limitations expressed above. ${ }^{15}$ Our view is that the second and third of these--the departure from LOP and the effect of geography--are particularly important in practice. We regard it as likely that it is the variance in nominal exchange-rate policies and geography, and not the variance in trade restrictions, that drives the cross-sectional variance of DISTORTION.

Why variability?

As mentioned previously, Dollar (1992) uses his measure of DISTORTION in conjunction with a measure of VARIABILITY, the latter being the coefficient of variation of DISTORTION measured on an annual basis. He is driven to do this because the country rankings using DISTORTION produce some "anomalies." For example, "Korea and Taiwan have the highest distortion measures of the Asian developing economies" and "the rankings within the developed country groups are not very plausible" (Dollar 1992, 530-531). The ten least distorted countries by this measure include not only Hong Kong, Thailand, Malta, but also Sri Lanka, Bangladesh, Mexico, South Africa, Nepal, Pakistan and Syria! Burma's rating (90) equals that of the United States. Taiwan (116) is judged more distorted than Argentina (113). Our discussion above indicated that DISTORTION is highly sensitive to the form in which trade policies are applied and to exchange-rate policies as well as omitted geographic characteristics. So such results are not entirely surprising.

Dollar states that the "number of anomalies declines substantially if the real exchange rate distortion measure is combined with real exchange rate variability to produce an outward orientation index" (Dollar 1992, 531). He thus produces a country ranking based on a weighted average of the DISTORTION and VARIABILITY indices. Since these two indices are entered

\footnotetext{
15 The sensitivity of Dollar's index to these assumptions highlights a generic difficulty with regression-based indices which use the residual from a regression to proxy for an excluded variable: such indices capture variations in the excluded variable accurately only as long as the model is correctly and fully specified. If some variables are excluded from the estimated equation, they will form part of the index.
} 
separately in his growth regressions, we shall not discuss this combined index of "outward orientation" further.

However, we do wish to emphasize the obvious point that the VARIABILITY index has little to do with trade restrictions, as commonly understood, or with inward- or outwardorientation per se. Remember that DISTORTION is the (adjusted) price level of tradables relative to a foreign benchmark. Consider what happens when this relative price fluctuates because of movements in the domestic price of tradables. Suppose first that the prices of nontradables move in synch with the price of tradables. In this case, VARIABILITY captures the movement of the entire domestic price structure in relation to foreign prices, and whatever "distortions" or "biases" are thereby created do not discriminate between tradables and nontradables (and much less among tradables). Alternatively, suppose that the prices of tradables fluctuate against non-tradables as well. Now, domestic relative prices do exhibit instability, but the effect of this on relative production and consumption incentives cannot be deduced a priori. Since the tradable and non-tradable sectors share a common relative price, one of these sectors cannot experience greater price risk without the other doing the same. The economy-wide risk may result in lower investment overall, but there is no presumption that this makes the economy more inward oriented.

What does VARIABILITY really measure? The ten countries with the highest VARIABILITY scores are Iraq, Uganda, Bolivia, El Salvador, Nicaragua, Guyana, Somalia, Nigeria, Ghana, and Guatemala. For the most part, these are countries that have experienced very high inflation rates and/or severe political disturbances during the 1976-85 period. It is plausible that VARIABILITY measures economic instability at large. In any case, it is unclear to us why we should think of it as an indicator of trade orientation.

\section{Empirical results}

We check the robustness of Dollar's (1992) empirical results by extending them in two directions. First, we rerun his regressions in a more conventional form, following standard practice in recent cross-national work on growth. Second, we redo his calculations for the DISTORTION and VARIABILITY indices using more recent Summers-Heston Mark 5.6 data to see whether his regression results hold with the revised data.

The first column of Table III.2 shows our replication of the core Dollar (1992) result for 95 developing countries. Dollar's benchmark specification includes on the right-hand side the investment rate (as a share of GDP, averaged over 1976-85) in addition to DISTORTION and VARIABILITY. As shown in column (1), DISTORTION and VARIABILITY both enter with negative and highly significant coefficients using this specification. (Our results are virtually identical to those in Dollar (1992), with the difference that our t-statistics are based on heteroskedasticity-corrected standard errors.)

None of Dollar's runs include standard regressors such as initial income, education, and regional dummies. The other columns of Table III. 2 show the results as we alter Dollar's specification to make it more compatible with recent cross-national work on growth (e.g., Barro 1997). First, we add regional dummies for Latin America, East Asia, and Sub-Saharan Africa to 
ensure that the results are not due to omitted factors correlated with geographical location (column 2). Next we drop the investment rate (column 3), and add in succession initial income (column 4) and initial schooling (column 5). ${ }^{16}$ The dummies for Latin America and Sub-Saharan Africa are negative and statistically significant. Initial income and education also enter significantly, with the expected signs (negative and positive, respectively).

We find that the VARIABILITY index is robust to these changes, but that DISTORTION is not. In fact, as soon as we introduce regional dummies in the regression, the estimated coefficient on DISTORTION comes down sizably and becomes insignificant. Whatever DISTORTION may be measuring, this raises the possibility that the results with this index are spurious, arising from the index's correlation with (omitted) regional effects. ${ }^{17}$

Dollar's original results were based on data from Mark 4.0 of the Summers-Heston database (Summers and Heston 1988). In Table III.3, we carry out a similar exercise using the more recent version (Mark 5.6) of the Summers-Heston data. We have re-calculated Dollar's DISTORTION and VARIABILITY indices using the revised data, but have confined ourselves to the same period examined by Dollar (1976-85). The revised data allow us to generate these indices for 112 developing countries. We show results with Dollar's original sample of 95 countries also.

The correlation between the revised and original DISTORTION measures, although positive, is only moderately high $(0.56) .{ }^{18}$ The correlation between the two VARIABILITY indices is higher (0.71). One consequence is that the benchmark Dollar specification now has a much poorer fit (an $\mathrm{R}^{2}$ of 0.16 versus 0.38 in the original version). Moreover, the estimated coefficient on DISTORTION is positive, small, and statistically insignificant, even without the addition of regional dummies (Table III.3, column 1). Two countries, Ghana and Uganda, have much higher values for DISTORTION in the revised data than in the original. Including a dummy for these two countries renders the estimated coefficient on DISTORTION negative and statistically significant at the 90 percent level (column 2). With the inclusion of regional dummies, DISTORTION turns insignificant once again (columns 3 and 4). The results with the original 95-country sample are similar (columns 5-8), except that DISTORTION is now statistically significant (at the 90 percent level) when all the controls--including, most critically,

\footnotetext{
${ }^{16}$ The income variable comes from the Summers-Heston (Mark 4.0) data set used in Dollar (1992). Schooling is from Barro and Lee (1994).

${ }^{17}$ An alternative interpretation is that there is insufficient intra-regional variation in trade policy to distinguish its effect on growth from that of omitted regional effects. Note, however, that in columns 2-5 DISTORTION is insignificant while the Latin America and Sub-Saharan Africa dummies have statistically significant coefficients. Thus the effect of the regional dummies appears to be stronger than that of the trade policy indicators, shedding doubt on the interpretation that they are picking up only trade policy effects.

${ }^{18}$ This correlation is in great part influenced by two large outliers, Ghana and Uganda, which have much higher price levels in the more recent data. If one takes these two outliers out, the correlation between the two indices is .68
} 
the dummy for Ghana and Uganda--are introduced (column 8). ${ }^{19}$ The estimated coefficient on VARIABILITY is negative and statistically significant throughout.

We have carried out a number of similar exercises for cross-sections over different periods, as well as panel regressions with fixed effects. ${ }^{20}$ We don't report those results here for reasons of space. However, the bottom line that emerges is in line with the regressions just discussed: the estimated coefficient on VARIABILITY is generally robust to alterations in specifications; the coefficient on DISTORTION is not.

\section{Jeffrey Sachs and Andrew Warner (1995)}

We turn next to the paper "Economic Reform and the Process of Global Integration" by Jeffrey Sachs and Andrew Warner (1995). This extremely influential paper ${ }^{21}$ is an ambitious attempt to solve the measurement error problem in the literature by constructing an index of openness that combines information about several aspects of trade policy. The Sachs-Warner (SW) openness indicator (OPEN) is a zero-one dummy, which takes the value 0 if the economy was closed according to any one of the following criteria:

1. it had average tariff rates higher than $40 \%$ (TAR);

2. its nontariff barriers covered on average more than $40 \%$ of imports (NTB);

3. it had a socialist economic system (SOC);

4. it had a state monopoly of major exports (MON);

5. its black market premium exceeded $20 \%$ during either the decade of the 1970 s or the decade of the 1980s (BMP). ${ }^{22}$

The rationale for combining these indicators into a single dichotomous variable is that they represent different ways in which policymakers can close their economy to international trade. Tariffs set at 50 percent have exactly the same resource-allocation implications as quotas at a level that raised domestic market prices for importables by 50 percent. To gauge the effect of openness on growth, it is necessary to use a variable that classifies as closed those countries

\footnotetext{
${ }^{19}$ This significance is in great part driven by Zaire. When an additional dummy for Zaire is introduced into equation 8 , the t-statistic on the distortion variable drops to 1.11 .

${ }^{20}$ In four replications of Dollar's baseline specification for different decades we were able to find a negative effect of DISTORTION on growth only for the 1976-85 subperiod. Fixed effects and random effects panel estimates (with five or ten year averages as time periods) reveal no significant negative effect of DISTORTION on growth after a set of standard cross-country regressors are added. VARIABILITY has a negative and significant coefficient in all regressions except for the 1960-69 subperiod.

${ }^{21}$ A partial listing of papers that have made use of the Sachs-Warner index includes Hall and Jones (1998), Wacziarg (1998), Sala-i-Martin (1997), Burnside and Dollar (1997), and Collins and Bosworth (1996).

${ }^{22}$ Sachs and Warner use data from the following sources: Lee (1993) for non-tariff barriers, Barro and Lee (1993) for tariffs, World Bank (1994) for state monopoly of exports, Kornai (1992) for the classification of socialist and non-socialist countries, and International Currency Analysis (various years) for black market premia. There are 6 economies which Sachs and Warner rate as open or closed relying on information not contained in any of these data sets. These are Morocco, South Africa, Haiti, Luxembourg, Australia and New Zealand. For those economies, they either make a general assessment of their trade policies or rely on information from other reports on the level of protection. The results in this paper hold irrespective of how one classifies these six economies.
} 
that were able to effectively restrict their economies' integration into world markets through the use of different combinations of policies that would achieve that result. Furthermore, if these openness indicators are correlated among themselves, introducing them separately in a regression may not yield reliable estimates due to their possibly high level of collinearity.

The Sachs-Warner dummy has a high and apparently robust coefficient when inserted in growth regressions. The point estimate of its effect on growth (in the original benchmark specification) is 2.44 percentage points: economies that pass all five requirements experience on average economic growth two and a half percentage points higher than those that do not. The tstatistic is 5.50 (5.83 if estimated using robust standard errors). This coefficient appears to be highly robust: in a recent paper which subjects 58 potential determinants of growth to an exhaustive sensitivity analysis, the average p-value for the Sachs-Warner index is less than 0.1 percent. $^{23}$

In this section we ask several questions about the Sachs-Warner results. First, we ask which, if any, of the individual components of the index are responsible for the strength of the Sachs-Warner dummy. We find that the Sachs-Warner dummy's strength derives mainly from the combination of the black market premium (BMP) and the state monopoly of exports (MON) variables. Very little of the dummy's statistical power would be lost if it were constructed using only these two indicators. In particular, there is little action in the two variables that are the most direct measures of trade policy: tariff and non-tariff barriers (TAR and NTB).

We then ask to what extent the black-market premium and state monopoly variables are measures of trade policy. We suggest that their significance in explaining growth can be traced to their correlation with other determinants of growth: macroeconomic problems in the case of the black-market premium, and location in Sub-Saharan Africa in the case of the state monopoly variable. We show that the Sachs-Warner indicator is not robust against alternative indicators that combine measures of macroeconomic distress with location in Sub-Saharan Africa. We conclude that the Sachs-Warner indicator serves as a proxy for a wide range of policy and institutional differences, and that it yields an upwardly-biased estimate of the effects of trade restrictions proper.

Which individual variables account for the significance of the Sachs-Warner dummy?

In Table IV.1 we show the simple correlations between economic growth and the components of the SW dummy during the 1970-89 period, the period analyzed by Sachs and Warner (1995). These correlations suggest that two of the underlying variables used to construct the index are significantly associated with growth: whether the economy has a state monopoly of its main exports (MON) and whether its black market premium exceeded 20\% in the 1970s or 1980s (BMP). ${ }^{24}$ In Table IV.2 we see that this result is confirmed when the variables are

${ }^{23}$ Sala-i-Martin (1997). The variable used by Sala-i-Martin is the number of years an economy was open according to the Sachs-Warner criteria, whereas here we follow Sachs and Warner's (1995) original article and use a dummy which captures whether or not the economy was open during the 1970-89 time period.

${ }^{24}$ The strength of the BMP variable is in part derived from its dichotomous nature. The correlation of the black market premium with growth is -0.29 for the 1970 s and -0.26 for the 1980 s. See the next subsection for more discussion of this point. 
inserted simultaneously in a growth regression. We use the same controls used by Sachs and Warner (1995), most of which are standard in the empirical growth literature. ${ }^{25}$ The variables BMP and MON are highly significant, whereas the rest are not (column 2). An F-test for the joint significance of the other three components (SOC, TAR and NTB) yields a p-value of $0.25 .^{26}$ (Note that the number of observations is lower in the regression where the components are entered individually because not all of the 79 countries in the original sample have data for each of the five SW components.)

Another way to check whether BMP and MON drive the Sachs-Warner result is to ask the following question: suppose that we had built a dummy variable, in the spirit of Sachs and Warner, which classified an economy as closed only if it was closed according to BMP and MON. That is, suppose we ignored the information the other three variables give us as to the economy's openness. How significant would the coefficient of our variable be in a growth regression? How different would the partition between open and closed economies that it generates be from that generated by the SW dummy? Suppose alternatively that we also constructed an openness dummy based only on the information contained in SOC, NTB, and TAR. How significant would that variable be in a growth regression? And how correlated would it be with openness?

Columns (3)-(6) of Table IV.2 address the question of significance. We denote as BM a variable that takes the value 1 when the economy is "open" according to criteria 4 and 5 above, whereas SQT equals 1 when the economy passes criteria 1, 2 and 3. We substitute these variables for the SW openness index in the regression Sachs and Warner present in their paper. Entered on its own, BM is highly significant, with an estimated coefficient that is very close to that on OPEN (2.09 versus 2.44; see column 3). When SQT is substituted for BM, the estimated coefficient on SQT is much smaller (0.88) and significant only at the 90 percent level (column 4). We next enter BM and SQT simultaneously: the coefficient of SQT now has a t-statistic of 1.59, whereas the coefficient on BM retains a t-statistic of 5.09 and a point estimate (2.12) close to that on the openness variable in the original equation (column 5). Once the investment rate and investment prices, which are likely to be endogenous, are taken out of the equation, the tstatistic on SQT drops to 1.30 and that on BM rises to 5.94 (column 6).

The comparability of the results in Table IV.2 is hampered by the fact that the sample size changes as we move from one column to the next. As noted above, this is because not all of the 79 countries in the sample have data for each of the individual Sachs-Warner components. To check whether this introduces any difficulties for our interpretation, we have also run these regressions holding the sample size fixed. We restricted the sample to those countries which have the requisite data for all the components, using both the original specification $(n=71)$ and a specification where we drop two of the Sachs-Warner regressors with t-statistics below unity

\footnotetext{
${ }^{25}$ These are log of GDP in 1970, secondary schooling in 1970, primary schooling in 1970, government consumption as a percent of GDP, number of revolutions and coups per year, number of assassinations per million population, relative price of investment goods, and ratio of investment to GDP.

26 The result is not due to multicollinearity: the $\mathrm{R}^{2} \mathrm{~s}$ from regressions of either of SOC, NTB and TAR on the other two are, respectively, 0.02, 0.05. and 0.05 .
} 
(primary schooling and revolutions and coups) to gain additional observations $(n=74)$. In both cases, our results were similar to those reported above: Regardless of whether BM and SQT are entered separately or jointly, the coefficient on BM is highly significant (with a point estimate that is statistically indistinguishable from that on OPEN) while the coefficient on SQT is insignificant. $^{27}$

Hence, once BM is included, there is little additional predictive power coming from regime type (socialist or not), level of tariffs, or coverage of non-tariff barriers. ${ }^{28}$ The strength of the Sachs-Warner index derives from the low growth performance of countries with either high black market premia or state export monopolies (as classified by Sachs and Warner [1995]).

This point is underscored by Figures IV.1 and IV.2, which show the partial associations between economic growth and these two alternative indicators of openness (based on column 5 of Table 2). The partial association between BM and growth is quite strong, while that between SQT and growth is weak. ${ }^{29}$

The reason why BM performs so much better than SQT is that BM generates a partition between closed and open economies that is much closer to that generated by OPEN than the partition generated by SQT. Only six economies are classified differently by BM when compared to OPEN, while OPEN and SQT disagree in 31 cases. The disagreement between OPEN and SQT is concentrated in 15 African and 12 Latin American economies which SQT fails to qualify as closed but BM (and therefore OPEN) does: the African economies are found to

\footnotetext{
${ }^{27}$ The largest t-statistic we obtained for SQT in these runs is 1.4. These results are not shown to save space, but are available on request.
}

${ }^{28}$ A different form in which the "horse race" can be run, suggested to us by Jeffrey Sachs, is to introduce OPEN and BM together in the regression, to see if OPEN clearly "wins." When we do this, we find that the point estimate of the coefficient on OPEN is generally larger than that on BM, but that the two coefficients are statistically indistinguishable from each other. This is true regardless of whether we rely only on the raw data to classify countries or use Sachs and Warner's qualitative evaluation for six economies. The respective coefficients on OPEN and $\mathrm{BM}$ are 1.31 (1.86) and 0.99 (1.78) when we use the raw data, and 1.64 (2.64) and 0.99 (1.79) when we use the Sachs-Warner subjective evaluations (t-statistics in parentheses). The two coefficients cannot be distinguished statistically because OPEN and BM are highly collinear with each other (as we discuss further below). On the other hand, when OPEN and SQT are entered together, SQT has the wrong (negative) sign and the equality of coefficients can be rejected easily.

${ }^{29}$ This conclusion is true regardless of how we rate the countries in which Sachs and Warner's classification did not correspond to the values of the underlying data. As noted in a previous footnote, there are 6 economies for which Sachs and Warner rely on qualitative assessments and information from other reports instead of their primary data to classify them as open or closed. As it is not always clear what dimension of trade policy these general assessments pertain to, the results in the text rate an economy as closed according to BM and SQT when it was rated as closed according to this additional information. If we base our classification only on the raw data and ignore these supplementary assessments, the t-statistic on SQT goes down to 1.21. The t-statistic on SQT can be made to increase up to 2.01 if one classifies New Zealand as a closed economy in terms of quotas but not in terms of other trade policies, as Sachs and Warner's comments on New Zealand seem to imply. This is still well below the tstatistic on BM of 5.07. Furthermore, the characterization of New Zealand as a closed economy on the basis of its quotas is inconsistent with the definition of the NTB variable for other countries, which use data for 1985-88 (Lee, 1993), a time by which New Zealand's Fourth Labor Government had already started an aggressive liberalization program bringing quotas down below the threshold level of 40\% (Laird and Yeats 1990, Table 4.2; Roper 1997). 
be closed because of their state monopolies of exports and those of Latin America because of their high levels of black market premia. The average rate of growth of these economies is 0.24 , much lower than the sample average of 1.44 .

Our result is not due to an arbitrary distinction between BM and SQT. SQT performs more poorly than any other openness index constructed on the basis of three of the five indicators used by Sachs and Warner, and BM performs more strongly than any index constructed with two of these five indicators (Table IV.3, upper panel). A similar result applies to partitions along other dimensions: those constructed using four indicators which exclude either BMP or MON do more poorly than any of those which include them; and either BMP or MON individually do better than any of the other indicators (Table IV.3, lower panel).

In view of the overwhelming contribution of the black market premium and the dummy on state monopoly of exports to the statistical performance of the Sachs-Warner openness index, we next ask what exactly these two variables measure. To what extent are they indicators of trade policy? Could they be correlated with other variables that have a detrimental effect on growth, therefore not giving us much useful information on trade openness per se? We turn now to these questions, first with an analysis of the state monopoly of exports variable, and then with a discussion of the black market premium variable.

\section{What does the State Monopoly of Exports variable represent?}

Sachs and Warner's rationale for using an indicator of the existence of a state monopoly on major exports is the well-known equivalence between import and export taxes (Lerner 1936). The MON variable is meant to capture cases in which governments taxed major exports and therefore reduced the level of trade (exports and imports). Sachs and Warner use an index of the degree of distortions caused by export marketing boards, taken from the World Bank study Adjustment in Africa: Reforms, Results, and the Road Ahead (World Bank 1994). ${ }^{30}$

We note that the World Bank study covers only 29 African economies that were under structural adjustment programs from 1987 to 1991. This results in a double selection bias. First, non-African economies with restrictive policies towards exports automatically escape scrutiny. Second, African economies with restrictive export policies but not undergoing adjustment programs in the late 1980s are also overlooked. Since Africa was the slowest growing region during the period covered and economies that need to carry out structural adjustment programs are likely to be doing worse than those that are not, the effect is to bias the coefficient on openness upwards on both accounts.

How this selection bias affects the country classification can be illustrated by two examples: Indonesia and Mauritius. Both of these economies are rated as open in the SachsWarner sample. Both are excluded from the sample used to construct the state monopoly on exports variable: Indonesia because it is not in Africa, and Mauritius because, due to its good economic performance, it was not undergoing a World Bank adjustment program during the late

\footnotetext{
${ }^{30}$ Sachs and Warner (1995) cite a different source in their paper, but World Bank (1994) appears to be the correct source.
} 
1980s. Yet both of these economies would seem to satisfy the conditions necessary to be rated as closed according to the export monopoly criterion: Indonesian law restricts oil and gas production to the state oil company, PERTAMINA, and Mauritius sells all of its export sugar production through the Mauritius Sugar Syndicate. ${ }^{31}$ Indonesia and Mauritius are also among the ten fastest growing economies in the Sachs-Warner sample.

One of the problems that this selection bias causes in the Sachs-Warner estimation is that it makes the MON variable virtually indistinguishable from a sub-Saharan Africa dummy. ${ }^{32}$ There are 13 African countries (out of 47) in the Sachs-Warner study that are not rated as closed according to MON. (Twelve of these were not included in World Bank study.) But for all but one of these observations MON adds no additional information, either because they are dropped from the sample due to unavailability of other data or because they are rated as closed by other trade policy indicators used to construct the index. The result is that the only difference between having used an export marketing board variable to construct the Sachs-Warner index and having used a sub-Saharan Africa dummy is a single observation. That observation is Mauritius, the fastest growing African economy in the sample. ${ }^{33}$

We conclude that the export marketing board variable, as implemented, is not a good measure of trade policy and creates a serious bias in the estimation. Except for Mauritius, whose classification as open seems to us to be due exclusively to selection bias, the inclusion of MON in the Sachs-Warner dummy is indistinguishable from the use of a Sub-Saharan Africa dummy. In that respect, the only information that we can extract from it is that African economies have grown more slowly than the rest of the world during the seventies and eighties.

\section{What does the Black Market Premium variable measure?}

The second source of strength in the Sachs-Warner openness variable is the black market premium. Indeed, the simple correlation between the openness dummy and BMP is 0.63 . A simple regression of growth on the black market premium dummy and all the other controls gives a coefficient of -1.05 with a t-statistic of nearly 2.5 in absolute value. How good an indicator of openness is the black market premium?

\footnotetext{
${ }^{31}$ See Pertamina (1998) for Indonesia and Gulhati and Nahari $(1990,22)$ as well as World Bank $(1989,6)$ for Mauritius. Oil represented $61.2 \%$ of Indonesian exports and sugar represented between $60-80 \%$ of Mauritius exports during the period covered by the Sachs-Warner study (see World Bank 1983, Table E, and 1998). Although manufactures have recently outstripped sugar as Mauritius's main export, this is a recent development: in 1980 sugar represented $65 \%$ of Mauritius's total exports and agriculture was surpassed by manufacturing as the main source of exports only in 1986 (World Bank 1998).

32 This is true despite the fact that the Sachs-Warner dummy's coefficient is still significant after the estimation is carried out controlling for a Sub-Saharan Africa dummy. The reason is that the SW dummy still has substantial explanatory power left due to its use of the Black Market Premium variable.

${ }^{33}$ Both Lesotho and Botswana had higher growth rates than Mauritius but Lesotho was not rated due to insufficient data (Sachs and Warner 1995, 85) and Botswana is dropped from their sample because of unavailability of government consumption data.
} 
The black market premium measures the extent of rationing in the market for foreign currency. The theoretical argument for using the black market premium in this context is that, under certain conditions, foreign exchange restrictions act as a trade barrier. Using our notation from the previous section (but omitting country subscripts), the domestic price of importcompeting goods relative to exportables can be expressed as follows:

$$
\frac{p^{m}}{p^{x}}=\frac{e^{m} p^{m^{*}}\left(1+t^{m}\right)\left(1+t^{x}\right)}{e^{x} p^{x^{*}}}
$$

where an asterisk refers to border prices. We now allow for the possibility that the exchange rates applicable to import and export transactions $\left(e^{m}\right.$ and $e^{x}$, respectively) can differ. Foreign currency rationing can drive a wedge between these two exchange rates.

Suppose the form that rationing takes is as follows: all imports are financed at the margin by buying foreign currency in the black market, while all export receipts are handed to the central bank at the official exchange rate. In this case, $e^{m} / e^{x}=(1+B M P)$, and the presence of a black market premium works exactly like a trade restriction (by raising $p^{m} / p^{x}$ ). ${ }^{34}$ On the other hand, if at the margin exporters can sell their foreign-currency receipts on the black market as well, then the wedge between $e^{m}$ and $e^{x}$ disappears. In this case, the black-market premium does not work like a trade restriction. ${ }^{35}$

But there is a deeper problem with interpreting the black-market premium as an indicator of trade policy. Sachs and Warner rate an economy closed according to BMP if it maintains black market premia in excess of 20 percent for a whole decade (the 1970s or the 1980s). Such levels of the black market premium are indicative of sustained macroeconomic imbalances. Overvaluation of this magnitude is likely to emerge (i) when there is a deep inconsistency between domestic aggregate demand policies and exchange rate policy, or (ii) when the government tries to maintain a low level of the exchange rate in order to counteract transitory confidence or balance of payments crises. Such imbalances may be sparked by political conflicts, external shocks, or sheer mismanagement, and would typically manifest themselves in inflationary pressures, high and growing levels of external debt, and a stop-go pattern of policymaking. In addition, since black market premia tend to favor government officials who can trade exchange rate allocations for bribes, we would expect them to be high wherever there are high levels of corruption. Therefore, countries with greater corruption, a less reliable bureaucracy, and lower capacity for enforcement of the rule of law are also likely have higher black market premia.

Hence it is reasonable to suppose that the existence of sizable black market premia over long periods of time reflects a wide range of policy failures. It is also reasonable to think that these failures will be responsible for low growth. What is more debatable, in our view, is the attribution of the adverse growth consequences exclusively to the trade-restrictive effects of black market premia.

\footnotetext{
34 The distributional effects can differ of course, as import tariffs are paid in to the treasury while scarcity rents in the foreign-currency market can be appropriated by individuals.

${ }^{35}$ In one respect, Sachs and Warner (1995) treat BMP differently from a trade restriction: the cutoff for tariffs (TAR) is set at 40 percent while that for BMP is set at 20 percent.
} 
As shown in Table IV.4, many of the relationships just discussed are present in the data. The simple correlations of black market premia with the level of inflation, the debt/exports ratio, wars and institutional quality are all sufficiently high to warrant preoccupation. Indeed, of the 48 economies ranked as closed according to the BMP criteria, 40 had one or more of the following characteristics: average inflation over 1975-1990 higher than 10 percent, debt to GNP ratio in 1985 greater than 125 percent, a terms-of-trade decline of more than 20 percent, an institutional quality index less than 5 (on a scale of 1 to 10), or involvement in a war.

Table IV.5 shows that there are also important threshold effects in the black market premium. If we insert the black market premium in the 1970s and 1980s as continuous variables in the regression, the estimated coefficients are extremely weak and they fail to pass an F-test for joint significance at 10 percent. $^{36}$ The strength of the Sachs-Warner result comes in great part from the dichotomous nature of the BMP variable and from the fact that the 20 percent threshold allows more weight to be placed on the observations for which the black market premia--and probably also the underlying macroeconomic imbalances--are sufficiently high.

That the effect of the black market premium is highly sensitive to the macroeconomic and political variables that one controls for is shown in Table IV.6, where we present the results of controlling for each of the indicators of macroeconomic and political distress in Table IV.4. In three out of 5 cases, each one of these variables individually is enough to drive the coefficient on BMP below conventional levels of significance. If we insert all our controls together, the estimated coefficient on BMP goes down by more than half and the t-statistic drops below 1 .

This kind of evidence does not by itself prove that higher black market premia are unrelated to growth performance. The results in Table IV.6 can be due to high multicollinearity between the black market premium and the indicators of macroeconomic and political distress that we have chosen. But what they do show is that there is very little in the data to help us distinguish the effect of high black market premia from those of other plausible right-hand side variables relating to macroeconomic distress. In other words, they show that the black market premium is not a good measure of trade policy, because it is also a proxy for many other variables unrelated to trade policy.

\section{$\underline{\text { Sensitivity of results }}$}

The interpretational problems with the State Monopoly of Exports and Black Market Premium variables would not be so important if these two were responsible for only part of the effect of the Sachs-Warner index on growth. But the fact that they seem to be its overwhelming determinant makes us worry about the extent to which the results speak meaningfully about the role of trade policies.

The arguments in the previous two sections have shown that the individual coefficients on MON and BMP are not very robust to controlling for variables such as an Africa dummy or indicators of macroeconomic and political distress. However, much of the force of the Sachs-

\footnotetext{
${ }^{36}$ Their joint inclusion raises the adjusted $\mathrm{R}^{2}$ from 0.359 to 0.382 .
} 
Warner variable comes from its combination of the effects of MON and BMP. ${ }^{37}$ The reason is that the Sachs-Warner dummy uses MON to classify as closed all but one of the economies in Sub-Saharan Africa and then uses BMP to classify as closed a set of economies with macroeconomic and political difficulties. It thus builds a "super variable" which is 1 for all nonAfrican economies without macroeconomic or political difficulties. This variable will be statistically stronger than either an Africa dummy or macroeconomic controls because it jointly groups information from both.

To show how the Sachs-Warner approach works, we use two indicators of economic and political disequilibrium, which are similar in method of construction to the Sachs-Warner variable. These are two synthetic indicators of macroeconomic and political distress and institutional quality. The first indicator, ICRG, is an index of institutional quality based on underlying numerical evaluations relating to the rule of law, bureaucratic quality, corruption, expropriation risk, and governmental repudiation of contracts (taken from Knack and Keefer 1995). It ranges from 0 to 10, with higher values indicating superior institutions. The second indicator, which we call DISEQ, is a dummy variable which is equal to one if the country exhibited signs of macroeconomic or political distress such as a debt-GNP ratio greater than $125 \%,{ }^{38}$ an average inflation greater than $10 \%$, a decline in its terms of trade of more than $20 \%$, or involvement in war. DISEQ is also equal to 0 if the country was in Africa. ${ }^{39}$

The correlations of DISEQ and ICRG with OPEN are respectively 0.64 and 0.72 . Indeed, if one introduces DISEQ and ICRG in a growth equation along with openness, the coefficient on openness falls to less than half its original value and the t-statistic on it is barely above 2 (regression 2, Table IV.7). Moreover, the Mauritius and Indonesia observations are key here: the t-statistic falls to 1.62 if one classifies these countries as closed because of their export monopolies (regression 3), and to 1.25 after regional dummies for Sub-Saharan Africa, Asia and Latin America are introduced (regression 4). ${ }^{40}$

Alternatively, simply controlling for ICRG and a set of continent dummies also drives the openness coefficient below conventional significance levels (regression 5). Even though this coefficient can be rendered significant again if one controls for the central government budget

\footnotetext{
${ }^{37}$ For example, if MON and BMP are inserted, together with an Africa dummy and a measure of institutional quality neither MON nor BMP are individually significant and the p-value for a joint significance test is 0.09 . (If we add NTB, TAR and SOC, the p-value rises to 0.31), but OPEN gets a t-statistic of 3.06 and BM one of 2.93 (SQT gets 1.46).

${ }^{38}$ Our source data for the debt/GDP ratio is World Bank (1995). Although this data covers only developing countries, OECD (1998) indicates that for no OECD country did the gross government public debt exceed $125 \%$ of GDP in 1985.

${ }^{39}$ The rationale for including an Africa dummy in this regression is our argument that the MON variable is essentially an Africa dummy. The Africa dummy therefore puts DISEQ on an equal footing with the Sachs-Warner dummy.

${ }^{40}$ The t-statistic can fall even further (to 0.72) if one changes Sachs and Warner's questionable classification of New Zealand as a closed economy (see footnote 8).
} 
surplus and population growth, the t-statistic on the openness variable remains barely above 2, with an absolute value less than half of that in the original regression (regression 6).

Statistically, the explanation for the fragility of the results on the coefficient of OPEN is that we have introduced in the regression a set of measures of macroeconomic and political distress which are highly correlated with growth and with the Sachs-Warner variable. Indeed, the high variability of the estimated coefficients in Table 7 is strongly indicative of multicollinearity.

Therefore, we do not pretend to have answered in this analysis the question of whether it is macroeconomic and political disruption that cause trade policy or the other way around. ${ }^{41}$ Nor do we give an answer to the question of whether all of these are determined in turn by some other underlying variables such as poor institutions or anti-market ideology. What we believe we have established is that the statistical power of the Sachs-Warner indicator derives not from the direct indicators of trade policy it incorporates, but from two components that we have reasons to believe will yield upwardly biased estimates of the effects of trade restrictions. The Sachs-Warner measure is so correlated with plausible groupings of alternative explanatory variables--macroeconomic instability, poor institutions, location in Africa--that it is risky to draw strong inferences about the effect of openness on growth based on its coefficient in a growth regression.

\section{$\underline{\text { V. Sebastian Edwards (1998) }}$}

The third paper that we discuss is Sebastian Edward's recent Economic Journal paper “Openness, Productivity and Growth: What Do We Really Know?" (Edwards 1998). The papers by Dollar and by Sachs and Warner deal with data problems by constructing new openness indicators. Edwards takes the alternative approach of analyzing the robustness of the openness-growth relationship to the use of different indicators. As Edwards states, " the difficulties in defining satisfactory summary indexes suggest that researchers should move away from this area, and should instead concentrate on determining whether econometric results are robust to alternative indexes" $(1998,386)$. The presumption is that the imperfections in specific indicators would not seem quite as relevant if the estimated positive coefficient on openness is found to be robust to differences in the way openness is measured.

To carry out this robustness analysis, Edwards runs regressions of total factor productivity growth on nine alternative indicators of openness (as well as initial income and a measure of schooling). ${ }^{42}$ His estimates of total factor productivity growth are the Solow residuals from panel regressions of growth on changes of capital and labor inputs. The nine

\footnotetext{
${ }^{41}$ The Sachs-Warner view is that causality goes from restrictive trade policies to macroeconomic instability (personal communication with Sachs). For the purposes of the present paper, we are agnostic about the existence or direction of any causality. An argument that macroeconomic imbalances are largely unrelated to trade policies is not difficult to make, and receives considerable support from cross-national evidence (see Rodrik 1999, chap. 4).

${ }^{42}$ In an earlier and heavily cited paper, Edwards (1992) carried out a similar analysis for growth rates of real GDP per capita using a somewhat different set of nine alternative indicators of trade policy distortions. We focus here on Edwards (1998) because it is more recent and the data set used in the earlier paper was not immediately available.
} 
indicators of openness he uses are: (i) the Sachs-Warner openness index; (ii) the World Bank's subjective classification of trade strategies in World Development Report 1987; (iii) Edward Leamer's (1988) openness index, built on the basis of the average residuals from regressions of trade flows; (iv) the average black market premium; (v) the average import tariffs from UNCTAD via Barro and Lee (1994); (vi) the average coverage of non-tariff barriers, also from UNCTAD via Barro and Lee (1994); (vii) the subjective Heritage Foundation index of Distortions in International Trade; (viii) the ratio of total revenues on trade taxes (exports + imports) to total trade; and (ix) Holger Wolf's regression-based index of import distortions for 1985.

The results Edwards presents are weighted least squares (WLS) regressions of TFP growth on (i)-(ix), where the weighting variable is GDP per capita in 1985. They are shown in column 1, rows 1-9, of Table V.1: six of the nine indicators are significant and all but one have the expected sign. He repeats the analysis using instrumental weighted least squares (column 1, Table V.2), and finds 5 of 9 indicators significant at 10\% (3 at 5\%) and all having the "correct" sign. ${ }^{43}$ He also builds an additional indicator as the first principal component of (i), (iv), (v), (vi) and (ix), which he finds to be significant in WLS estimation (row 10, Table V.1). He concludes that "these results are quite remarkable, suggesting with tremendous consistency that there is a significantly positive relationship between openness and productivity growth."

We will argue that Edwards' evidence does not warrant such strong claims. The robustness of the regression results, we will show, is largely an artifact of weighting and identification assumptions that seem to us to be inappropriate. Of the 19 different specifications reported in Edwards (1998), only 3 produce results that are statistically significant at conventional levels once we qualify these assumptions. Furthermore, the specifications that pass econometric scrutiny are based on data that suffer from serious anomalies and subjectivity bias.

\section{The problem with weighting}

The justification for the resort to weighted least squares estimation is not provided in the paper, but it is presumably to correct for possible heteroskedasticity in the residuals. If disturbances are not homoskedastic, ordinary least squares estimates will be inefficient. If the form of the skedastic function is known, then it is appropriate to use weighted least squares. This is indeed what Edwards implicitly assumes when he uses GDP per capita as his weighting variable. If it is unknown, one can use White's (1980) heteroskedasticity-consistent covariance matrix estimator, which is not dependent on the form taken by the heteroskedasticity.

When there is heteroskedasticity, the standard deviation of the disturbance in the growth equation varies systematically across countries. Edward's decision to weight his observations by the level of GDP per capita implies an assumption that the standard deviation of the disturbances in the growth equation is inversely proportional to the square root of the level of GDP per capita in 1985. In other words, if the United States is--as it in effect was in 1985 according to the Summers-Heston data-59 times wealthier than Ethiopia, the standard deviation of the growth

\footnotetext{
${ }^{43}$ In his paper, Edwards erroneously claims that two additional variables are significant in the IV-2SLS estimation: Leamer's index and Tariffs. This mistake was apparently due to two typographical errors in his Table 4, p. 393.
} 
rate conditional on having the United States' income is $7.7\left(59^{1 / 2}\right)$ times higher than conditional on having Ethiopia's income. Using the estimates of the residuals' standard deviation from one of the Edwards equations, we can calculate the implied root mean squared error of the growth rate conditional on having the incomes of the United Sates and of Ethiopia. The former is 8 percentage points, whereas the latter is 6 percentage points. It may be reasonable to suppose that growth data for poor countries are less reliable than that for rich countries, but the errors implied by Edwards' weighting assumption for poor countries' growth data seem to us to be unreasonably high. As a matter of fact, it is hard to think of a reason to be doing regression analysis on a broad cross-section of primarily poor countries if we believe that underdeveloped nations' economic data are this uninformative.

Column 2 of Tables V.1 and V.2 repeat Edwards' regressions using the log of 1985 per capita GDP as the weighting variable. In terms of our calculations above, the ratio between the US and Ethiopian standard deviations would now be a more reasonable 1.31. This set of regressions results in six of the eighteen coefficients having the "wrong" sign. Five out of nine coefficients are significant among the least squares regressions (four at 5\%), and two out of nine in the instrumental variables regressions. The coefficient on the principal components variable now becomes insignificant. ${ }^{44}$

One way to put aside doubts about the appropriateness of alternative assumptions regarding the nature of the skedastic function is to use White's (1980) heteroskedasticityconsistent standard errors, which are robust to the form of heteroskedasticity. We show these estimates in column 3 of Tables V.1 and V.2. Four out of nine coefficients are now significant among the least squares regressions (three at 5\%) and two out of nine among the IV regressions. Only twelve of the eighteen coefficients have the correct sign. The principal components variable is also insignificant.

The problem with identification

The two significant IV coefficients in Table V.2 are moreover quite sensitive to the specification of the instrument lists. In particular, equations 12 and 17 in Table V.2 are two of the only three equations in which the Heritage Foundation Index of Property Rights Protection is used as an instrument by Edwards. ${ }^{45}$ If this instrument is not excludable from the second stage regression, Edwards' IV estimation will give biased estimates of the coefficient of openness on

\footnotetext{
${ }^{44}$ Why does weighting by GDP give such different results? The reason seems to be that there is a relationship between the openness indices used by Edwards and TFP growth at high levels of income. This relationship in itself is apparently driven by the fact that the great majority of economies with restrictive trade practices and high levels of GDP per capita in 1985 were oil exporters. Because of their high incomes, these economies are weighted very heavily in the WLS regressions. It is well-known that oil exporting economies had very low rates of growth during the 1980s (see for example the studies in Gelb, 1988). If one redoes regressions 1-19 using GDP per capita weights but including a dummy for oil exporters one gets very similar results to those in column 3 of Tables 1 and 2: only the coefficients for the World Development Report Index (equations 2,12), the Heritage Foundation Index (equations 7,17) and the least squares estimate of the collected taxes ratio (equation 8) remain significant, and the least squares coefficient on quotas changes sign.

${ }^{45}$ His other instruments include: TFP growth in the 1970s and the black market premium, export/GDP, import/GDP and terms of trade changes for the 1975-79 period.
} 
growth. Theoretically, it seems to us unreasonable to assert that the protection of property rights can effectively be assumed not to be an important determinant of growth, given the extensive literature concerned precisely with such an effect. ${ }^{46}$ In Table V.3 we show that, if property rights are included in the second-stage regression for these two equations, this term gets a significant coefficient in equation 12 (World Development Report Index) and a positive albeit insignificant coefficient in Equation 17 (Heritage Foundation Index). Chi-squared tests of the overidentifying restrictions also reject the null hypothesis that these restrictions hold for equation 12 .

Furthermore, in both equations the t-statistic on the openness proxy falls to well below .5 in absolute value.

If we take seriously the fact that property rights are not excludable from the productivity growth regressions, we are left with the conclusion that, among 19 different specifications, we find evidence of a negative and statistically significant correlation between trade-restricting policies and productivity growth in only 3 cases. Those are the ones that use the Collected Taxes Ratio, the World Development Report Index, or the Heritage Foundation Index. We take up some problems with these indices in the next subsection.

\section{Data issues}

Edwards reports that the Collected Taxes Ratio (which measures trade tax revenue as a proportion of total trade) is calculated from raw data provided by the IMF. We are puzzled by this data because many of the numbers for developing countries are implausible. India, a country with one of the world's highest tariff rates, is listed as having an average ratio of 2.4 percent, lower than the sample average and barely above the value for Chile ( 2.3 percent). The mean value of the Collected Taxes Ratio in the sample is 2.8 percent, which strikes us as very low.

We have attempted to replicate Edwards' results using data from the World Bank's most recent (1998) World Development Indicators. This source, which was not available at the time the Edwards analysis was first conducted, provides collected trade tax ratios for imports and exports separately, which we have combined to derive an index in the spirit of Edwards' variable. $^{47}$ According to this index, India's average trade tax is 37.3 percent (a more plausible figure than Edwards' 2.4 percent). We replicate equation 7 of Table V.1 with this data, and the results are shown in Table V.4. The coefficient on average duties is now positive albeit insignificant (column 2). If we introduce import and export duties separately (column 3), import duties in fact get a positive and significant coefficient (contrary to the expected negative coefficient) and export duties are insignificant. One shortcoming of these specifications

\footnotetext{
${ }^{46}$ Barro (1997) names "the importance of institutions that ensure property rights and free markets," for economic growth as one of the "dominant themes" of his recent research (p. xiv). For examples of the literature emphasizing the importance of property rights for economic growth, see Clague, Knack, Keefer, and Olson (1996), Acheson and McFetridge (1996), Jodha (1996), Tornell (1997), Park and Ginarte (1997) and Grossman and Kim (1996).

${ }^{47}$ As our earlier discussion showed, when imports and exports are both taxed, their distortionary effect is multiplicative rather than additive. So instead of summing import and export taxes, we use the formula $(1+$ mdut $) x(1+x d u t)-1$, where mdut (xdut) is import (export) duties as a percent of imports (exports). We take the average of observations for 1980-85. Our results (on the sign and insignificance of the coefficient on trade taxes) are unchanged, however, when we take the simple sum mdut + xdut.
} 
(including Edwards') is the small sample size (between 43 and 45). Since export duties are not reported for many countries, one way of increasing the sample size is to introduce only the import duty variable from the World Development Indicators database. This increases the sample size to 66 countries. The estimated coefficient on import duties is once again positive and insignificant (column 4).

These results are in line with others we have reported earlier: there is little evidence that simple averages of trade taxes are significantly and negatively correlated with growth.

The other two variables that are significant are the subjective indexes constructed by the World Bank and the Heritage Foundation. It is striking that two subjective indexes are the only variables that are robust to our econometric analysis, since subjective indexes are well known to suffer from judgment biases. Indeed, a look at the two indexes reveals some striking contrasts. In the Heritage Foundation Index, for example, Chile and Uganda are in the same category (4 on a scale of 1 to 5, where 5 is most protected), and Bolivia is as open as the United States (with a score of 2).

There is an additional problem in the use of the Heritage Index, aside from subjectivity bias. The index rates trade policy restrictions in 1996, well after the end of the period covered by Edwards' dependent variable (1980-1990). Changes in trade policy that occurred in the late 1980s or after 1990 should not be relevant for explaining TFP growth between 1980 and 1990. For example, there are several countries--such as Bolivia and Turkey--which liberalized their trade regimes significantly in the second half of the 1980s and which get high openness ratings from the Heritage Index, but would be classified quite differently for the early 1980s.

To gauge the magnitude of the problem, we recalculate the Heritage Foundation Index using the same methodology but with tariff and non-tariff barrier data from 1985-88 from Lee (1993), the earliest date for which there is systematic information. ${ }^{48}$ The resulting index is highly correlated with the Heritage Index (the simple correlation is 0.71). But it enters with an insignificant coefficient (with a t-statistic below 1) when we replicate equation (7) using it instead of the 1996 Heritage Foundation Index (Table V.4, column 6). We conclude from this exercise that the significance of the Heritage Index variable in Edwards' regressions probably derives from changes in trade policies that took place after 1990 (perhaps because faster growing countries liberalized faster in the late 1980s and early 1990s).

The remaining significant variable is the World Bank's 1987 World Development Report subjective index. This index divides countries into four groups using primary data on the effective rate of protection, use of non-tariff barriers, use of export incentives, and degree of exchange rate overvaluation. Since this index rates only a small number of countries, regression (2) in Table V.1 uses only 32 observations. Again the anomalies in this index are striking: highgrowth Korea is rated as more open than moderate-growth Malaysia despite having higher tariff

\footnotetext{
48 We follow as closely as possible the procedure described in the Heritage Foundation Report (Johnson and Sheehy 1996, 27). Specifically, we rate a country according to the maximum of its tariff rate and non-tariff barrier coverage ratio: higher than 20\%: "very high" (a rating of 5); between 15 and 20\%: "high" (4); between 10 and $15 \%$ : "moderate" (3); between 5 and 10\%: "low" (2); and between 0 and 5\%: "very low" (1).
} 
rates and non-tariff barrier coverage (according to Lee 1993), higher exchange rate distortions (according to Dollar) and a lower export/GDP ratio. Moderate-growth Tunisia, which had average tariffs of $21 \%$ and average non-tariff coverage of $54 \%$, is classified in the same group as Chile, Malaysia and Thailand. In fact, in his 1993 literature review, Edwards (1993, 1386-1387) himself drew attention to serious problems with this index. As he noted, Chile, which in other studies is rated as the most open economy in the developing world, was grouped in the second category (moderately outward oriented); Korea was classified in the group of most open economies for both the 1963-73 period and the 1973-85 period despite the fact that during 196373 the Korean trade regime was considerably more restrictive than in the latter subperiod. Given that the primary data which was used to construct this index is no different from that used in some of the other empirical work we have discussed in this and other sections of our paper, we believe it is likely that its significance derives from the subjective biases that have entered into the process of classifying countries.

In sum, we do not concur with Edwards's assertion that the cross-country data reveal the existence of a robust relationship between openness and productivity or GDP growth. ${ }^{49}$ In our view, there is little evidence to support such an assertion. The results reviewed in this section are for the most part highly dependent on questionable weighting and identification assumptions. The trade-policy indicators whose significance is not affected by these assumptions either are subjective indexes apparently highly contaminated by judgement biases or lack robustness to the use of more credible information from alternative data sources.

\section{Dan Ben-David (1993)}

The last of the papers we discuss takes an altogether different approach to studying the impact of openness on economic growth. Dan Ben-David's 1993 QJE paper "Equalizing Exchange: Trade Liberalization and Income Convergence" measures the effect of trade policies on income by asking whether trade liberalization leads to a reduction in the dispersion of income levels among liberalizing countries (i.e., whether it contributes to what has been called $\sigma$ convergence). We pick Ben-David as an example of a strand of the literature which has centered on studying the effect of trade on convergence. Another example can be found in Sachs and Warner's BPEA paper discussed in Section IV, in which the authors show that countries that were open according to their definition experienced faster growth if their initial income levels were low ( $\beta$-convergence) while countries that were closed showed no relationship between growth rates and initial income levels. In addition, a distinctive aspect of Ben-David's work is that it is non-parametric and not regression-based.

The expectation that trade liberalization might lead to income convergence is grounded in the factor price equalization (FPE) theorem. According to trade theory, free trade in goods leads to the equalization of factor prices under certain conditions (including an equal numbers of goods and factors, identical technologies, and absence of transport costs). As barriers to trade are

\footnotetext{
${ }^{49}$ Our results are basically unaltered if we use growth of GDP per capita from 1980 to 1990 instead of TFP growth as the dependent variable. In this case the World Bank and Heritage Foundation indexes remain significant but the Collected Trade Taxes Ratio is now only significant at a 10\% level and the Black Market Premium is insignificant. Similar results emerge for instrumental variables estimation.
} 
relaxed (and assuming in addition that differences in capital-labor ratios and labor-force participation ratios do not countervail), a tendency towards FPE can be set into motion, resulting in convergence in per capita incomes.

In a recent critique of this strand of the literature, Matthew Slaughter (1997) has argued that a great part of the convergence experienced by the European economies studied by BenDavid and by Sachs and Warner's "open" economies occurs because of convergence in capitallabor ratios rather than factor prices. It is less clear how this convergence could be caused by trade liberalization.

Let us however assume that there is a valid channel of causation from trade liberalization to convergence in capital-labor ratios. In itself, there is no necessary relationship between the level of dispersion in incomes and the growth rate. Countries could in principle be converging to lower levels of GDP per capita. But in the case of the European Community, on which BenDavid concentrates, the convergence experienced was indeed to higher level of incomes. Overall growth from 1945 to 1994 of the EC5 (Belgium, France, the Netherlands, Italy, and Germany) was 3.45 percent, compared to 1.21 percent between 1900 and 1939 and $1.16 \%$ from 1870 to 1899. Therefore, if Ben-David's claim is right, convergence in the EEC was achieved by raising the income of poor countries rather than by lowering that of rich countries.

That a decrease in the dispersion of incomes among European economies coincided with economic integration is straightforward to establish. The dispersion of log incomes among Belgium, France, the Netherlands and Italy is reproduced as the solid line in Figure VI.1. This series is taken from Ben-David's paper, which relied on Maddison's (1982) long-run growth data. It is evident that there is a pronounced decrease in dispersion during the post-war period. ${ }^{50}$

Ben-David's argument, of course, goes beyond simply ascertaining that a decrease in dispersion occurred during the postwar era. He tries to show that trade liberalization caused this decrease by discarding other plausible alternatives. Thus he argues (i) that the observed convergence was not simply a continuation of a long-term convergence trend unrelated to postwar economic integration; (ii) that the European countries that chose not to enter a free-trade agreement did not experience the same levels of convergence as the EEC; (iii) and that other subsets of economies in the world which were not economically integrated did not experience convergence. We examine each of his arguments in turn.

Was European convergence a continuation of a long-term trend?

In support of the argument that the reduction in dispersion was not simply the continuation of a long-run trend, Ben-David argues that the series of per capita income dispersion (solid line in Figure VI.1) does not show any visible downward tendency before the postwar era. When presenting this series, Ben-David excludes Germany from the calculations, ${ }^{51}$ arguing that not doing so would bias the conclusion in favor of convergence:

\footnotetext{
${ }^{50}$ Similar results obtain if one uses the Summers and Heston data.

${ }^{51}$ Luxembourg is also excluded because Maddison does not provide data for it.
} 
Germany was always among the poorest, in per capita terms, of the six countries. Today, it is one of the wealthiest countries in Europe. As a result of its heightened prosperity, it might be claimed that all of the convergence that has been witnessed within the EEC is due to the behavior of Germany. Thus, its exclusion should bias the results away from convergence. (Ben-David 1993, 662)

Note however that the purpose of Figure VI.1 (Figure VII in Ben-David's paper) is not only to establish the existence of convergence following postwar liberalization, but also to establish the absence of a long-term trend in convergence pre-dating it. Thus the exclusion of Germany from the series, which biases the results against convergence, would also bias the results in favor of the hypothesis that there was no pre-war convergence trend, had Germany's convergence occurred before the post-war period.

That is indeed what happened. Between 1870 and the eve of World War II, Germany's income went from less than $50 \%$ to $87 \%$ of the average for the remaining members of the EEC. And by 1958, one year after the EEC was formed, Germany had surpassed Belgium as the leader of the five. The exclusion of Germany therefore has the effect of understating the fall in dispersion before the creation of the EEC. The dashed line in Figure VI.1, which calculates dispersion of log per capita incomes including Germany, shows this. Once Germany is included in the sample, it appears that dispersion has been on a downward trend since 1870. The hypothesis that postwar convergence was simply a continuation of a long-term trend can no longer be rejected easily, raising doubts about the conclusion that convergence was caused by postwar trade policies. $^{52}$

Figure VI. 2 plots the standard deviation of log incomes for the original members of the EEC, now using Maddison's more recent (1995) estimates and including Germany. We reach the same conclusion as in Figure VI.1: ${ }^{53}$ dispersion has followed a downward trend since the beginning of the $20^{\text {th }}$ century. From a peak of 0.36 in 1897 , dispersion had fallen to 0.25 in 1930, and 0.19 in 1939. By the time the EEC was created, it had fallen to 0.16. It appears therefore that the further reduction in dispersion that followed the creation of the EEC (to 0.06 by 1994) was a continuation of a long-term trend that predated European integration. Moreover, this conclusion is not sensitive to whether Germany is included in the sample: that is because Maddison's (1995) revised estimates suggest that there was a uniform pattern of convergence

\footnotetext{
${ }^{52}$ Ben-David (in personal communication) has pointed out to us that much of the pre-war convergence is due to the fact that "while the other countries were in the Depression, Germany surged ahead as Hitler built his war machine." Indeed, dispersion appears trendless from 1900 to 1932, and starts falling only as Germany's income rises during the National Socialist period. But we are not sure of what to make of that fact. Germany's income remained high after the war--compared to other European countries--suggesting that not all of the convergence was due to the policies of the Nazi period or to the buildup of the war machine. In any case, Nazi Germany pursued highly protectionist policies, so that its experience sheds doubt on the argument that poor countries that close their economies experience slower growth. Finally, the observation for 1870 in Figure VI.1 suggests that dispersion was much higher in the late nineteenth century than in 1930. The last point is confirmed when we examine Maddison's (1995) more recent estimates (see Figure VI.2), which provide a fuller picture of trends in dispersion since 1820. These estimates were not available to Ben-David at the time his paper was written.

${ }^{53}$ Figure VI.2 may strike the eye as different from Figure VI.1 because it plots dispersion since 1825 (Figure VI.1 starts in 1870) and uses yearly data for the 1870-1900 period (Figure VI.1 had just 1 observation for 1870 and yearly observations for 1900 on).
} 
during the pre-World War I period, with Italy, France, and Germany all catching up with Belgium and the Netherlands.

A closer look at Figure VI.2 suggests that there is in fact very little association between episodes of economic integration and $\sigma$-convergence over time (see also Table VI.1). The period leading up to 1878 was an era of continuous trade liberalization, at the level of both national markets and international ones. This period witnessed the creation of the German Zollverein (1833) and the unification of Italy (1860), as well as the signing of free trade agreements between Prussia and Belgium (1844), France and Belgium (1842), France and Prussia (1862), France and Italy (1863), and France and the Netherlands (1865). ${ }^{54}$ Most of these bilateral agreements had most favored nation clauses, extending the benefits of bilateral liberalization to third countries. Yet, despite increasing economic integration, dispersion more than doubled from 1820 to 1880 (from 0.14 to 0.29 ). ${ }^{55}$

The retreat from free trade started during the 1880s, with Germany's Tariff Act of 1879. Italy raised tariffs in 1878 and 1887, France in 1881 and $1892 .^{56}$ This rise in protection followed the depression of the 1870 s and was motivated by the desire to protect European farmers from the influx of cheap American grain imports (which began to undersell German grain in 1875) while at the same time compensating industry for the increased wages of their workers. ${ }^{57}$ Nevertheless, as Figure VI.2 shows, the period from the 1880s to World War I was, if anything, one of convergence. ${ }^{58}$

The breakdown in world trade that followed World War I and the spread of beggar-thyneighbor protectionist policies adopted during the great depression seem also to have had very

\footnotetext{
${ }^{54}$ The discussion in this and the following two paragraphs borrows heavily from Chapter V of Pollard (1974). Above we list treaties between countries included in Figure VI.2, but the extent of trade liberalization from 1820 to 1878 in Europe was impressive. Prussia signed free trade treaties with Britain (1841 and 1860), Turkey (1839), Greece (1840), Austria (1868), Spain (1868), Switzerland (1869), Mexico (1869) and Japan (1869), France with Britain (1860), Switzerland (1864), Sweden, Norway, the Hanse Towns and Spain (1865), Austria (1866) and Portugal (1867), Belgium with Britain (1862), Italy with Britain (1862), Turkey and Greece (1839-40). Aside from the MFN clause, measures were taken to ease international trade such as the inclusion in the Treaties of Berlin of clauses extending commercial freedoms to foreign citizens $(1878,1885)$. There were even attempts to create customs unions between France and Germany and France and its neighbors.

${ }^{55}$ A caveat applies here: for the 1820-1850 period, we rely on just two observations: one for 1820, and another one for 1850. Since the 1850 observation for Italy was not available, we constructed it as the result of a linear interpolation between the 1820 and the 1870 observation. Even if we disregard the evidence before 1870 , the yearly data from 1870-1880 indicate that the increase in dispersion predated the first protectionist measures.

${ }^{56}$ Again, tariff adoption was widespread, with only Holland and the United Kingdom resisting the reversion towards protectionism.

${ }^{57}$ In effect, high tariffs worked to the detriment of labor in what came to be known in Germany as the "compact of rye and iron." See Gerschenkron (1943) and Rogowski (1989) for detailed discussions of this era. As Rogowski points out, the reversion towards protectionism was more accentuated in capital poor countries such as Germany, Italy and France than in capital rich countries such as Belgium and the Netherlands.

${ }^{58}$ O'Rourke's (1997) econometric study of this period (1975-1914), covering a panel of 10 countries, finds that higher tariffs were correlated with faster economic growth, and that the estimated effects are quantitatively large.
} 
little effect on dispersion. Even though fascist governments in Italy and Germany raised agricultural tariffs and other protectionist barriers, and in France the power of agricultural groups was high enough to drive the French price of wheat in 1939 to three times its price in London (Cobban 1965, 156), on the eve of World War II dispersion stood at its lowest level since the 1860s.

In sum, Figure VI.2 shows no long-run tendency for trade liberalization to be associated with greater convergence in per-capita incomes. If anything, it shows increasing dispersion during the $19^{\text {th }}$ century and falling dispersion during the $20^{\text {th }}$ century. While one can interpret this evidence in different ways, we find the most straightforward reading to be that World War II convergence was in fact a continuation of a long-run trend that got started around the turn of the 20th century.

\section{Did non-EEC European countries experience convergence?}

Ben-David also claims that countries in Europe that did not undertake trade liberalization failed to experience convergence. He supports his argument by showing that (a) there was no convergence among the UK, Denmark and Ireland until they began to relax their trade restrictions vis-à-vis Europe, and that (b) EFTA countries experienced significant convergence with the EEC as trade barriers among them were liberalized.

To demonstrate (a), Ben-David plots the standard deviation among the UK, Denmark and Ireland, both of which started liberalizing trade with the EEC in the mid-1960s. He shows that their dispersion among themselves started falling only after 1965. It is not clear to us why this is the relevant test, since the trade liberalization in question took place between these countries and Europe as well as amongst themselves. In Figure VI.3, we show that even if there is an indication of convergence among these three countries after 1965, it is not caused by convergence to the mean income of EEC members. Ireland has shown very little convergence to the EEC until recent years, and Denmark has oscillated close to the EEC average since the 1950s. The UK has been converging--downward--to the EEC level steadily (at least) since the 1950s. None of the three countries seem to experience different patterns of convergence after they relaxed trade restrictions with the EEC in 1965.

As regards (b), there has indeed been substantial convergence by EEC and EFTA member countries to the European mean since the 1950s. But we are skeptical whether such convergence can be attributed to trade liberalization. In Figure VI.4, we plot the contribution to the variance around the European mean ${ }^{59}$ of three subsets of European countries: the six members of the European Economic Community, the seven members of the European Free

\footnotetext{
${ }^{59}$ This is defined as:

$\frac{1}{N_{\text {EUROPE }}} \sum_{i \in J}\left(\frac{y_{i}-\bar{y}_{\text {EUROPE }}}{\bar{y}_{\text {EUROPE }}}\right)^{2}$ for J=\{EEC6, EFTA6, Others $\}$. Normalization by the mean achieves the same purpose as calculating the variance of log incomes--and is more appropriate for large income differences--and putting the expression in terms of the variance--and not the standard deviation--ensures that the three components sum to the total.
} 
Trade Association, ${ }^{60}$ and six remaining European countries which did not join either EFTA or the EEC. ${ }^{61}$ It is evident from Figure VI.5 that all subgroups have experienced substantial convergence. The non-EFTA and non-EEC countries have seen their contribution to the variance around the European mean fall from 0.085 to 0.034 from 1950 to 1992 (see Table VI.2). ${ }^{62}$ European convergence seems to be the result of factors largely unrelated to trade liberalization.

Did other areas of the world experience convergence?

To add plausibility to the story that trade liberalization was behind the European trend towards convergence in the postwar era, Ben-David shows that subsets of countries that have not become integrated have experienced no tendency to converge. He points to the well-known fact that the dispersion of world incomes has not decreased in the postwar era (it has actually increased). He also shows that the dispersion of incomes among the world's 25 richest countries (excluding the EEC6) has not decreased either. He compares these experiences with those of economically integrated Europe and U.S. states to show that convergence seems to occur only when there is substantial trade liberalization.

There is an asymmetry in his selection of diverging and converging areas, however. Whereas the regions he shows to be converging are all close to each other geographically, those which are diverging are not. To have a fair standard of comparison, one must ask whether trade liberalization--or its absence--among geographically adjacent economies would lead towards convergence or divergence.

Did subsets of geographically adjacent economies that liberalized trade tend to observe convergence? Figures VI.5 and VI.6 show two important cases in which the trends in convergence go counter to what we would expect on the basis of Ben-David's argument. They plot the dispersion of per capita incomes for two regions with radically different trade policies and which are by conventional accounts the canonical examples of open and closed economies: East Asia and Latin America. ${ }^{63}$ According to conventional wisdom, the relatively open East Asian economies should have converged, whereas the relatively closed South American economies should have diverged. Figure VI.5 shows that East Asia seems to have steadily diverged since the 1960s, with the standard deviation of its log incomes going from 0.47 in 1960

\footnotetext{
${ }^{60}$ Austria, Switzerland, Sweden, Denmark, Norway, Finland and the United Kingdom. Even though Portugal was officially a member of EFTA, it was allowed to implement tariffs and to deviate from EFTA policies, so we follow Ben-David in treating it as a non-EFTA country.

${ }^{61}$ Cyprus, Greece, Iceland, Ireland, Portugal and Spain.

${ }^{62}$ If one includes Turkey as a seventh country in this group the contribution to dispersion goes from 0.103 in 1950 to 0.053 in 1992. An alternative measure of dispersion around the European mean is the standard deviation of $\log$ incomes around the mean log income. The latter measure for the non-EEC, non-EFTA countries falls from 0.15 in 1950 to 0.05 in 1990 ( 0.20 to 0.10 if Turkey is included).

${ }^{63}$ The East Asian countries are Hong Kong, Indonesia, Japan, South Korea, Malaysia, Philippines, Singapore, Taiwan, and Thailand (data are from Summers-Heston). Latin American countries are Argentina, Brazil, Chile, Colombia, Mexico, and Peru (data are from Maddison 1995, Summers-Heston 1994, and World Bank 1998).
} 
to 0.81 in $1989 .{ }^{64}$ As for Latin America, Figure VI.6 shows a steady decrease in dispersion during the period of import substitution, ${ }^{65}$ from 0.55 before the Great Depression to 0.20 in the late 1980s. More striking, dispersion jumps upwards just as Latin America starts to liberalize its trade. $^{66}$

Figure VI.7 points to another important counter-example: it plots the ratio of U.S. GDP per capita to the average GDP per capita for its three main European trading partners (the UK, France and Germany) up to $1938 .^{67}$ Trade with Europe was approximately two-thirds of total U.S. trade during the nineteenth century, ${ }^{68}$ and the bulk of that was with these three countries. It is however evident from Figure VI.7 that despite declining levels of import duties the U.S. and Europe steadily diverged between 1820 and 1938. Again, there seems to be no evident relationship between trade liberalization and income convergence.

The point of these examples is to show that it is relatively easy to come up with cases of regions of the world which have diverged or converged in ways unrelated to trade policy. Whereas Europe is a case of a region in which convergence has been accompanied by trade liberalization, there are many other cases where the opposite has happened. Hence we remain doubtful that there is a systematic relationship between trade liberalization and convergence.

We close by drawing attention to Slaughter's (1998) recent examination of the same issue. Slaughter undertakes a systematic analysis by comparing convergence patterns among liberalizing countries before and after liberalization with the convergence pattern among randomly chosen control countries before and after liberalization. As he emphasizes, this

\footnotetext{
${ }^{64}$ From 0.50 to 0.73 if the Philippines is excluded.

${ }^{65}$ Latin American import substitution policies started rather spontaneously as a response to the collapse of worldwide demand for raw materials in 1929 and the adoption of protectionist measures by the U.S. and Britain in 1930 and 1931. Most countries abandoned convertibility and imposed trade barriers during this period and did not liberalize until recent years (see Díaz Alejandro, 1981).

${ }^{66}$ Chile liberalized in 1975-79, Mexico in 1986, Argentina and Brazil in 1990, Colombia and Peru in 1991 (dates are from Edwards 1995). Although data from Maddison is available for Venezuela, it is omitted from the graph because Venezuela's low growth during the postwar period, mainly caused by falling per capita oil revenues, tends to amplify the convergence (private communication with Ben-David). If it is included, dispersion goes from an average value of 0.48 in the $1930 \mathrm{~s}$ to 0.55 in the $1950 \mathrm{~s}$, and then drops steadily to 0.29 in the 1980 s. Dispersion for a wider sample of Latin American countries from 1950-1992 from the Summers-Heston or World Bank data is generally either stable or falling from 1950 to the mid-1980s, but rises sharply during the late 1980s and early 1990s.

${ }^{67}$ The cutoff date of 1938 is chosen because during World War II the Americas overtook Europe as the main destination for U.S. exports. The Americas overtook Europe as the main source of imports much earlier, during World War I. Including observations after 1940 would not change our results: U.S. GDP per capita in 1994 was still $27 \%$ higher than that of its three main European trading partners despite the fact that after 1944 tariff rates stayed well into the single digits (Bureau of the Census, 1989). Choosing the Americas instead of Europe as a standard of comparison would strengthen our results, as the divergence between U.S. and Latin American incomes during the $19^{\text {th }}$ and $20^{\text {th }}$ century has been extremely high (see Haber 1997) and Canada represents only about half of U.S. trade with the Americas.

${ }^{68}$ Before World War II exports to Europe were $43 \%$ of total exports and imports from Europe were $29 \%$ of total imports (Bureau of the Census 1989).
} 
difference-in-differences approach avoids the pitfalls of before-and-after comparisons (nonliberalizing countries too may exhibit the same pattern before and after) or of comparing liberalizing countries to non-liberalizing ones (the liberalizing countries may have been converging prior to the liberalization as well). Hence Slaughter's approach amounts to a more systematic version of the kind of exercise we have carried out above by way of specific illustrations (note, however, but using only post-World War II data).

Slaughter focuses specifically on four instances of trade liberalization: formation of the EEC, formation of EFTA, liberalization between EEC and EFTA, and Kennedy Round tariff cuts under the GATT. His conclusion:

trade liberalization did not trigger convergence in any of the four cases. If anything, trade [liberalization] seems to have caused income divergence... In all four cases, the large majority of the 10,000 difference in difference estimates are not significantly different from zero, and the average among the significant estimates indicates that liberalization tends to diverge incomes. (Slaughter 1998, 1)

Slaughter finds convergence in all of his cases prior to liberalization; none of his cases, furthermore, exhibit an acceleration of convergence post-liberalization. This parallels our results above.

\section{Other recent work}

Before we close, we mention briefly some other recent papers that have examined the connection between openness and economic growth. We focus on three papers in particular: Lee (1993), Harrison (1996), and Wacziarg (1998). These papers are of interest because they contain some methodological innovations.

Lee (1993) reasons, on the basis of an analytical model, that the distortionary effects of trade restrictions should be larger in economies that, in the absence of trade restrictions, would be more exposed to trade. Hence he interacts an indicator of trade policy with a measure of what he calls "free trade openness" (FREEOP $).{ }^{69}$ The latter is constructed by regressing observed import shares on land area, distance from major trading partners, import tariffs, and black-market premia, and then calculating the predicted value of imports when the actual values of tariffs black-market premia are replaced by zeros. He finds that this composite measure (FREETAR) enters a growth regression with an estimated coefficient that is negative and statistically significant.

Lee uses two indicators of trade policy: an import-weighted tariff average and the blackmarket premium. We have discussed above the shortcomings of the latter as a measure of trade policy (when reviewing Sachs and Warner, 1995). The problem with Lee's tariff variable, as Lee $(1993,320)$ acknowledges, is that the underlying tariff data are from "various years in the 1980s"--the tail-end of the 1960-85 period over which his growth regressions are run. This raises the possibility of reverse causation: countries that perform well tend to liberalize their trade regime eventually. To check for this possibility, we have repeated Lee's regression, using

\footnotetext{
${ }^{69}$ Specifically, the composite measure is constructed as FREETAR $=$ FREEOP $\times \log (1+$ tariff $)$.
} 
the same specification and tariff variable, but over the subsequent time period 1980-94. ${ }^{70}$ While the estimated coefficient on FREETAR is negative for this later period, it is nowhere near significant $(\mathrm{t}$-statistic $=-0.80)$.

Harrison's (1996) main methodological contribution is to examine the relationship between trade policy and growth in a panel setting, using fixed effects for countries. This approach has the advantage that it enables the analyst to look for evidence of the effects of trade liberalization within countries. ${ }^{71}$ But it has the disadvantage that the available time series are necessarily short, requiring the use of annual data or (at most) five-year averages. It may be a lot to ask such data to reveal much about the relationship between trade policy and growth, both because of the likely lags involved and the contamination from business-cycle effects. ${ }^{72}$

Harrison uses seven indicators of trade policy, and finds that three of these "exhibit a robust relationship with GDP growth" $(1996,443)$. These three are the following: (a) the blackmarket premium; (b) a measure based on the price level of a country's tradables (relative to international prices); and (c) a subjective measure of trade liberalization constructed at the World Bank. We have already discussed at length the problems involved in interpreting measures of each of these types as indicators of trade policy.

Finally, the paper by Wacziarg (1998) is an ambitious attempt to uncover the channels through which openness affects economic growth. Wacziarg's index of trade policy is a linear combination of three indicators: (a) the average import duty rate; (b) the NTB coverage ratio; and (c) the Sachs-Warner indicator. ${ }^{73}$ The weights used to construct the combined index come from a regression of trade volumes (as a share of GDP) on these three indicators plus some other determinants. Using a panel made up of five-year averages for 57 countries during 1970-89, Wacziarg finds that investment is the most important channel through which openness increases growth, accounting for more than sixty percent of the total effect.

We have two worries about this paper. First, we are not sure that the regularities revealed by the data over time horizons of five years or less are particularly informative about the relationship between trade policy and long-run economic performance. It would be interesting to see if the results hold up with averages constructed over a decade or more. Second, as discussed

\footnotetext{
${ }^{70}$ Since Summers-Heston data are not available for the 1990s, we used World Bank data on GDP per capita (at constant prices).

${ }^{71}$ Harrison (1996) cites disappointing results with cross-section regressions as a motivation for going the panel route.

${ }^{72}$ Indeed, when Harrison (1996) controls for some business-cycle conditions, about half of her significant coefficients (on openness-related variables) disappear. The empirical evidence on the short-run relationship between trade liberalization and economic growth is judiciously reviewed in Greenaway et al. (1998), who point to both positive and negative findings. These authors attempt to trace out the dynamics of the output response using three different indicators of policy (including the Sachs-Warner index), and report finding a J-curve effect: output first falls and then increases.

${ }^{73}$ More specifically, Wacziarg uses the timing of trade liberalizations in Sachs and Warner (1995) to assign a value to each country for any given five-year period.
} 
previously, we are skeptical that the Sachs-Warner measure, on which the Wacziarg indicator is partly based, is a meaningful indicator of trade policy. Wacziarg remarks in a footnote $(1998, \mathrm{fn}$. 9) that the "exclusion of [the Sachs-Warner indicator] from the trade policy index reduced the precision of the estimates ... but did not change the qualitative nature of the results." We would have preferred to see estimates based only on tariff and NTB indicators.

\section{Concluding remarks}

We have scrutinized in this paper some of the more prominent recent empirical studies on the relationship between trade barriers and economic growth. While we do not pretend to have undertaken an exhaustive survey, we believe that the weaknesses we have identified are endemic to this literature. Still, in view of the voluminous research on the subject, a natural question that arises is whether we shouldn't take comfort from the fact that so many authors, using varying methods, have all arrived at the same conclusion? ${ }^{74}$ Don't we learn something from the cumulative evidence, even if individual papers have shortcomings?

We take a different message from this large literature. Had the negative relationship between trade restrictions and economic growth been convincingly demonstrated, we doubt that this issue would continue to generate so much empirical research. We interpret the persistent interest in this area as reflecting the worry that the existing approaches haven't gotten it "quite right." One indication of this is that the newer papers are habitually motivated by exegeses on the methodological shortcomings of prior work.

We are especially struck and puzzled by the proliferation of indices of trade restrictions. It is common to assert in this literature that simple trade-weighted tariff averages or non-tariff coverage ratios - which we believe to be the most direct indicators of trade restrictions-are misleading as indicators of the stance of trade policy. Yet we know of no papers that document the existence of serious biases in these direct indicators, much less establish that an alternative indicator "performs" better (in the relevant sense of calibrating the restrictiveness of trade regimes). ${ }^{75}$ An examination of simple averages of taxes on imports and exports and NTB coverage ratios leaves us with the impression that these measures in fact do a decent job of rankordering countries according to the restrictiveness of their trade regimes. We provide in Table VIII.1 a simple measure of import duties for a large sample of countries and three different periods, so that the reader can form his/her judgement on this.

As we mentioned in the introduction, we are skeptical that there is a strong negative relationship in the data between trade barriers and economic growth, at least for levels of trade

\footnotetext{
${ }^{74}$ As T.N. Srinivasan $(1997,34)$, a critic of the methods and data used in this literature notes: "Nonetheless, the fact that a number of studies using different data sets, countries and methodologies happened to arrive at similar conclusions [on the relationship between openness and growth] that are also consistent with a priori reasoning, suggests that they deserve serious consideration, with due allowances being made for their conceptual and statistical deficiencies."

75 Pritchett (1996) comes closest. The point of his paper, however, is to document the weak correlation between commonly used indicators of trade restrictions, and not to argue for the superiority of one indicator over the others.
} 
restrictions observed in practice. We view the search for such a relationship as futile. We think there are two other fruitful avenues for future research.

First, in cross-national work, it might be productive to look for contingent relationships between trade policy and growth. Do trade restrictions operate differently in low- versus highincome countries? In small versus large countries? In countries with a comparative advantage in primary products versus those with comparative advantage in manufactured goods? In periods of rapid expansion of world trade versus periods of stagnant trade? Further, it would help to disaggregate policies and to distinguish the possibly dissimilar effects of different types of trade policies (or of combinations thereof). Are tariff and non-tariff barriers to imports of capital goods more harmful to growth than other types of trade restrictions? Does the provision of dutyfree access to imported inputs for exporters stimulate growth? Are export-processing zones good for growth? Does the variation in tariff rates (or NTBs) across sectors matter? The crossnational work has yet to provide answers to such questions.

Second, we think there is much to be learned from micro-econometric analysis of plantlevel data sets. These data sets constitute a rich source for uncovering the ways in which trade policy influences production, employment and technological performance of firms (see Roberts and Tybout 1996). Recent research by Bernard and Jensen (1995, 1998), Aw, Chung, and Roberts (1998), and Clerides, Lach and Tybout (forthcoming) has already shed new light on the relationship between trade and firm performance. For example, these papers (based on the experiences of countries as diverse as the United States, Taiwan, and Mexico) find little evidence that firms derive technological or other benefits from exporting per se; the more common pattern is that efficient producers tend to self-select into export markets. In other words, causality seems to go from productivity to exports, not vice versa. Relating these analyses to trade policies is the obvious next step in this line of research.

Let us close by restating our objective in this paper. We do not want to leave the reader with the impression that we think trade protection is good for economic growth. We know of no credible evidence--at least for the post-1945 period--that suggests that trade restrictions are systematically associated with higher growth rates. On the other hand, we believe that there has been a tendency in academic and policy discussions to greatly overstate the systematic evidence in favor of trade openness. We view this paper as a corrective to this tendency. What we would like the reader to take away from this paper is some caution and humility in interpreting the existing cross-national evidence on the relationship between trade policy and economic growth. What we believe we have shown is that the challenge of identifying the connections between trade policy and economic growth is one that still remains before us. 


\section{$\underline{\text { References }}$}

Acheson, A. L. Keith and Donald McFetridge, "Intellectual Property and Endogenous Growth," in Howitt, Peter, ed. The Implications of Knowledge-Based Growth for Microeconomic Policies, Calgary, University of Calgary Press, 1996.

Aw, Bee Yan, Sukkyun Chang, and Mark J. Roberts, "Productivity and Turnover in the Export Market: Micro Evidence from Taiwan and South Korea," Pennsylvania State University, processed, March 1998.

Balassa, Bela, The Structure of Protection in Developing Countries, Baltimore, Johns Hopkins University Press, 1971.

Balassa, Bela, "Exports, Policy Choices, and Economic Growth in Developing Countries after the 1973 Oil Shock," Journal of Development Economics, 18(2), May/June 1985, 23-35.

Barro, Robert J., Determinants of Economic Growth: A Cross-Country Empirical Study, Cambridge, MA, MIT Press, 1997.

Barro, Robert J. and Jong-Wha Lee, "International Comparisons of Educational Attainment," Journal of Monetary Economics 32(3), 1993, 363-94.

Barro, Robert J. and Jong-Wha Lee, “Data Set for a Panel of 138 Countries," Harvard University, January 1994.

Ben-David, Dan "Equalizing Exchange: Trade Liberalization and Income Convergence," Quarterly Journal of Economics, 108(3), 1993.

Bernard, Andrew B., and J. Bradford Jensen, "Exporters, Jobs, and Wages in U.S. Manufacturing, 1976-1987," Brookings Papers on Economic Activity: Microeconomics 1995, 1995, 67-112.

Bernard, Andrew B., and J. Bradford Jensen, "Exporting and Productivity," paper presented at the 1998 Summer Institute, NBER, Cambridge, MA, August 1998.

Bhalla, Surjit, and Lawrence J. Lau, "Openness, Technological Progress, and Economic Growth in Developing Countries," World Bank, 1992.

Buffie, Edward, "Trade Policy in Developing Countries," unpublished book manuscript, November 1998.

Bureau of the Census, Historical Statistics of the United States, Colonial Times to 1970, White Plains, New York, Kraus International Publications, 1989.

Clague, Christopher, Phillip Knack, Steve Keefer and Mancur Olson, "Property and Contract Rights in Autocracies and Democracies," Journal of Economic Growth, 1(2), June 1996, 243-76. 
Clerides, Sofronis, Saul Lach, and James Tybout, "Is 'Learning-by-Exporting' Important? Micro-Dynamic Evidence from Colombia, Mexico, and Morocco," Quarterly Journal of Economics, forthcoming.

Cobban, Alfred, A History of Modern France, New York, Braziller, 1965.

Collins, Susan M. and Barry P. Bosworth "Economic Growth in East Asia: Accumulation versus Assimilation,” Brookings Papers on Economic Activity, 1996:2, 135-91.

Díaz-Alejandro, Carlos, "Southern Cone Stabilization Plans." In William Cline and Sydney Weintraub, eds., Economic Stabilization in Developing Countries, Washington, DC, The Brookings Institution, 1981.

Dollar, David, "Outward-Oriented Developing Economies Really Do Grow More Rapidly: Evidence from 95 LDCs, 1976-85," Economic Development and Cultural Change, 1992, 523544.

Dollar, David, and Craig Burnside, "Aid, Policies, and Growth," World Bank Policy Research Working Paper No. 1777, June 1997.

Edwards, Sebastian, "Trade Orientation, Distortions, and Growth in Developing Countries," Journal of Development Economics, 39(1), July 1992, 31-57.

Edwards, Sebastian, "Openness, Trade Liberalization, and Growth in Developing Countries," Journal of Economic Literature, XXXI(3), September 1993, 1358-1393.

Edwards, Sebastian, Crisis and Adjustment in Latin America: From Despair to Hope, New York, NY, Oxford University Press, 1995.

Edwards, Sebastian “Openness, Productivity and Growth: What Do We Really Know?" Economic Journal 108, March 1998, 383-398.

Esfahani, Hadi S., "Exports, Imports, and Growth in Semi-Industrialized Countries," journal of Development Economics, 35(1), January 1991, 93-116.

Falvey, Rod, and Norman Gemell, "Factor Endowments, Nontradables Prices and Measures of 'Openness,"' Journal of Development Economics 58, February 1999, 101-122.

Feder, Gershon, "On Exports and Economic Growth," Journal of Development Economics, 12(1/2), February/April 1983, 59-73.

Feenstra, Robert, "Trade and Uneven Growth," NBER Working Paper No. 3276, 1990.

Frankel, Jeffrey, and David Romer, "Does Trade Cause Growth?" unpublished, University of California at Berkeley, June 1998. 
Gelb, Alan H. and Associates, Oil Windfalls : Blessing or Curse? New York, Oxford University Press, 1988.

Gerschenkron, Alexander, Bread and Democracy in Germany, Berkeley and Los Angeles, University of California Press, 1943.

Greenaway, David, Wyn Morgan, and Peter Wright, "Trade Reform, Adjustment and Growth: What Does the Evidence Tell Us?" The Economic Journal, 108, September 1998, 1547-1561.

Grossman, Gene, and Elhanan Helpman, Innovation and Growth in the Global Economy, Cambridge, MA, MIT Press, 1991.

Grossman, Herschel and Minseong Kim, "Predation and Accumulation," Journal of Economic Growth, 1(3), September 1996, pages 333-50.

Gulhati, Ravi and Nallari, Raj, Succesful Stabilization and Recovery in Mauritius, Washington, The World Bank, 1990.

Haber, Stephen, How Latin America Fell Behind: Essays on the Economic Histories of Brazil and Mexico, 1800-1914, Stanford, Stanford University Press, 1997.

Hall, Robert E., and Charles I. Jones, "Why Do Some Countries Produce So Much More Output per Worker than Others?" NBER Working Paper No. W6564, 1998.

Harrison, Ann, "Openness and Growth: A Time-Series, Cross-Country Analysis for Developing Countries," Journal of Development Economics, 48, 1996, 419-447.

IMF, World Economic Outlook, Washington, DC, May 1997.

International Currency Analysis World Currency Yearbook, Brooklyn, N.Y.: International Currency Analysis, Inc, 1995.

Jodha, Narpat "Property Rights and Development," in Hanna et al, eds. Rights to Nature: Ecological, Economic, Cultural and Political Principles of Institutions for the Environment, Washington, DC, Island Press, 1996.

Johnson, Bryan T., and Thomas P. Sheehy, 1996 Index of Economic Freedom, The Heritage Foundation, Washington, 1996.

Knack, Stephen, and Philip Keefer, "Institutions and Economic Performance: Cross-Country Tests Using Alternative Institutional Measures" Economics \& Politics, November 1995, 207228.

Kornai, Janos The Socialist System: The Political Economy of Communism Princeton, NJ, Princeton University Press, 1992. 
Krueger, Anne O., "Why Trade Liberalisation is Good for Growth," The Economic Journal, 108, September 1998, 1513-1522.

Laird, Sam and Alexander Yeats Quantitative Methods for Trade-Barrier Analysis, New York, New York University Press, 1990.

Leamer, Edward "Measures of Openness," in Robert Baldwin, ed. Trade Policy and Empirical Analysis, Chicago, Chicaho University Press, 1988.

Lee, Jong-Wha, "International Trade, Distortions, and Long-Run Economic Growth," International Monetary Fund Staff Papers, 40(2), 1993, 299-328.

Lerner, Abba, P., "The Symmetry Between Import and Export Taxes," Economica, 11, 1936, 306-313.

Little, Ian, Tibor Scitovsky, and Maurice Scott, Industry and Trade in Some Developing Countries, London and New York, Oxford University Press, 1970.

Maddison, Angus, Phases of Capitalist Development, Oxford, New York, Oxford University Press, 1982.

Maddison, Angus, Monitoring the World Economy: 1820-1992. Development Centre Studies. Paris and Washington, DC, Organisation for Economic Co-operation and Development, 1995.

Matsuyama, Kiminori, "Agricultural Productivity, Comparative Advantage, and Economic Growth," Journal of Economic Theory, 58(2), December 1992, 317-334.

OECD, Open Markets Matter: The Benefits of Trade and Investment Liberalisation, Paris, OECD, 1998.

OECD, Economic Outlook No. 63, June, 1998.

O'Rourke, Kevin H., "Tariffs and Growth in the Late Nineteenth Century," CEPR Discussion Paper No. 1700, October 1997.

Park, Walter and Juan Carlos Ginarte, "Intellectual Property Rights and Economic Growth," Contemporary Economic Policy, 15(3), July 1997, 51-61.

Pertamina Web Page http://www.pertamina.co.id/ptmhp.htm, 1998.

Pollard, Sidney, European Economic Integration, 1815-1970, London, Thames and Hudson, 1974.

Pritchett, Lant, "Measuring Outward Orientation: Can it be Done?" Journal of Development Economics, 49(2), May 1996. 
Radelet, Steven, Jeffrey D. Sachs, and Jong-Wha Lee, "Economic Growth in Asia." HIID Development Discussion Paper, 1997.

Roberts, Mark J., and James R. Tybout, eds., Industrial Evolution in Developing Countries, Oxford University Press for the World Bank, New York, 1996.

Rodrik, Dani, The New Global Economy and Developing Countries: Making Openness Work, Overseas Development Council, Washington, DC, 1999.

Rogoff, Kenneth, "The Purchasing Power Parity Puzzle," Journal of Economic Literature, XXXIV, June 1996, 647-668.

Rogowski, Ronald Commerce and Coalitions: How Trade Affects Domestic Political Alignments Princeton, Princeton University Press, 1989.

Roper, Brian "New Zealand's Postwar Economic History," in Chris Rudd and Brian Roper, eds. The Political Economy of New Zealand, Auckland, Oxford University Press, 1997

Sachs, Jeffrey, and Andrew Warner, "Economic Reform and the Process of Global Integration," Brookings Papers on Economic Activity, 1995:1, 1-118.

Sala-i-Martin, Xavier “I Just Ran Two Million Regressions,” American Economic Review 87(2), May 1997, 178-83.

Slaughter, Matthew J. "Per Capita Income Convergence and the Role of International Trade," American Economic Review 87(2), May 1997, 194-99.

Slaughter, Mathew J. "International Trade and Per Capita Income Convergence: A Difference-inDifferences Analysis," NBER Working Paper No. 6557, May 1998.

Srinivasan, T.N., "As the Century Turns: Analytics, Empirics, and Politics of Development," Economic Growth Center, Yale University, December 1997.

Stiglitz, Joseph E., "Towards a New Paradigm for Development: Strategies, Policies, and Processes," 1998 Prebisch Lecture at UNCTAD, Geneva, October 19, 1998 (1998a).

Stiglitz, Joseph E., "Knowledge for Development: Economic Science, Economic Policy and Economic Advice," address to the World Bank's 10th Annual Bank Conference on Development Economics (ABCDE), Washington, D.C., April 20, 1998 (1998b).

Summers, Robert, and Alan Heston, "A New Set of International Comparisons of Real Product and Price Levels: Estimates for 130 Countries, 1950-1985," Review of Income and Wealth, 34, March 1988, 1-25.

Summers, Robert and Alan Heston, Penn World Tables Mark 5.6, http://www.nber.org, 1994. 
Thompson, Mark and Francis Rushing, "An Empirical Analysis of the Impact of Patent Protection on Economic Growth," Journal of Economic Development, 21(2), December 1996, 61-79.

Tornell, Aaron, "Economic Growth and Decline with Endogenous Property Rights," Journal of Economic Growth, 2(3), September 1997, 219-250.

Wacziarg, Romain, “Measuring the Dynamic Gains from Trade,” World Bank Working Paper, no. 2001, November 1998.

White, Halbert L. " A Heteroskedasticity-Consistent Covariance Matrix Estimator and a direct Test for Heteroskedasticity,” Econometrica, 48, 817-38, 1980.

Wolf, Holger, “Trade Orientation: Measurement and Consequences," Estudios de Economia 20(20), 52-72, 1993.

World Bank, Mauritius Economic Memorandum: Recent Developments and Prospects, Washington, DC, The World Bank, 1983.

World Bank, Mauritius: Managing Success, Washington, DC, The World Bank, 1989.

World Bank, Adjustment in Africa: Reforms, Results, and the Road Ahead, Washington, DC, 1994.

World Bank, World Tables, Washington, DC, The World Bank, 1995.

World Bank, World Development Indicators CD-ROM, Washington, DC, The World Bank, 1998. 
Data Appendix

$\underline{\text { Section I }}$

1. Import Duties as \% of Imports. Source: World Bank (1998).

2. Non-Tariff Barriers. Source: Barro and Lee (1994).

$\underline{\text { Section III }}$

3. bmpav: average black market premium. Source: Sachs and Warner (1995).

4. rcoast: coastal length over total land area. Source: Radelet, Sachs and Lee (1997).

5. tropics: dummy for tropical countries. Source: Radelet, Sachs and Lee (1997).

6. Latin America: dummy for countries in Latin America and the Caribbean.

7. SSA: dummy for countries in sub-Saharan Africa

8. East Asia: dummy for countries in East Asia

9. TAR: own import-weighted ratio of tariff revenues to trade. Source: Barro and Lee (1994).

10. NTB: own-import weighted non-tariff frequency on capital goods and intermediates. Source: Barro and Lee (1994).

11. DISTORTION: ratio of consumption price level to US price level, measured in identical currencies, divided by the fitted value of a regression on GDP, GDP squared, year dummies and continent dummies. Source: Dollar (1992).

12. VARIABILITY: Coefficient of variation of DISTORTION. Source: Dollar (1992).

13. Investment/GDP: Source: Summers and Heston, 1988 for Table III.2, Summers and Heston (1994) for Table III.3.

14. Log initial income: Source: Summers and Heston, 1988 for Table III.2, Summers and Heston (1994) for Table III.3.

15. Schooling, 1975: Barro-Lee (1994).

\section{$\underline{\text { Section IV }}$}

16. BMP: Dummy variable equal to 1 if Black Market Premium exceeds $20 \%$ during either the 1970s or the 1980s. Source: Sachs and Warner (1995).

17. BMP70, BMP80: Black Market Premium during (respectively) 70s and 80s. Source: Sachs and Warner (1995).

18. MON: Dummy variable equal to 1 if the country had a score of 4 (highest score) on the Export Marketing Index in World Bank, 1994. Source: Sachs and Warner (1995).

19. SOC: Dummy variable equal to 1 if the country was classified as socialist in Kornai (1992). Source: Sachs and Warner (1995).

20. TAR: own import-weighted ratio of tariff revenues to trade. Source: Barro and Lee (1994).

21. NTB: own-import weighted non-tariff frequency on capital goods and intermediates. Source: Barro and Lee (1994).

22. OPEN: Variable equal to 0 if the country had $\mathrm{BMP}=1, \mathrm{MON}=1, \mathrm{SOC}=1, \mathrm{TAR}>0.4$ or NTB>0.4. Source: Sachs and Warner (1995). 
23. BM, SQT, QT, etc.: Openness Indices constructed using subsets of the Sachs-Warner information. The label for each index denotes the openness indicators used to construct that index. $M=$ State Monopoly of Main Export, $S=$ Socialist Economic System, $Q=$ Non-Tariff Barriers, $\mathrm{T}=$ Tariffs, $\mathrm{B}=$ Black Market Premium. For example SMQT is set to 0 if it is closed according to either of the criteria for S,M, Q or T, and to 1 otherwise.

24. Inflation, 75-90. Source: World Bank (1998).

25. Debt/Exports, 1985. Source: World Bank (1998).

26. Change in Terms of Trade: Source: Barro-Lee (1994).

27. War: Dummy for countries that participated in at least one external war over the period, 1960-85. Source: Barro-Lee(1994).

28. Quality of Institutions: Institutional Quality Index from Keefer and Knack (1995).

29. Government Budget Surplus, 1970-90. Source: World Bank (1998).

30. Population Growth. Source: World Bank (1998).

$\underline{\text { Section V }}$

31. Sachs-Warner: Same as OPEN in Section IV.

32. World Development Report: World Development Report Outward Orientation Index 197385. Source: Edwards (1998).

33. Leamer: Openness index estimated by Leamer (1988) using residuals from disaggregated trade flows regressions. Source: Edwards (1998).

34. Black Market Premium: same as BMP80 in Section IV.

35. Tariffs: Same as TAR in Section IV.

36. Quotas: Same as NTB in Section IV.

37. Heritage Foundation: Subjective Index of the extent to which government policies distort trade, from Johnson and Sheehy (1996). Source: Edwards (1998).

38. Collected Trade Taxes Ratio: Average for 1980-85 of ratio of total revenues on international trade taxes to total trade. Source: Edwards (1998).

39. Wolf's Index of Import Distortions: A regression-based index from Wolf (1993). Source: Edwards (1998).

40. Principal Components Factor: First Principal component of OPEN, Black Market Premium, Tariffs, Quotas, and Wolf's Index. The equation used to calculate it is

$\mathrm{COM}=-.469 * \mathrm{OPEN}+.320 * \mathrm{BLACK}+.494 * \mathrm{TARIFF}+.553 * \mathrm{QR}+.354 * \mathrm{WOLF}$.

41. Log of GDP per Capita, 1985. From Summers and Heston (1994). Source: Edwards (1998).

42. Property Rights: Heritage Foundation Index of Property Rights Protection, from Johnson and Sheehy (1996). Source: Edwards (1998).

43. Average Import and Export Duties (World Bank): From World Bank (1998). Average duty is calculated as $(1+$ export duty)*(1+import duty)- 1 .

44. Merged Duty Index: Simple average of Average duty (43) and (38).

45. Trade Distortion Index based on Lee data. Analog of Heritage Index using data from Lee (1993) in Barro and Lee (1994). Countries are rated on a score of 1 to 5 according to the maximum of its tariff rate and non-tariff barrier coverage ratio: higher than 20\%: "very high" (a rating of 5); between 15 and 20\%: "high" (4); between 10 and 15\%: "moderate" (3); between 5 and 10\%: "low" (2); and between 0 and 5\%: "very low" (1). 


\section{Section VI}

46. Contributions to Variance around EC Mean: From Summers and Heston (1994).

47. GDP per Capita (Figure VI.1): Madisson, 1982. Source: Ben-David (1993).

48. GDP per Capita (Figures VI.2 and VI.6, Table 1): Maddison (1995).

49. GDP per Capita (Figures VI.3-VI.5): Summers and Heston (1994).

50. Ratio of Import Duties to Imports, US (Figure VI.6), from Bureau if the Census (1989), Series U211. 
Table III.1 Effect of geographical and exchange-rate policy variables on Dollar's index

Dependent Variable: Dollar's Distortion

Index

\begin{tabular}{lcc} 
& $(1)$ & $(2)$ \\
\hline bmpav & $0.07^{\star * *}$ & $0.083^{\star *}$ \\
& $(1.971)$ & $(2.47)$ \\
rcoast & $-0.045^{\star}$ & $-0.053^{\star}$ \\
& $(-3.321)$ & $(-3.032)$ \\
tropics & $0.209^{\star * *}$ & 0.145 \\
& $(1.829)$ & $(1.004)$ \\
Latin & 0.012 & -0.037 \\
America & & \\
& $(0.097)$ & $(-0.257)$ \\
SSA & $0.451^{*}$ & $0.46^{* *}$ \\
& $(3.319)$ & $(2.43)$ \\
East Asia & -0.12 & -0.145 \\
& $(-0.921)$ & $(-0.889)$ \\
TAR & & -0.017 \\
& & $(-0.08)$ \\
NTB & & $-0.276^{* * *}$ \\
& & $(-1.851)$ \\
$R^{2}$ & 0.52 & 0.58 \\
$\mathrm{~N}$ & 89 & 71 \\
\hline
\end{tabular}

Notes: Heteroskedasticity-corrected t-statistics in parentheses. See appendix for variable definitions.

Regressions include a constant term and cover only developing countries. Levels of statistical significance indicated by asterisks:* 99 percent; ${ }^{* *} 95$ percent; ${ }^{* * *} 90$ percent. 
Table III.2: Replication and extension of Dollar's (1992) results

Dependent variable: growth of real GDP per capita,

1976-85

\begin{tabular}{|c|c|c|c|c|c|}
\hline & (1) & (2) & (3) & (4) & (5) \\
\hline DISTORTION & $\begin{array}{l}-0.018^{\star} \\
(-3.128)\end{array}$ & $\begin{array}{c}-0.008 \\
(-1.009)\end{array}$ & $\begin{array}{c}-0.003 \\
(-0.406)\end{array}$ & $\begin{array}{c}-0.004 \\
(-0.514)\end{array}$ & $\begin{array}{c}-0.008 \\
(-0.899)\end{array}$ \\
\hline VARIABILITY & $\begin{array}{l}-0.080^{\star} \\
(-2.64)\end{array}$ & $\begin{array}{l}-0.080^{* *} \\
(-2.084)\end{array}$ & $\begin{array}{c}-0.103^{*} \\
(-3.3)\end{array}$ & $\begin{array}{c}-0.107^{*} \\
(-3.51)\end{array}$ & $\begin{array}{l}-0.099^{*} \\
(-3.212)\end{array}$ \\
\hline Investment/GDP & $\begin{array}{c}0.137^{*} \\
(3.515)\end{array}$ & $\begin{array}{l}0.100^{* *} \\
(2.278)\end{array}$ & & & \\
\hline Latin America & & $\begin{array}{c}-0.015^{\star *} \\
(-2.34)\end{array}$ & $\begin{array}{c}-0.016^{*} \\
(-2.65)\end{array}$ & $\begin{array}{l}-0.014^{\star *} \\
(-2.362)\end{array}$ & $\begin{array}{l}-0.019^{*} \\
(-3.337)\end{array}$ \\
\hline East Asia & & $\begin{array}{c}0.007 \\
(0.747)\end{array}$ & $\begin{array}{c}0.010 \\
(0.937)\end{array}$ & $\begin{array}{c}0.011 \\
(0.976)\end{array}$ & $\begin{array}{c}0.004 \\
(0.382)\end{array}$ \\
\hline SSA & & $\begin{array}{l}-0.018^{* *} \\
(-2.419)\end{array}$ & $\begin{array}{l}-0.026^{*} \\
(-3.824)\end{array}$ & $\begin{array}{l}-0.029^{*} \\
(-4.129)\end{array}$ & $\begin{array}{l}-0.028^{*} \\
(-3.411)\end{array}$ \\
\hline log initial income & & & & $\begin{array}{c}-0.004 \\
(-1.097)\end{array}$ & $\begin{array}{c}-0.011^{\star *} \\
(-2.182)\end{array}$ \\
\hline schooling, 1975 & & & & & $\begin{array}{l}0.005^{\star *} \\
(2.531)\end{array}$ \\
\hline $\mathrm{N}$ & 95 & 95 & 95 & 95 & 80 \\
\hline $\mathrm{R}^{2}$ & 0.38 & 0.45 & 0.40 & 0.41 & 0.49 \\
\hline
\end{tabular}

Notes: Heteroskedasticity-corrected t-statistics in parentheses. Regressions include a constant term and cover only developing countries. Levels of statistical significance indicated by asterisks:* 99 percent; ** 95 percent; ${ }^{* \star *} 90$ percent. 
Table III.3: Dollar (1992) regressions using Summers-Heston version 5.6 data

Dependent variable: growth of real GDP per capita, 1976-85

\begin{tabular}{|c|c|c|c|c|c|c|c|c|}
\hline & \multicolumn{5}{|c|}{ largest sample } & \multicolumn{3}{|c|}{ Dollar sample } \\
\hline & $(1)$ & $(2)$ & (3) & (4) & $(5)$ & (6) & $(7)$ & $(8)$ \\
\hline \multirow[t]{2}{*}{ DISTORTION } & 0.000 & $-0.011^{* * *}$ & -0.003 & -0.010 & 0.000 & $-0.015^{\star}$ & -0.007 & $-0.012^{\star \star *}$ \\
\hline & $(0.029)$ & $(-1.951)$ & $(-0.453)$ & $(-1.664)$ & $(0.093)$ & $(-2.829)$ & $(-1.267)$ & $(-1.951)$ \\
\hline \multirow[t]{2}{*}{ VARIABILITY } & $-0.053^{\star *}$ & $-0.081^{*}$ & $-0.075^{\star}$ & $-0.101^{\star}$ & $-0.063^{\star *}$ & $-0.092^{*}$ & $-0.081^{*}$ & $-0.092^{*}$ \\
\hline & $(-2.302)$ & $(-3.376)$ & $(-2.809)$ & $(-4.105)$ & $(-2.615)$ & $(-3.865)$ & $(-2.857)$ & $(-3.779)$ \\
\hline \multirow{2}{*}{ Investment/GDP } & $0.081^{*}$ & $0.08^{* *}$ & & & 0.061 & 0.055 & & \\
\hline & (2.659) & (2.633) & & & (1.606) & $(1.518)$ & & \\
\hline \multirow{2}{*}{$\begin{array}{l}\text { dummy for Ghana } \\
\text { and Uganda }\end{array}$} & & $0.08^{*}$ & $0.044^{\star \star \star}$ & $0.085^{\star \star \star}$ & & $0.099^{\star}$ & $0.065^{\star}$ & $0.086^{*}$ \\
\hline & & (3.199) & $(1.691)$ & (3.772) & & $(4.108)$ & $(2.707)$ & (3.838) \\
\hline \multirow[t]{2}{*}{ Latin America } & & & $-0.017^{*}$ & $-0.016^{\star * *}$ & & & $-0.018^{*}$ & $-0.021^{*}$ \\
\hline & & & $(-2.832)$ & $(-2.895)$ & & & $(-2.822)$ & $(-3.803)$ \\
\hline \multirow[t]{2}{*}{ East Asia } & & & 0.008 & 0.006 & & & 0.007 & 0.001 \\
\hline & & & $(0.927)$ & $(0.653)$ & & & $(0.83)$ & $(0.17)$ \\
\hline \multirow[t]{2}{*}{ SSA } & & & $-0.019^{*}$ & $-0.022^{\star \star \star}$ & & & $-0.02^{*}$ & $-0.023^{*}$ \\
\hline & & & $(-3.135)$ & $(-3.993)$ & & & $(-3.302)$ & $(-4.116)$ \\
\hline \multirow[t]{2}{*}{ log initial income } & & & & $-0.01^{\star *}$ & & & & $-0.012^{*}$ \\
\hline & & & & $(-2.625)$ & & & & $(-3.065)$ \\
\hline \multirow[t]{2}{*}{ schooling, 1975} & & & & 0.002 & & & & $0.004^{*}$ \\
\hline & & & & $(1.408)$ & & & & $(2.600)$ \\
\hline $\mathrm{N}$ & 112 & 112 & 112 & 84 & 95 & 95 & 95 & 80 \\
\hline$R^{2}$ & 0.1575 & 0.2035 & 0.2611 & 0.4644 & 0.159 & 0.2374 & 0.3462 & 0.4892 \\
\hline
\end{tabular}

Notes: Heteroskedasticity-corrected t-statistics in parentheses. Regressions include a constant term and cover only developing countries. Levels of statistical significance indicated by asterisks: 99 percent; ${ }^{* *} 95$ percent; ${ }^{* *} 90$ percent. 
Table IV.1: Simple Correlations with Growth

Variable

\begin{tabular}{ll}
\hline OPEN & 0.556 \\
MON & -0.423 \\
SOC & -0.148 \\
BMP & -0.368 \\
NTB & -0.083 \\
TAR & -0.048 \\
\hline \multicolumn{2}{l}{ See appendix for variable definitions }
\end{tabular}

See appendix for variable definitions 
Table IV.2 Effect of Different Openness Indicators on Growth

Dependent variable:growth of GDP per capita, 1970-89
(1)
(2)
(3)
(4)
(5)
(6)
(7)

$2.44^{*}$
OPEN

BMP

$-1.701^{*}$

$(-3.65)$

MON

$-2.020^{*}$

$(-2.84)$

SOC

$-1.272$

$(-1.39)$

NTB

$-0.453$

$(-0.81)$

TAR

$-0.134$

$(-0.18)$

BM

$2.086^{*}$

(4.82)

$2.119^{*} 2.519^{*} \quad 2.063^{*}$

$\begin{array}{lll}2.119^{\star} & 2.519^{\star} & 2.063 \\ (5.09) & (5.94) & (4.64)\end{array}$

SQT

$\begin{array}{lll}0.877^{\star * *} & 0.735 & 0.663\end{array}$

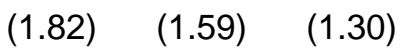

SOC

QT

.657

$\mathrm{R}^{2}$

.593

.637

0.522

0.455

0.617

(1.28)

$\mathrm{N} \quad 79$

78

75

$74 \quad 74$

.619

All Equations except column 6 include the following controls: Log of GDP in 1970, investment rate, 1970, government consumption/GDP, assassinations per capita, deviation from world investment prices, secondary schooling ratio, primary schooling ratio, revolutions and coups, and a constant term. Column 6 drops the investment rate and deviation from world investment prices. Numbers in parentheses are t-statistics based on Huber-White heteroskedasticity-consistent standard errors. 
Table IV.3: Alternative Partitions of Openness Index

\begin{tabular}{|c|c|c|c|c|}
\hline Regression & $\begin{array}{l}\text { Openness Index (Three } \\
\text { Variables) }\end{array}$ & Coefficient and t-statistic & Openness Index (Two Variable) & Coefficient and t-statistic \\
\hline 1 & SQT & $\begin{array}{l}73 \\
(1.59)\end{array}$ & $\mathbf{B M}$ & $\begin{array}{l}2.12 * \\
(5.09)\end{array}$ \\
\hline 2 & MQB & $\begin{array}{l}2.57 * \\
(5.34)\end{array}$ & TS & $\begin{array}{l}.38 \\
(0.65)\end{array}$ \\
\hline 3 & MBT & $\begin{array}{l}2.33^{*} \\
(5.51)\end{array}$ & QS & $\begin{array}{l}0.66 \\
(1.38)\end{array}$ \\
\hline 4 & SMB & $\begin{array}{l}2.12 * \\
(5.09)\end{array}$ & TQ & $\begin{array}{l}.73 \\
(1.59)\end{array}$ \\
\hline 5 & SMQ & $\begin{array}{l}1.32 * \\
(3.01)\end{array}$ & TB & $\begin{array}{l}1.91 * \\
(4.36)\end{array}$ \\
\hline 6 & SQB & $\begin{array}{l}1.91 * \\
(3.90)\end{array}$ & TM & $\begin{array}{l}1.42 * \\
(2.87)\end{array}$ \\
\hline 7 & SMT & $\begin{array}{l}1.65^{*} \\
(3.56)\end{array}$ & BQ & $\begin{array}{l}1.86^{*} \\
(3.87)\end{array}$ \\
\hline 8 & MQT & $\begin{array}{l}1.53^{*} \\
(3.55)\end{array}$ & BS & $\begin{array}{l}1.35^{*} \\
(3.22)\end{array}$ \\
\hline 9 & SBT & $\begin{array}{l}1.91 * \\
(4.36)\end{array}$ & QM & $\begin{array}{l}1.32 * \\
(3.01)\end{array}$ \\
\hline 10 & QBT & $\begin{array}{l}1.95^{*} \\
(4.42) \\
\end{array}$ & MS & $\begin{array}{l}1.97^{*} \\
(4.06) \\
\end{array}$ \\
\hline & Opennes Index (Four Variables) & Coefficient and t-statistic & Openness Index (one variable) & Coefficient and t-statistic \\
\hline 11 & SMQT & $\begin{array}{l}1.53 * \\
(3.55)\end{array}$ & $\mathbf{B}$ & $\begin{array}{l}1.35^{*} \\
(3.23)\end{array}$ \\
\hline 12 & SQBT & $\begin{array}{l}1.97 * \\
(4.64)\end{array}$ & $\mathbf{M}$ & $\begin{array}{l}1.92 * \\
(3.64)\end{array}$ \\
\hline 13 & SMBT & $\begin{array}{l}2.33^{*} \\
(5.51)\end{array}$ & Q & $\begin{array}{l}.66 \\
(1.38)\end{array}$ \\
\hline 14 & MQBT & $\begin{array}{l}2.40 * \\
(5.19)\end{array}$ & $\mathrm{S}$ & $\begin{array}{l}0.97 \\
(1.53)\end{array}$ \\
\hline 15 & SMQB & $\begin{array}{l}2.68 * \\
(5.60)\end{array}$ & $\mathrm{T}$ & $\begin{array}{l}-.13 \\
(-.224)\end{array}$ \\
\hline
\end{tabular}

The label for each index denotes the openness indicators used to construct that index. M=State Monopoly of Main Export, S=Socialist Economic System, Q=Non-Tariff Barriers, T=Tariffs, B=Black Market Premium. For example SMQT is set to 0 if it is closed according to either of the criteria for S,M, Q or T, and to 1 otherwise. All results are for regressions which control for log of GDP in 1970, investment rate, 1970, government consumption/ GDP, assassinations per capita, deviation from world investment prices, secondary schooling ratio, primary schooling ratio, revolutions and coups and a constant term. Numbers in parentheses are t-statistics based on Huber-White heteroskedasticityconsistent standard errors. 
Table IV.4: Correlations of Black Market Premium with Macroeconomic and Political Disequilibrium Variables Variable Correlation

Inflation 1975-1990 0.427

Debt/Exports, 1985

Change in Terms of Trade $\quad-0.064$

War 0.230

Quality of Institutions $\quad-0.473$ 
Table IV.5: Threshold Effects in Black Market Premium Dependent Variable: Growth of GDP per capita, 1970-89

(1)

(2)

\begin{tabular}{lcc}
\hline BMP & & $\begin{array}{c}-1.044^{\star *} \\
(-2.47)\end{array}$ \\
BMP70 & -0.009 & \\
& $(-0.03)$ & \\
BMP80 & $-0.235^{\star}$ & \\
& $(-1.83)$ & \\
F(BMP70, & 2.24 & \\
BMP80) & & \\
p-value & 0.11 & \\
R $^{2}$ & 0.461 & 0.476 \\
N & 80 & 80 \\
\hline
\end{tabular}


Table IV.6: Effect of Black Market Premium on Growth Before and After Controlling for Measures of Macroeconomic and Political Disequilibrium

Dependent Variable: Growth of GDP per capita, 1970-89
(1)
(2)
(3)
(4)
(5)
(6)
(7)

\begin{tabular}{|c|c|c|c|c|c|c|c|}
\hline $\begin{array}{l}\text { Black Market } \\
\text { Premium }\end{array}$ & $\begin{array}{c}-1.044^{* \star} \\
(-2.47)\end{array}$ & $\begin{array}{l}-0.727 \\
(-1.57)\end{array}$ & $\begin{array}{l}-0.768 \\
(-1.62)\end{array}$ & $\begin{array}{l}-1.200^{*} \\
(-2.84)\end{array}$ & $\begin{array}{c}-0.945^{\star *} \\
(-2.31)\end{array}$ & $\begin{array}{l}-0.551 \\
(-1.66)\end{array}$ & $\begin{array}{l}-0.438 \\
(-.98)\end{array}$ \\
\hline $\begin{array}{l}\text { Inflation, } \\
\text { 1975-1990 }\end{array}$ & & $\begin{array}{c}-3.201^{\star \star *} \\
(-1.78)\end{array}$ & & & & & $\begin{array}{c}-1.024 \\
(-.58)\end{array}$ \\
\hline $\begin{array}{l}\text { Debt/GDP } \\
\text { Ratio in } 1985\end{array}$ & & & $\begin{array}{l}-0.015^{*} \\
(-5.75)\end{array}$ & & & & $\begin{array}{l}-0.011^{*} \\
(-3.21)\end{array}$ \\
\hline $\begin{array}{l}\text { Terms of } \\
\text { Trade Shock }\end{array}$ & & & & $\begin{array}{l}1.038 \\
(0.42)\end{array}$ & & & $\begin{array}{l}3.894 \\
(1.48)\end{array}$ \\
\hline War & & & & & $\begin{array}{c}-1.378^{\star *} \\
(-2.32)\end{array}$ & & $\begin{array}{l}-0.135 \\
(-0.15)\end{array}$ \\
\hline $\begin{array}{l}\text { Quality of } \\
\text { Institutions }\end{array}$ & & & & & & $\begin{array}{l}0.441^{*} \\
(2.86)\end{array}$ & $\begin{array}{c}0.433^{* * *} \\
(2.00)\end{array}$ \\
\hline Statistics & & & & & & & \\
\hline $\mathrm{R}^{2}$ & 0.476 & .382 & .589 & .496 & .507 & .567 & .703 \\
\hline $\mathrm{N}$ & 80 & 76 & 54 & 77 & 80 & 75 & 46 \\
\hline
\end{tabular}

All Equations include the following controls: log of GDP in 1970, investment rate, 1970, government consumption/GDP, assassinations per capita, deviation from world investment prices, secondary schooling ratio, primary schooling ratio, revolutions and coups and a constant term. Numbers in parentheses are t-statistics based on Huber-White heteroskedasticity-consistent standard errors. 
Table IV.7: Sensitivity of Openness Result to Macroeconomic and Political Disequilibrium Dummy and Quality of Institutions

Dependent Variable: Growth of GDP per capita, 1970-89

\begin{tabular}{|c|c|c|c|c|c|c|}
\hline & & & & & & \\
\hline & (1) & (2) & (3) & (4) & (5) & (6) \\
\hline Open & $\begin{array}{l}2.443^{*} \\
(5.83)\end{array}$ & $\begin{array}{r}1.172^{\star \star} \\
(2.12)\end{array}$ & $\begin{array}{l}1.071 \\
(1.62)\end{array}$ & $\begin{array}{r}.913 \\
(1.25)\end{array}$ & $\begin{array}{l}0.829 \\
(1.49)\end{array}$ & $\begin{array}{r}1.163^{\star *} \\
(2.03)\end{array}$ \\
\hline DISEQ & & $\begin{array}{r}1.336^{*} \\
(3.25)\end{array}$ & $\begin{array}{l}1.418^{*} \\
(3.46)\end{array}$ & $\begin{array}{l}.435 \\
(.96)\end{array}$ & & \\
\hline $\begin{array}{l}\text { Quality of } \\
\text { Institutions }\end{array}$ & & $\begin{array}{l}.151 \\
(.76)\end{array}$ & $\begin{array}{l}.158 \\
(.74)\end{array}$ & $\begin{array}{r}.365 \\
(1.55)\end{array}$ & $\begin{array}{r}0.436^{* *} \\
(2.10)\end{array}$ & $\begin{array}{r}0.394^{* * *} \\
(1.96)\end{array}$ \\
\hline $\begin{array}{l}\text { Government } \\
\text { Budget } \\
\text { Surplus 1970- } \\
90\end{array}$ & & & & & & $\begin{array}{r}1.523^{\star *} \\
(2.54)\end{array}$ \\
\hline $\begin{array}{l}\text { Population } \\
\text { growth }\end{array}$ & & & & & & $\begin{array}{l}0.037 \\
(0.79)\end{array}$ \\
\hline Dummies & No & No & No & Yes & Yes & Yes \\
\hline $\mathrm{R}^{2}$ & .593 & .672 & .662 & .733 & .736 & .794 \\
\hline $\mathrm{N}$ & 79 & 70 & 70 & 70 & 74 & 69 \\
\hline
\end{tabular}

All Equations include the following controls: log of GDP in 1970, investment rate, 1970, government consumption/GDP, assassinations per capita, deviation from world investment prices, secondary schooling ratio, primary schooling ratio, revolutions and coups, and a constant term. Numbers in parentheses are t-statistics based on Huber-White heteroskedasticity-consistent standard errors. In equations 3 and 4 openness is set to 0 for Mauritius and Indonesia. DISEQ (political and macroeconomic disequilibrium dummy) equals 1 unless: country is in Africa, terms of trade fell by more than $20 \%$, debt/GNP ratio greater than $125 \%$, inflation greater than $10 \%$, or country was involved in war. 
TableV.1: Least Squares Regressions

Dependent Variable: TFP Growth, 1980-90

\begin{tabular}{|c|c|c|c|}
\hline & & \multirow{2}{*}{\multicolumn{2}{|c|}{ (3) }} \\
\hline & $(1)$ & & \\
\hline Equations & $\begin{array}{l}\text { Weighted Least } \\
\text { Squares } \\
\text { (weight=GDP) }\end{array}$ & $\begin{array}{c}\text { Weighted Least } \\
\text { Squares } \\
\text { (weight=log(GDP)) }\end{array}$ & $\begin{array}{l}\text { Robust Standard } \\
\text { Errors }\end{array}$ \\
\hline 1. Sachs-Warner & $\begin{array}{c}0.0094^{* *} \\
(2.12)\end{array}$ & $\begin{array}{l}0.0101^{* * *} \\
\quad(1.81)\end{array}$ & $\begin{array}{c}0.0102 \\
(1.54)\end{array}$ \\
\hline $\begin{array}{l}\text { 2. World Development } \\
\text { Report }\end{array}$ & $\begin{array}{c}0.0075^{\star} \\
(3.57)\end{array}$ & $\begin{array}{l}0.0070^{* *} \\
(2.45)\end{array}$ & $\begin{array}{c}0.0068^{*} \\
(3.67)\end{array}$ \\
\hline 3. Leamer & $\begin{array}{l}0.0010 \\
(1.03)\end{array}$ & $\begin{array}{c}0.0041 \\
(0.82)\end{array}$ & $\begin{array}{l}0.0041 \\
(0.82)\end{array}$ \\
\hline 4. Black Market Premium & $\begin{array}{c}-0.0217^{*} \\
(-3.59)\end{array}$ & $\begin{array}{c}-0.0108^{* *} \\
(-2.57)\end{array}$ & $\begin{array}{l}-0.0098^{* * *} \\
(-1.79)\end{array}$ \\
\hline 5. Tariffs & $\begin{array}{c}-0.0450^{*} \\
(-2.77)\end{array}$ & $\begin{array}{l}0.0065 \\
(0.51)\end{array}$ & $\begin{array}{l}0.0114 \\
(0.88)\end{array}$ \\
\hline 6. Quotas & $\begin{array}{c}-0.0047 \\
(-0.45)\end{array}$ & $\begin{array}{l}0.0029 \\
(0.35)\end{array}$ & $\begin{array}{l}0.0036 \\
(0.43)\end{array}$ \\
\hline 7. Heritage Foundation & $\begin{array}{c}-0.0074^{*} \\
(-4.50)\end{array}$ & $\begin{array}{c}-0.0066^{\star *} \\
(-3.02)\end{array}$ & $\begin{array}{l}-0.0064^{*} \\
(-2.87)\end{array}$ \\
\hline $\begin{array}{l}\text { 8. Collected Trade Taxes } \\
\text { Ratio }\end{array}$ & $\begin{array}{c}-0.4849^{*} \\
(3.04)\end{array}$ & $\begin{array}{c}-0.2808^{* *} \\
(-2.15)\end{array}$ & $\begin{array}{l}-0.2676^{\star *} \\
(-2.25)\end{array}$ \\
\hline $\begin{array}{l}\text { 9.Wolf's index of Import } \\
\text { Distortions }\end{array}$ & $\begin{array}{l}3.5 \mathrm{E}-05 \\
(0.27)\end{array}$ & $\begin{array}{l}4.8 \mathrm{E}-05 \\
(0.41)\end{array}$ & $\begin{array}{l}4.1 \mathrm{E}-05 \\
(0.36)\end{array}$ \\
\hline $\begin{array}{l}\text { 10. Principal Components } \\
\text { Factor }\end{array}$ & $\begin{array}{l}-0.0070^{* *} \\
(-2.38)\end{array}$ & $\begin{array}{c}-0.0047 \\
(-1.61)\end{array}$ & $\begin{array}{l}-0.0043 \\
(-1.37)\end{array}$ \\
\hline
\end{tabular}

\footnotetext{
Notes: These are the estimated coefficients from regressions where each of the trade policy indicators is entered separately. Each equation also includes log GDP per capita in 1965 and schooling in 1965 as regressors (as in the original Edwards [1998] specification). t-statistics are in parentheses (based on heteroskedasticity-consistent standard errors in column 3.)
} 
TableV.2: Instrumental Variables

Dependent Variable: TFP Growth, 1980-90

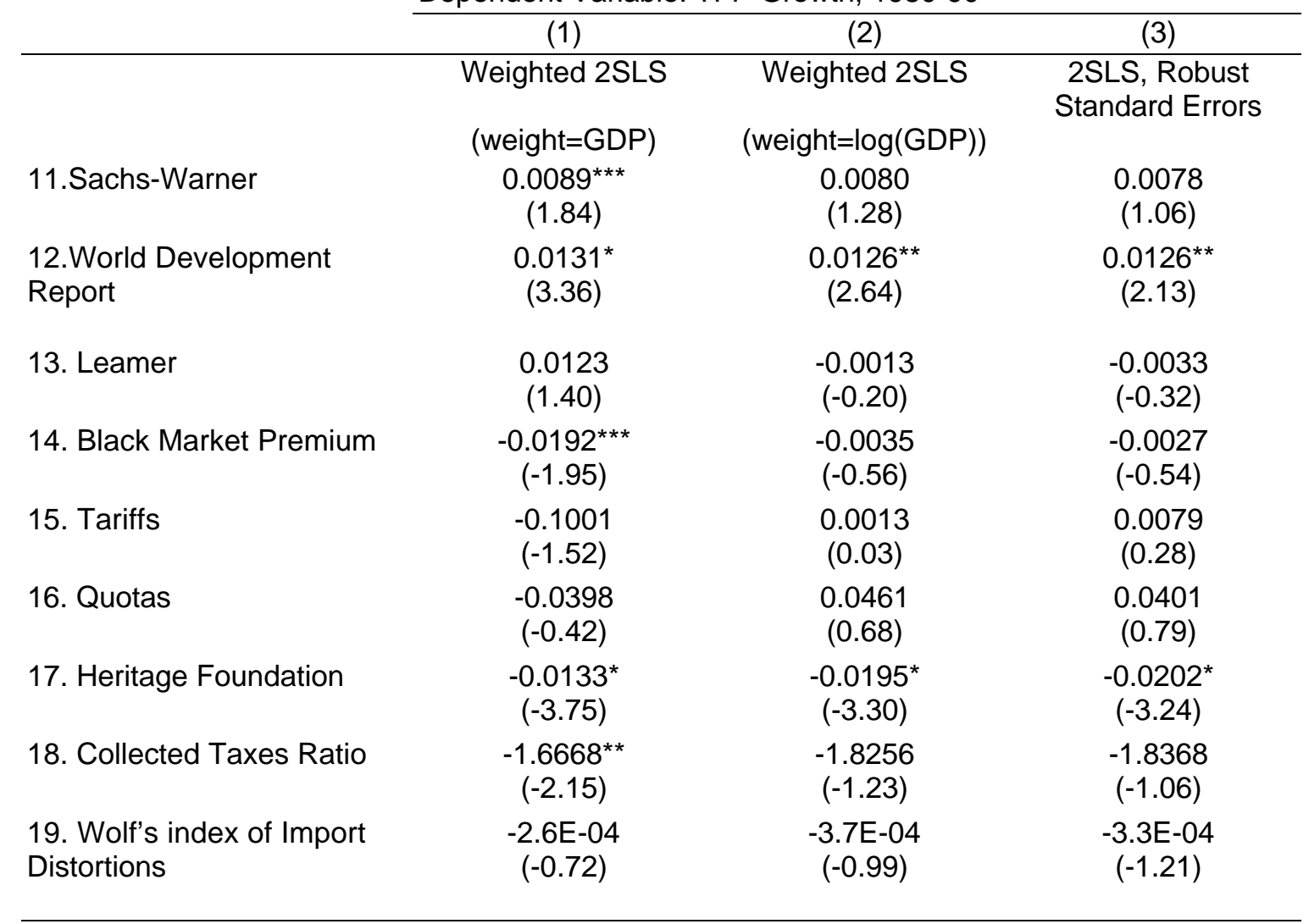

Notes: Same as previous table. 
TableV.3: Property Rights, Openness and Growth

\begin{tabular}{lllll} 
& \multicolumn{3}{c}{ Dependent Variable: TFP Growth, 1980-90 } \\
\cline { 2 - 5 } & \multicolumn{1}{c}{$(1)$} & $(2)$ & $(3)$ & $(4)$ \\
\hline World Development Report Index & $0.0126^{\star *}$ & 0.0023 & & \\
& $(2.13)$ & $(0.40)$ & & \\
Heritage Foundation Index & & & $-0.0202^{\star}$ & -0.003 \\
& & & $(-3.24)$ & $(-0.24)$ \\
Property Rights & & $-0.0107^{\star}$ & & -0.010 \\
& & $(-2.91)$ & & $(-1.43)$ \\
Test of Overidentifying Restrictions & 29.3244 & & 5.4072 & \\
p-value & $6.72 \mathrm{E}-06$ & & 0.2480 & \\
\hline No
\end{tabular}

Notes: Each equation also includes log GDP per capita in 1965 and schooling in 1965 as regressors. T-statistics based on heteroskedasticity-consistent standard errors in parentheses. 
TableV.4: Robustness of Trade Taxes and Heritage Index Results

Dependent Variable: TFP Growth, 1980-90

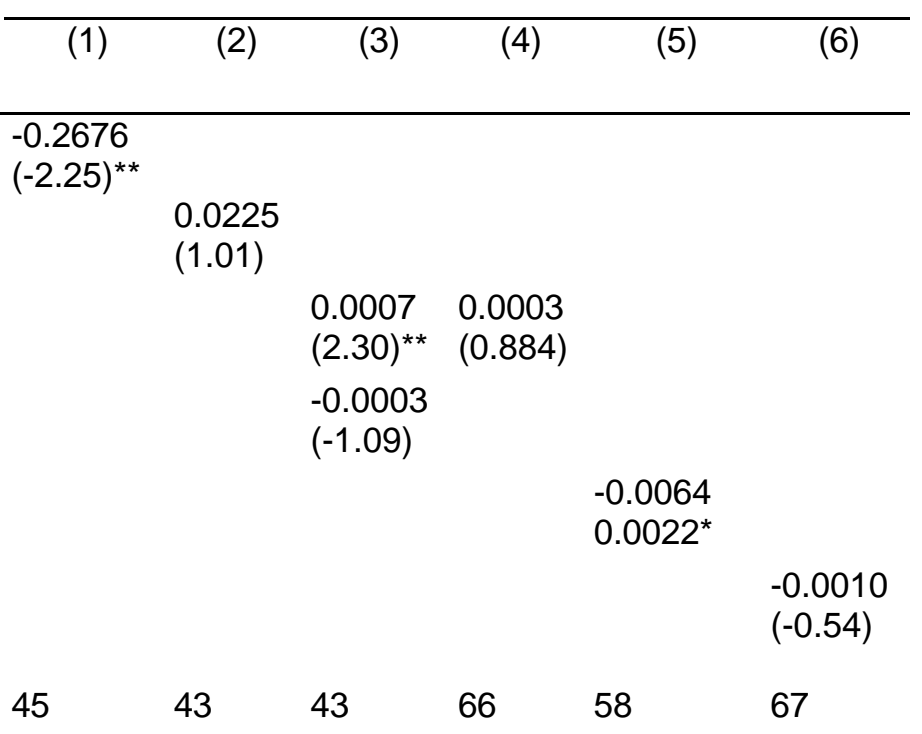

Notes: Each equation also includes log GDP per capita in 1965 and schooling in 1965 as regressors. t-statistics based on heteroskedasticity-consistent standard errors are in parentheses. 
Table VI.1: Average Growth Rates

\begin{tabular}{lrrrrrr} 
Growth Rate & Belgium & France & Germany & \multicolumn{2}{c}{ Italy } & \multicolumn{2}{c}{ Netherlands } & Average \\
\hline $1900-1913$ & 0.009 & 0.015 & 0.015 & 0.028 & 0.009 & 0.014 \\
$1921-1938$ & 0.010 & 0.022 & 0.026 & 0.016 & 0.010 & 0.017 \\
$1949-1960$ & 0.026 & 0.038 & 0.077 & 0.054 & 0.031 & 0.044 \\
$1960-1975$ & 0.039 & 0.037 & 0.029 & 0.040 & 0.032 & 0.035 \\
$1975-1994$ & 0.018 & 0.017 & 0.020 & 0.023 & 0.014 & 0.018 \\
\hline
\end{tabular}


Table VI.2: Contributions to variance around EC Mean

\begin{tabular}{lrrrrr} 
& 1950 & 1960 & 1970 & 1980 & 1990 \\
\hline EC6 & 0.036977 & 0.019967 & 0.010036 & 0.006338 & 0.007037 \\
EFTA6 & 0.068853 & 0.05347 & 0.036313 & 0.015968 & 0.010965 \\
Others & 0.08851 & 0.081835 & 0.056439 & 0.047611 & 0.034028 \\
Variance & 0.19434 & 0.155272 & 0.102788 & 0.069918 & 0.05203 \\
\hline
\end{tabular}


Table VIII.1: Import duties as percent of imports (averages for various years)

\begin{tabular}{|c|c|c|c|}
\hline & & & \\
\hline Albania & n.a. & n.a. & 10.03 \\
\hline Argentina & n.a. & 13.85 & 8.47 \\
\hline Australia & 9.80 & 8.56 & 4.58 \\
\hline Austria & 4.17 & 1.60 & 1.04 \\
\hline Bahamas, The & 19.63 & 24.38 & n.a. \\
\hline Bahrain & 2.12 & 4.07 & 3.62 \\
\hline Bangladesh & 11.40 & 14.53 & n.a. \\
\hline Barbados & 9.38 & 7.80 & n.a. \\
\hline Belize & n.a. & 20.31 & 29.74 \\
\hline Benin & 18.81 & n.a. & n.a. \\
\hline Bhutan & n.a. & 0.18 & 0.60 \\
\hline Bolivia & n.a. & 9.93 & 5.10 \\
\hline Botswana & 22.95 & 18.11 & 18.35 \\
\hline Brazil & n.a. & 6.23 & n.a. \\
\hline Bulgaria & n.a. & n.a. & 5.66 \\
\hline Burkina Faso & 18.70 & 13.64 & n.a. \\
\hline Burundi & n.a. & 16.72 & 12.95 \\
\hline Cameroon & 24.84 & 22.80 & 16.04 \\
\hline Canada & 5.56 & 3.92 & 1.73 \\
\hline China & n.a. & n.a. & 3.25 \\
\hline Colombia & 12.40 & 13.64 & 8.70 \\
\hline Comoros & n.a. & 25.59 & n.a. \\
\hline Congo, Dem. Rep. & 19.23 & 13.88 & 9.27 \\
\hline Congo, Rep. & 13.30 & n.a. & n.a. \\
\hline Costa Rica & 6.57 & 10.04 & 9.16 \\
\hline Cote d'Ivoire & n.a. & 31.10 & n.a. \\
\hline Croatia & n.a. & n.a. & 10.57 \\
\hline Cyprus & 8.22 & 9.67 & n.a. \\
\hline Czech Republic & n.a. & n.a. & 4.04 \\
\hline Denmark & 0.79 & 0.09 & 0.08 \\
\hline Dominican Republic & 23.81 & 18.83 & 26.85 \\
\hline Ecuador & 15.65 & 21.24 & 8.28 \\
\hline Egypt, Arab Rep. & 27.84 & 28.30 & 20.30 \\
\hline El Salvador & 6.94 & 6.54 & 6.27 \\
\hline Estonia & n.a. & n.a. & 0.54 \\
\hline Ethiopia & 28.08 & 13.97 & n.a. \\
\hline Fiji & 14.93 & 20.50 & 15.24 \\
\hline Finland & 2.92 & 1.27 & 0.74 \\
\hline France & 0.09 & 0.07 & 0.02 \\
\hline Gabon & 23.85 & 25.57 & n.a. \\
\hline Gambia, The & n.a. & 29.41 & n.a. \\
\hline Germany & 0.18 & 0.02 & n.a. \\
\hline Ghana & 13.77 & 15.88 & n.a. \\
\hline Guatemala & 9.27 & 7.15 & 8.71 \\
\hline Guinea-Bissau & n.a. & 0.02 & n.a. \\
\hline
\end{tabular}




\begin{tabular}{|c|c|c|c|}
\hline Honduras & 8.33 & n.a. & n.a. \\
\hline Hungary & n.a. & 6.82 & n.a. \\
\hline Iceland & n.a. & 13.78 & 1.79 \\
\hline India & 29.27 & 41.92 & 26.09 \\
\hline Indonesia & 8.04 & 3.87 & 4.03 \\
\hline Iran, Islamic Rep. & 11.38 & 25.01 & 5.28 \\
\hline Ireland & 10.01 & 5.96 & 3.90 \\
\hline Israel & 16.96 & 5.20 & n.a. \\
\hline Italy & 0.28 & 0.05 & 0.02 \\
\hline Jamaica & 7.41 & 3.76 & n.a. \\
\hline Japan & n.a. & 2.35 & n.a. \\
\hline Jordan & 11.81 & 14.39 & 14.65 \\
\hline Kenya & 12.97 & 14.75 & 14.25 \\
\hline Korea, Rep. & 5.56 & 8.59 & 4.57 \\
\hline Kuwait & 3.96 & 3.50 & 3.43 \\
\hline Latvia & n.a. & n.a. & 2.41 \\
\hline Lebanon & n.a. & n.a. & 9.84 \\
\hline Lesotho & 13.86 & 23.03 & n.a. \\
\hline Liberia & 11.14 & 21.00 & n.a. \\
\hline Lithuania & n.a. & n.a. & 2.42 \\
\hline Madagascar & n.a. & n.a. & 20.57 \\
\hline Malawi & 8.69 & 16.26 & n.a. \\
\hline Malaysia & 9.44 & 8.68 & 3.42 \\
\hline Maldives & n.a. & 12.04 & 14.91 \\
\hline Mali & 13.02 & 6.38 & n.a. \\
\hline Malta & 10.63 & 10.18 & n.a. \\
\hline Mauritania & 11.61 & n.a. & n.a. \\
\hline Mauritius & 10.23 & 19.79 & 16.45 \\
\hline Mexico & 13.23 & 7.99 & 5.07 \\
\hline Mongolia & n.a. & n.a. & 4.65 \\
\hline Morocco & 13.92 & 13.27 & n.a. \\
\hline Myanmar & 28.23 & 25.32 & 45.71 \\
\hline Nepal & 17.25 & 12.44 & 9.64 \\
\hline Netherlands Antilles & 0.74 & 1.43 & n.a. \\
\hline New Zealand & 5.19 & 5.46 & 3.83 \\
\hline Nicaragua & 6.70 & 8.06 & 11.66 \\
\hline Nigeria & 19.70 & 14.52 & n.a. \\
\hline Norway & 1.25 & 0.76 & 1.03 \\
\hline Oman & 0.68 & 3.70 & n.a. \\
\hline Pakistan & 16.98 & 24.45 & 26.99 \\
\hline Panama & n.a. & n.a. & 8.73 \\
\hline Papua New Guinea & 7.72 & 11.74 & 16.03 \\
\hline Paraguay & 11.97 & 6.37 & n.a. \\
\hline Peru & 15.42 & 26.10 & 13.02 \\
\hline Philippines & 17.37 & 14.28 & 14.18 \\
\hline Poland & n.a. & 8.79 & 16.83 \\
\hline Portugal & 10.16 & 2.79 & 0.01 \\
\hline Romania & n.a. & n.a. & 5.99 \\
\hline Russian Federation & n.a. & n.a. & 2.82 \\
\hline Samoa & n.a. & 29.51 & n.a. \\
\hline
\end{tabular}




\begin{tabular}{|c|c|c|c|}
\hline Senegal & 17.01 & 22.27 & n.a. \\
\hline Seychelles & n.a. & 29.52 & 64.86 \\
\hline Sierra Leone & 20.07 & 15.85 & 27.62 \\
\hline Singapore & 1.26 & 0.82 & n.a. \\
\hline Solomon Islands & 10.66 & 19.58 & n.a. \\
\hline Somalia & 27.84 & n.a. & n.a. \\
\hline South Africa & 4.22 & 3.37 & 1.79 \\
\hline Spain & 13.04 & 6.52 & 0.01 \\
\hline Sri Lanka & 6.81 & 15.82 & 9.38 \\
\hline St. Kitts and Nevis & n.a. & 17.56 & n.a. \\
\hline St. Lucia & n.a. & 13.49 & n.a. \\
\hline St. Vincent and the Grenadines & n.a. & 15.29 & 25.39 \\
\hline Sudan & 31.12 & n.a. & n.a. \\
\hline Suriname & 17.81 & 16.27 & n.a. \\
\hline Swaziland & 21.02 & 23.14 & n.a. \\
\hline Sweden & 2.09 & 0.79 & 1.11 \\
\hline Switzerland & n.a. & 3.66 & 5.00 \\
\hline Syrian Arab Republic & 14.45 & n.a. & n.a. \\
\hline Tanzania & 10.83 & 9.76 & n.a. \\
\hline Thailand & 14.74 & 13.74 & 8.27 \\
\hline Togo & n.a. & 16.71 & n.a. \\
\hline Trinidad and Tobago & n.a. & n.a. & 6.68 \\
\hline Tunisia & 20.51 & 26.47 & 20.26 \\
\hline Turkey & 21.18 & 6.25 & 3.38 \\
\hline Uganda & 12.99 & 6.15 & n.a. \\
\hline United Kingdom & 1.19 & 0.01 & 0.10 \\
\hline United States & 3.85 & 3.53 & 2.81 \\
\hline Uruguay & 7.11 & 13.50 & 6.71 \\
\hline Vanuatu & n.a. & 25.56 & n.a. \\
\hline Venezuela & 7.63 & 9.80 & 10.08 \\
\hline Yemen, Rep. & n.a. & n.a. & 29.91 \\
\hline Zambia & 6.78 & 8.20 & 15.52 \\
\hline Zimbabwe & n.a. & 22.89 & n.a. \\
\hline
\end{tabular}

Source: World Bank, World Development Indicators 1998.

Notes: Countries listed are those for which there is data for at least one of the years covered. 

Figure I.1: Partial Association between Growth and Import Duties

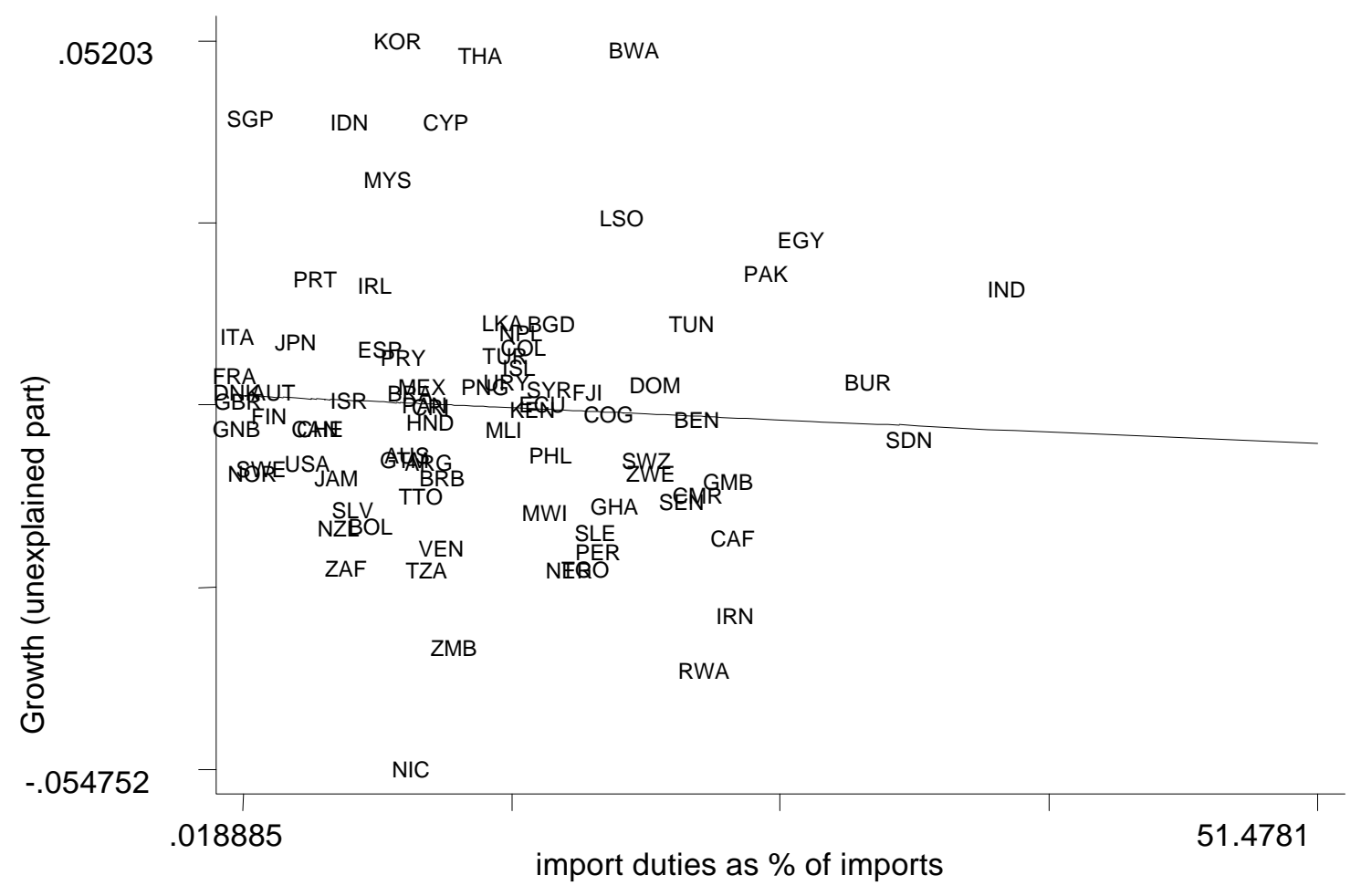


Figure I.2: Partial Association between Growth and Non-Tariff Barriers

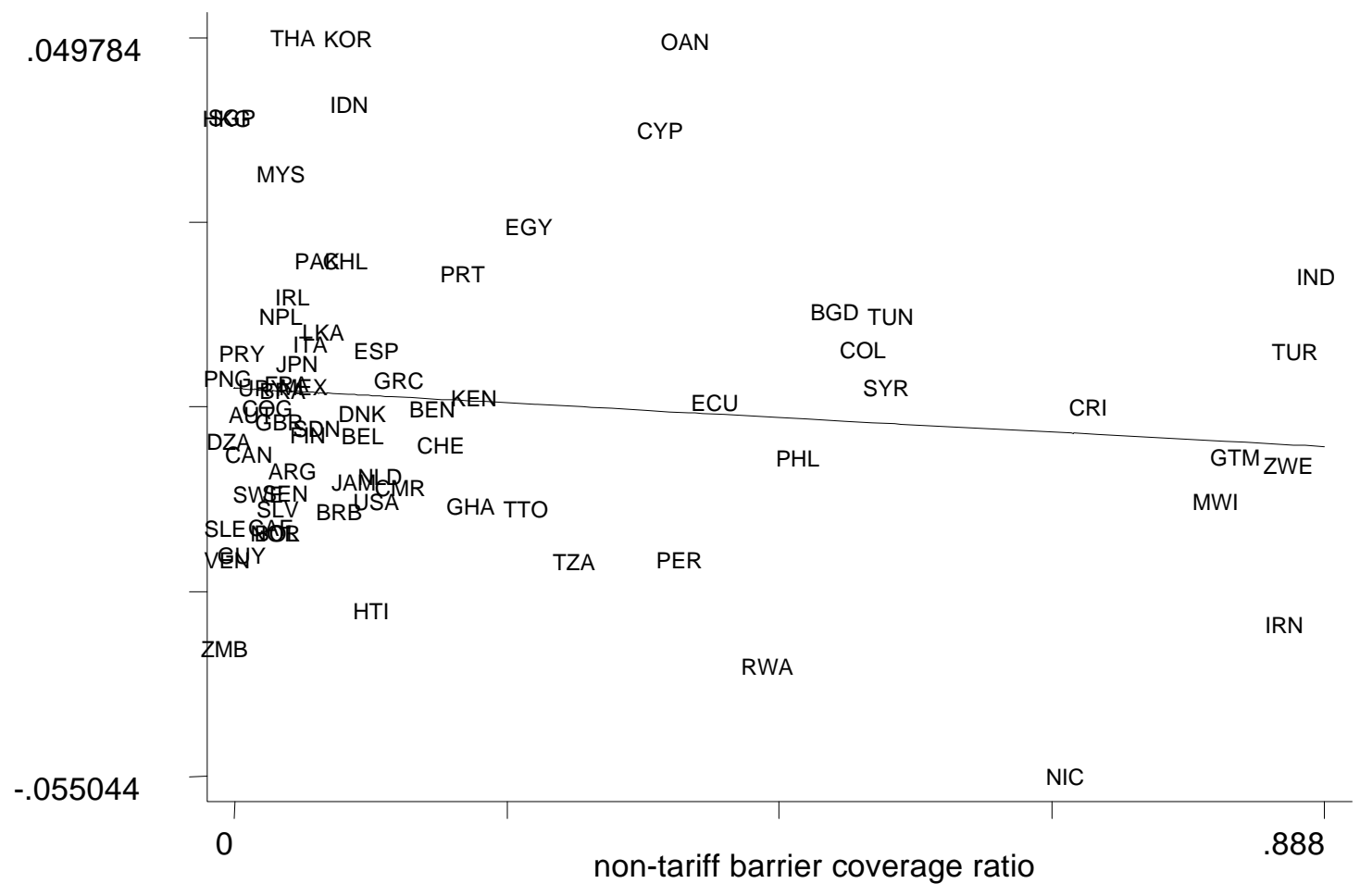


Figure Il.1: Growth rates of GDP at world prices

instantaneous growth rate $\longrightarrow$ "long run" growth rate

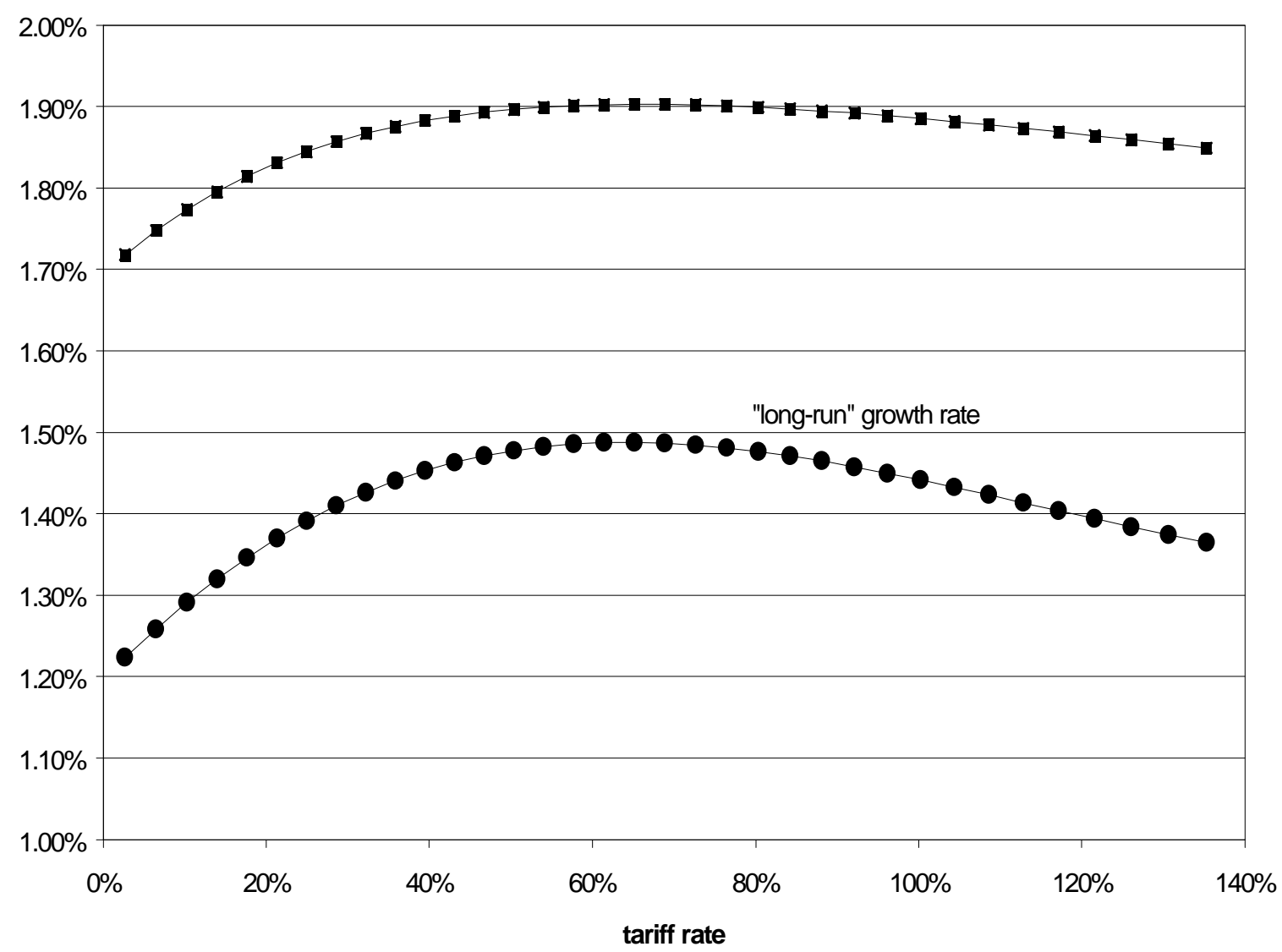


Figure IV.1: Partial Association between Growth and BM

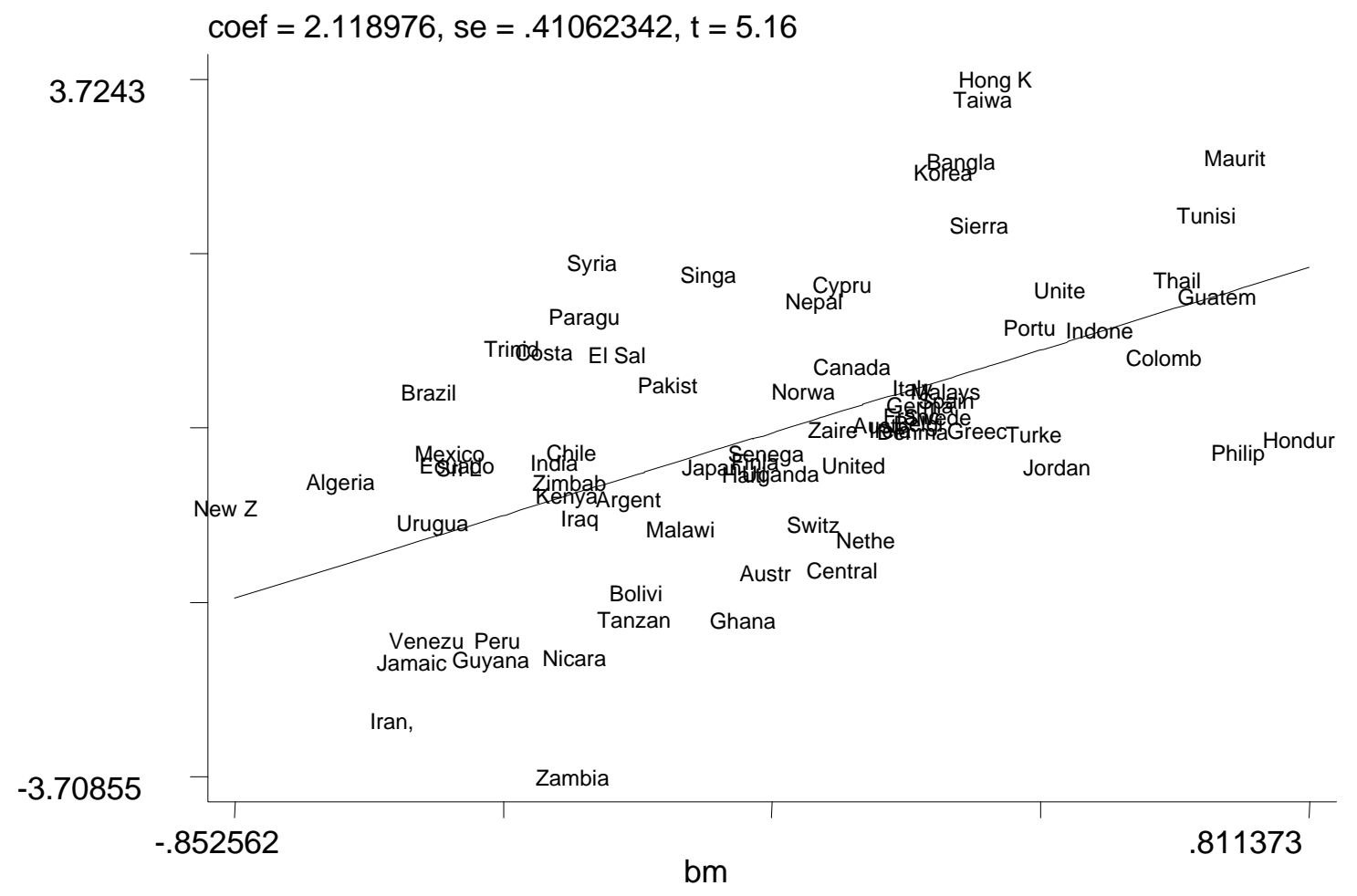




\section{Figure IV.2: Partial Association between Growth and SQT}

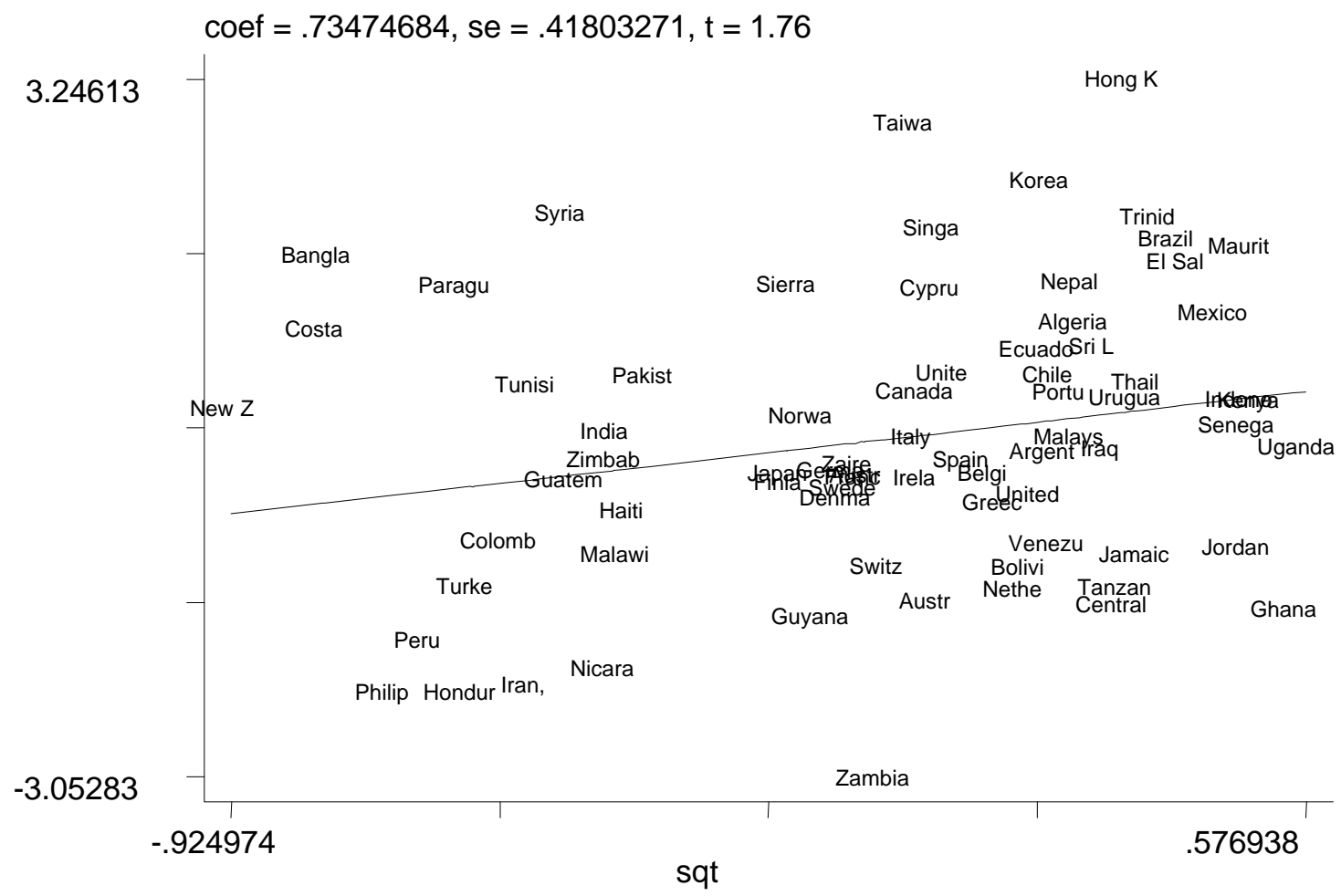


Figure VI.1: Effect of excluding Germany in Dispersion Calculations

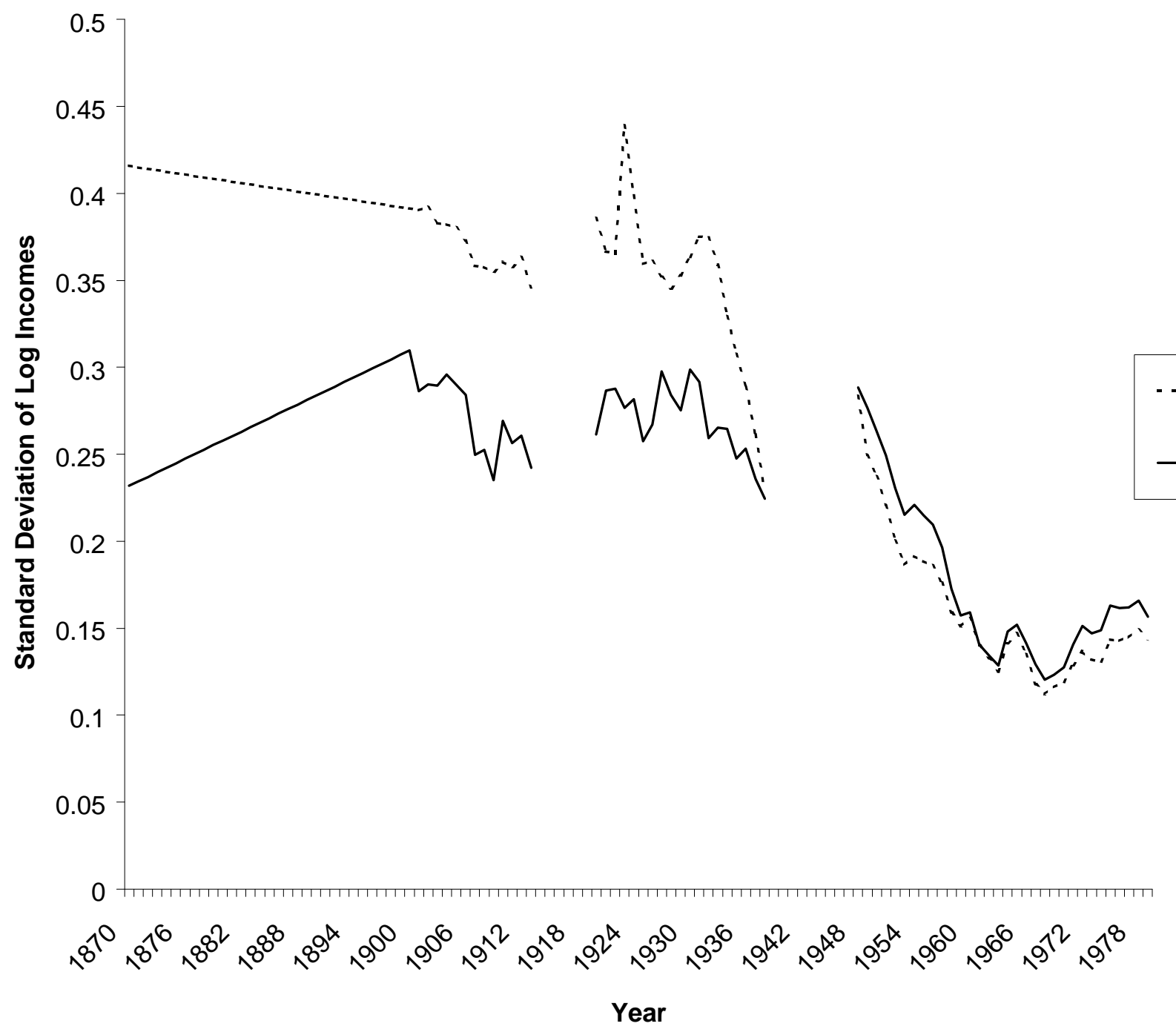




\section{Figure VI.2: Dispersion of Per Capita Incomes and Trade Policy Events}

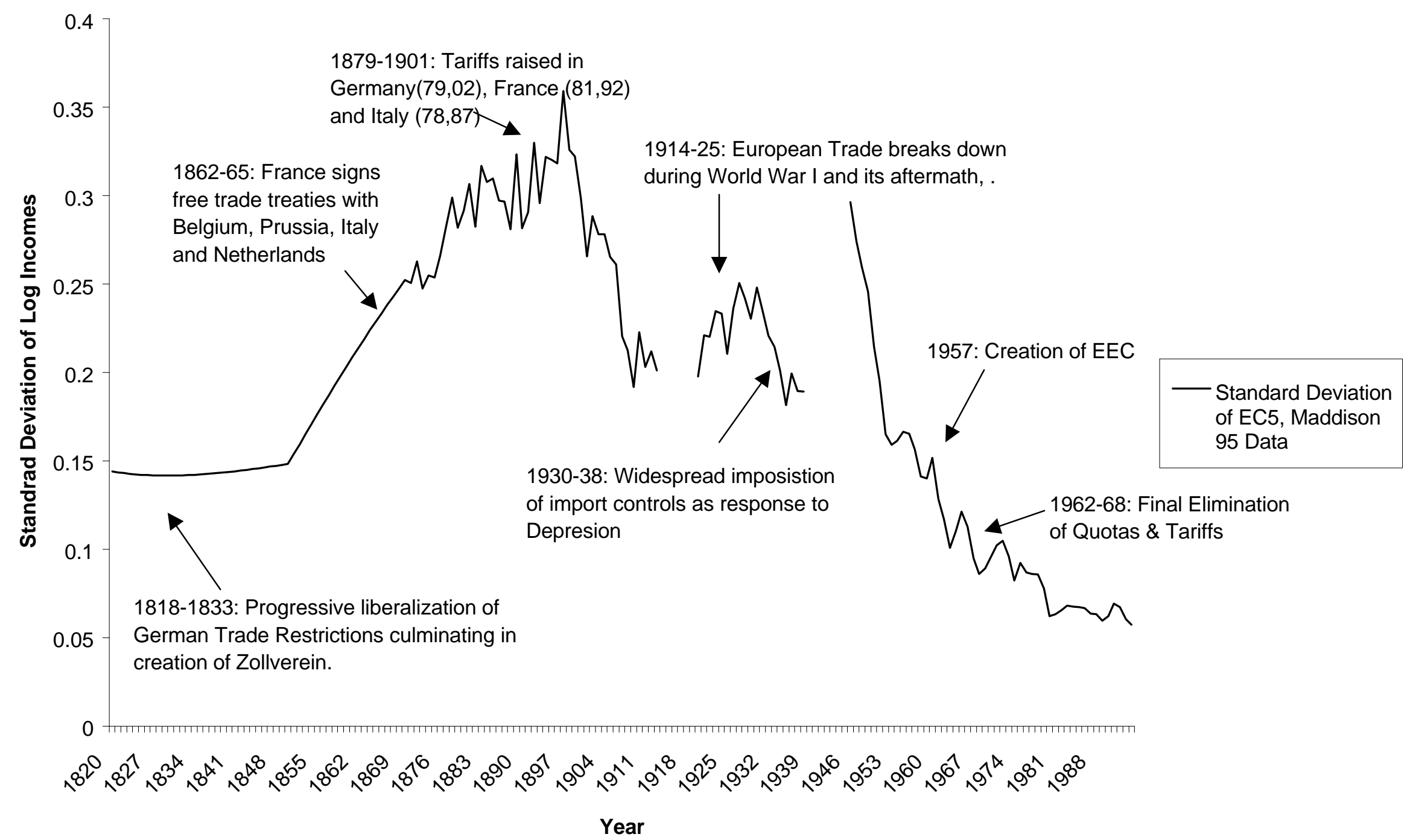


Figure VI.3: GDP of UK, Denmark and Ireland, relative to EEC Mean

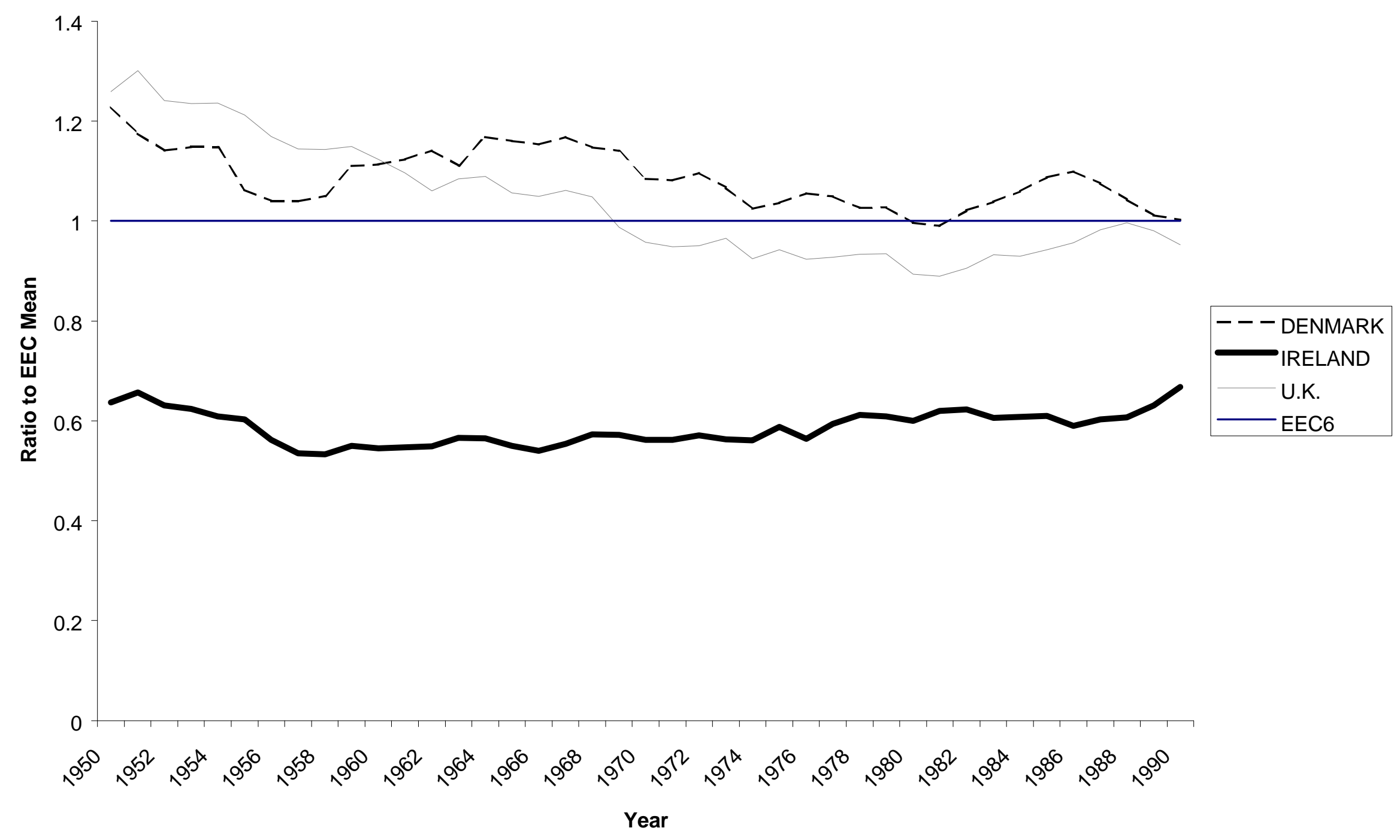


Figure VI.4: Contribution to Variance around European Mean

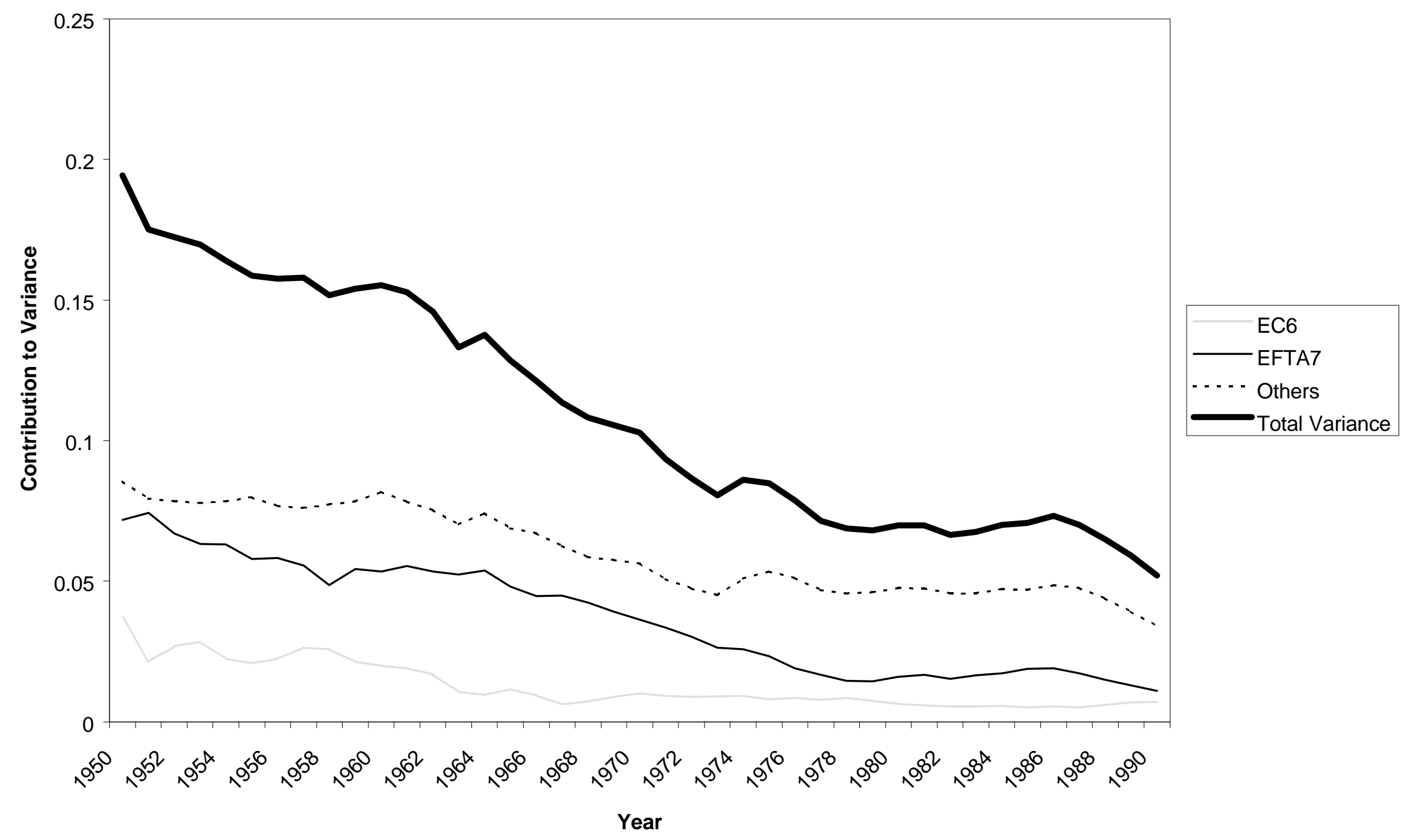


Figure VI.5: Standard Deviation of Log Incomes, East Asia

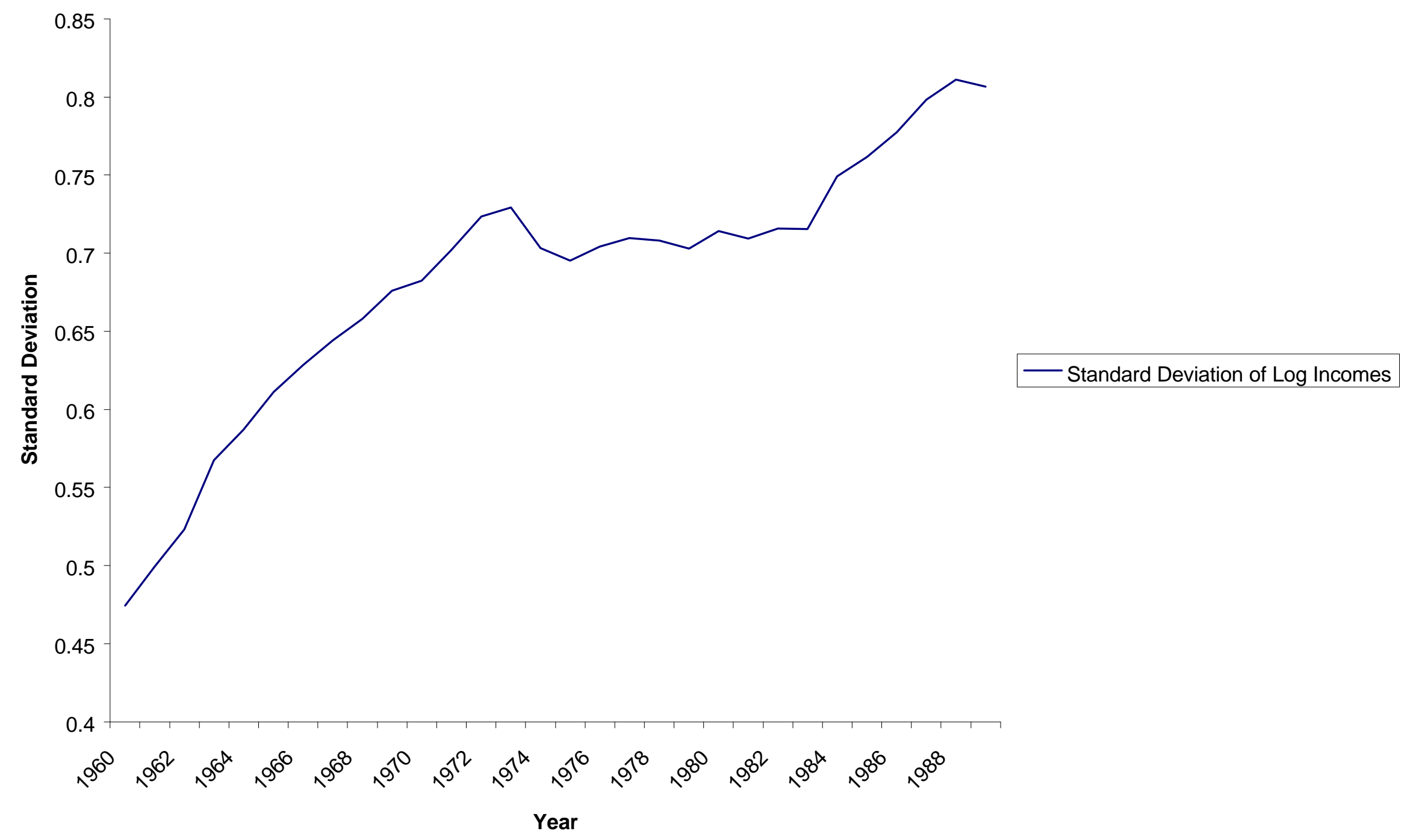


Figure VI.6 Standard Deviation for Six Latin American Countries

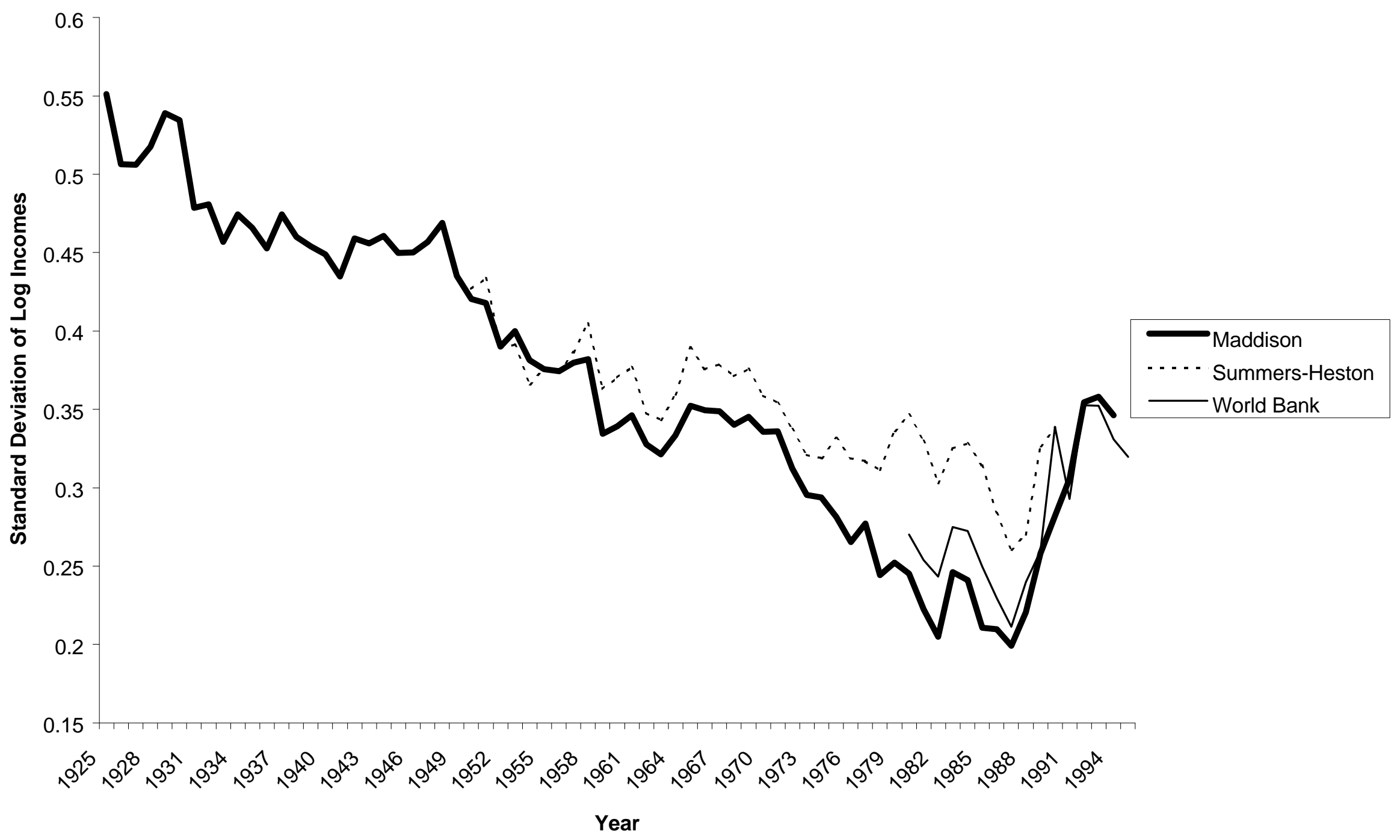


Figure VI.7: Ratio of US to European GDP and Import Duties, 1820-1938

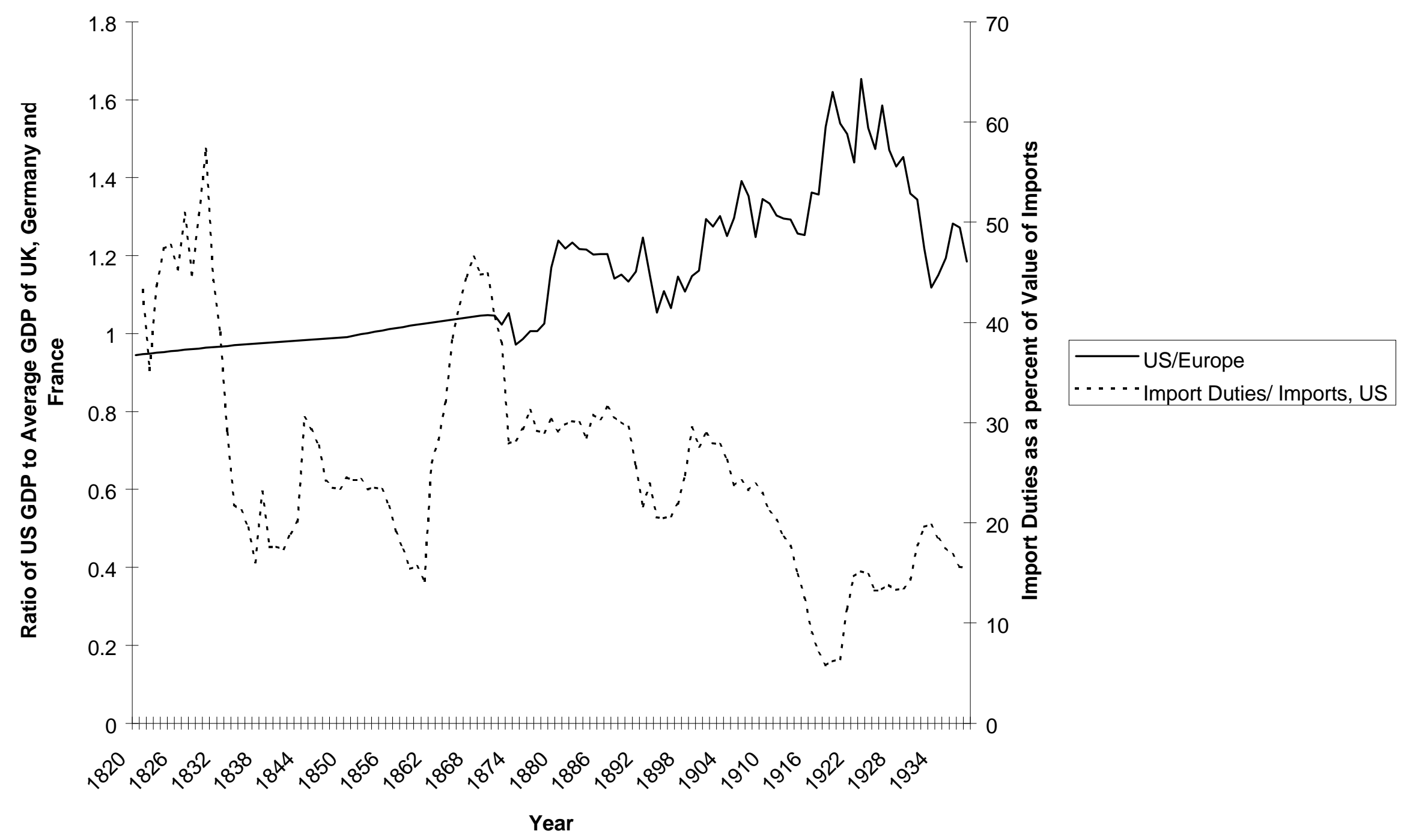

